\title{
130 years of cyclodextrin discovery for health, food, agriculture, and the industry: a review
}

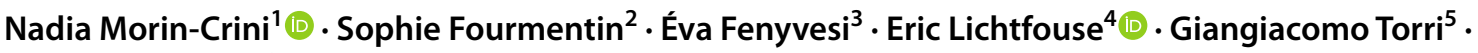 \\ Marc Fourmentin $^{6} \cdot$ Grégorio Crini $^{1}$ (1)
}

\begin{abstract}
Cyclodextrins are a group of cyclic oligosaccharides obtained by enzymatic degradation of starch. They are remarkable macrocyclic molecules that have led major theoretical and practical advances in chemistry, biology, biochemistry, health science, and agriculture. Their molecular structure is composed of a hydrophobic cavity that can encapsulate other compounds to form inclusion complexes through host-guest interactions. This unique feature is at the origin of many applications. Cyclodextrins and their derivatives have a wide variety of practical applications in almost all sectors of the industry, including pharmacy, medicine, foods, cosmetics, chromatography, catalysis, biotechnology, and the textile industry. Villiers published the first reference to cyclodextrins in 1891, and since then, these molecules have continued to fascinate academia and industry. Currently, more than 2000 publications on cyclodextrins are published each year. On the occasion of the 130th anniversary of their discovery, in this review, we present an historical overview of the development and applications of cyclodextrins. First, we present the discovery and first chemical studies on cyclodextrins. Then, the main results obtained during the 1911-1970 exploration period are discussed. A third part presents the historical landmarks in the development of cyclodextrins from 1970 to the present day.
\end{abstract}

Keywords Cyclodextrins $\cdot$ History $\cdot$ Applications

\section{Introduction}

Cyclodextrins are cyclic oligosaccharides obtained from the enzymatic degradation of starch and discovered by Villiers in 1891. Cyclodextrins are one of the most remarkable macrocyclic molecules with significant impacts in our daily lives. They have a particular structure composed of a hydrophobic cavity that can encapsulate other compounds to form inclusion complexes through host-guest interactions. This characteristic feature is at the origin of many applications. Today, all industrial sectors are concerned, e.g., pharmaceuticals, cosmetics, food, hygiene and toiletries, biotechnology,

\author{
Nadia Morin-Crini \\ nadia.crini@univ-fcomte.fr \\ Sophie Fourmentin \\ sophie.fourmentin@univ-littoral.fr \\ Éva Fenyvesi \\ fenyvesi.e@cyclolab.hu \\ Eric Lichtfouse \\ eric.lichtfouse@gmail.com \\ Giangiacomo Torri \\ torri@ronzoni.it \\ Marc Fourmentin \\ marc.fourmentin@univ-littoral.fr \\ Grégorio Crini \\ gregorio.crini@univ-fcomte.fr
}

1 Chrono-environnement, UMR 6249, UFR Sciences et Techniques, Université Bourgogne Franche-Comté, Besançon, France

2 Unité de Chimie Environnementale et Interactions sur le Vivant (UCEIV, EA 4492), SFR Condorcet FR CNRS 3417, ULCO, 59140 Dunkirk, France

3 CycloLab Cyclodextrin Research and Development Ltd., Illatos 7, Budapest 1097, Hungary

4 Aix Marseille Univ, CNRS, IRD, INRA, Coll France, CEREGE, Aix-en-Provence, France

5 Istituto di Chimica e Biochimica G. Ronzoni, 81 Via G. Colombo, Milan, Italy

6 Université du Littoral Côte d'Opale, Laboratoire de Physico-Chimie de l'Atmosphère (LPCA, EA 4493), ULCO, 59140 Dunkirk, France 
medical, radiology, agrochemistry, catalysis, packaging, textile industry, nanotechnology, and soil and water treatment (see recent selected reviews: Astray et al. 2020; Bezerra et al. 2020; Dhiman and Bhatia 2020; Gentili 2020; Hussain Asim et al. 2020; Kumari et al. 2020; Liu et al. 2020; Matencio et al. 2020; Morillo et al. 2020; Tian et al. 2020; Viernstein and Wolschann 2020; Zhang et al. 2020; Arora et al. 2019; Braga 2019; Fenyvesi et al. 2019; Kfoury et al. 2019; Crini et al. 2018).

Figure 1 shows that cyclodextrins occur in many daily products such as an ibuprofen tablet, a non-steroidal antiinflammatory drug, a whooping cough vaccine, a curative antidote, a hair loss solution, a stop smoking aid, toothpastes, shampoo, colognes, a deodorant toilet, razors, a turmeric-based food supplement, a butter, a mayonnaise, fish sausages, modified steaks, a horseradish powder, mustard sauces, a sweetener, honey, a cinnamon extract, green tea without bitterness, vanilla coffee, clarified fruit juices, chewing gums, chromatographic columns, biopesticides, catalysts, tubular materials, a curtain, cosmetotextiles, an ink, a detergent, a bioflocculant for swimming pool, or a bioadsorbent for water treatment (Morin-Crini et al. 2015; Crini et al. 2018; Fourmentin et al. 2018a, b).

The first important period on the history of cyclodextrins, from 1891 to 1911, covers their discovery by Villiers, and their characterization and chemistry by Schardinger (Thoma and Stewart 1965; Caesar 1968; Clarke et al. 1988; Szejtli 1998). In 1891, Villiers discovered a crystalline dextrin from the Bacillus amylobacter digest of potato starch, which he named "cellulosine" (Villiers 1891a, b, c, d). At the beginning of the last century, Schardinger also observed the formation of two crystallized products during his investigations of food spoilage, which he called crystallized dextrin- $\alpha$ and crystallized dextrin- $\beta$. Schardinger gave the first detailed description of the preparation and separation of these two dextrins. However, from 1911 to 1935 came a period of doubt and disagreement, in particular between the groups of Pringsheim and Karrer, although they published numerous studies on the composition, properties, and chemistry of the crystallized dextrins (Crini 2014; Crini et al. 2020). It was not until the mid-1930s that research on dextrins developed again. The exploration period from 1935 to 1950 was marked by the numerous results obtained by Freudenberg and French on the structure of the "Schardinger dextrin" molecules. In 1936, Freudenberg suggested a cyclic structure for $\alpha$-dextrin and $\beta$-dextrin. In 1942, French proposed that Schardinger dextrins be called cycloamyloses, described new protocols for the preparation of cycloamyloses with high purity and published the correct molecular weights of the two dextrins. The same year, Hudson discovered the enzyme in Bacillus macerans responsible for the conversion of starch into dextrins. In 1948, Freudenberg discovered $\gamma$-dextrin, and one year later, Cramer, his Ph.D. student, introduced the cyclodextrin-based nomenclature.

The period between 1950 and 1970, known as the period of maturation of notions, focused on inclusion complexes with Cramer's work in the foreground (Crini et al. 2020). In 1953, Freudenberg's group published the first patent concerning the applications of cyclodextrins in pharmaceutical formulations. In 1956, Cramer introduced and detailed the
Fig. 1 Commercial products containing cyclodextrins in our daily lives

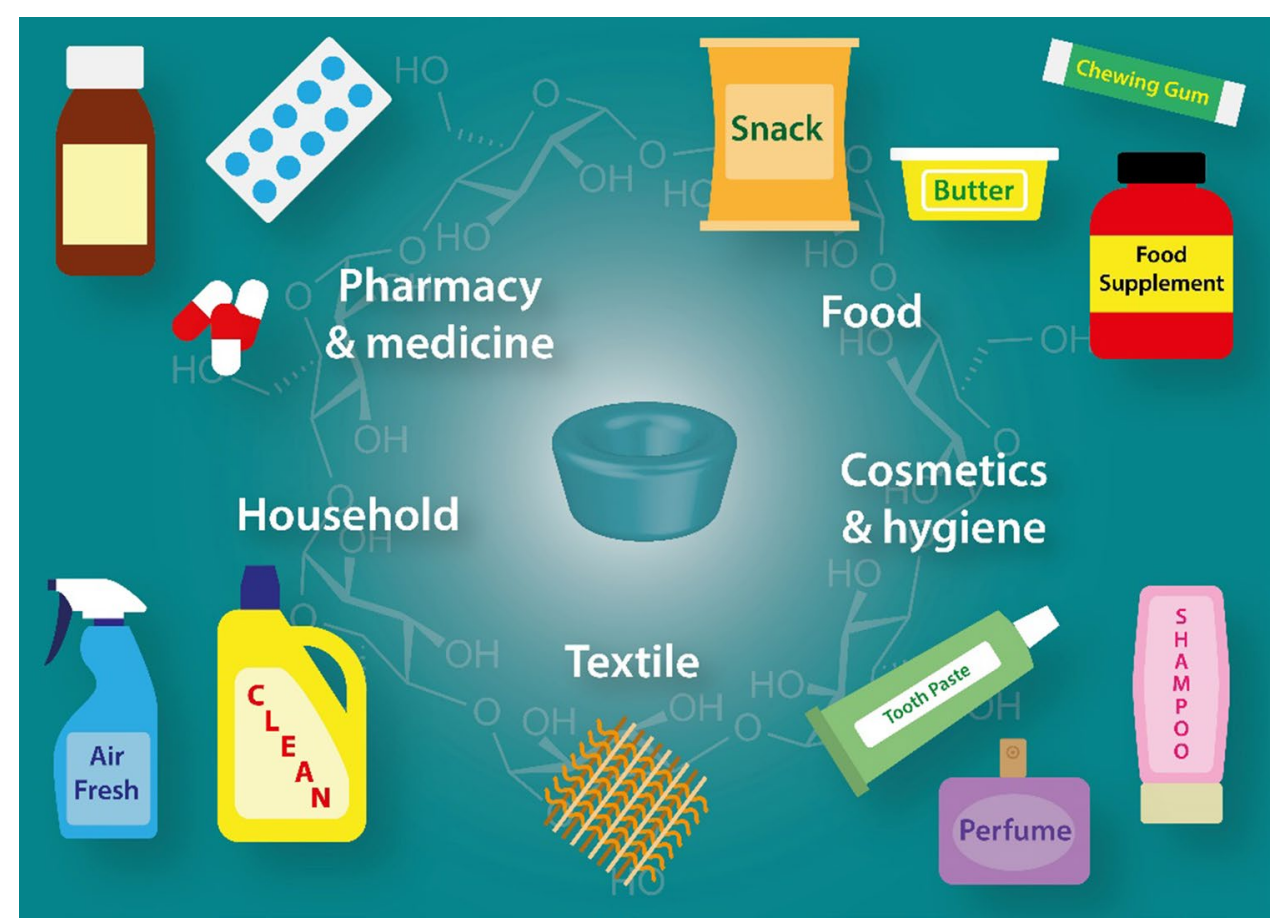


notion of an inclusion complex. From that time on, the interest in cyclodextrins increased. During the maturation period, the works of Casu on the conformation and spectroscopic characterization of cyclodextrins were acknowledged to have brought an important contribution. At the same time, much attention was also focused on their use for catalysis and as enzyme models (Crini 2014). Nonetheless, until the mid1970 s, the three main native cyclodextrins, i.e., $\alpha-, \beta$ - and $\gamma$-cyclodextrins, available only in small quantities, were long considered as just laboratory curiosities (Thoma and Stewart 1965; Caesar 1968; Kainuma 1984; Clarke et al. 1988). In the way of industrial development, the three main obstacles were their price, their presumed toxicity, and the lack of sufficient knowledge of these substances (Szejtli 1982a). In addition, very few researchers were convinced of the industrial potential of cyclodextrins.

The 1970s were marked by two important events (Crini et al. 2020). Firstly, several manufacturers started to produce and to commercialize cyclodextrins. Secondly, the first toxicological studies had established that $\beta$-cyclodextrin administrated orally was a harmless substance. As a result, this has led to spectacular progress. In the mid-1970 s, pharmaceutical and food applications started to appear and rapidly gained ground, especially in Japan (Hamada et al. 1975; Szejtli 1977; Pitha et al. 1983; Uekama and Otagiri 1987; Frömming and Szejtli 1994). Saenger (1980) published the first comprehensive review about the potential industrial applications of cyclodextrins. The first International Cyclodextrin Symposium organized by Szejtli took place in Budapest in 1981, and one year later, he wrote the first comprehensive cyclodextrin book (Szejtli 1982a). At that time, many interesting catalysts based on cyclodextrins were also constructed for biomimetic chemistry and other processes of interest such as artificial enzymes (Breslow 1979; Breslow and Dong 1998). Both from an academic and industrial point of view, the number of communications then started to increase exponentially, as did the filing of patents. In the mid-1980s, cyclodextrins were produced in large quantities and commercialized at a reasonable price, i.e., $10-15 \$ / \mathrm{kg}$ (Szejtli 1982a). Other industrial applications have become possible. In 1984, the first chromatographic columns were marketed (Armstrong 1984; Ward and Armstrong 1986, 1988; Armstrong and Jin 1989). Since then, an increasing interest in cyclodextrins and their possible applications has existed (Duchêne 1987, 1991; Szejtli 1988). An abundant scientific literature has built up since the 1980s. Currently, every year, more than 2000 publications, including articles and book chapters, are devoted to cyclodextrins (Cyclodextrin News, CycloLab, Ltd., Hungary). Nowadays, these molecules still fascinate researchers and industrials.

The objective of this review is to describe historical landmarks of the discovery, exploration, and utilization of cyclodextrins. We also present some highlights of their early industrial applications. To this end, an extensive list of data from about 500 original publications has been compiled. Although this historical chapter cannot hope to be exhaustive, it does highlight the work of those researchers who have contributed to the knowledge of cyclodextrins throughout the 130 years of its history. This article is an abridged version of the chapter published by Morin-Crini et al. (2020) in the series Environmental Chemistry for a Sustainable World.

\section{Discovery and first chemical studies of cyclodextrins}

\section{Discovery: 1891-1911}

During experiments on the degradation and reduction in carbohydrates under the action of ferments, Antoine Villiers, a French pharmacist and chemist, was the first to observe in 1891 the formation of unwanted crystals with particular properties, i.e., the formation of cyclodextrins. Villiers showed how easy it was to transform starch to yield "novel crystalline dextrins" with particular properties under the action of ferments. He first obtained a small amount of crystalline dextrins from digests of Bacillus amylobacter, i.e., Clostridium butyricum, on potato starch under certain conditions (Villiers 1891a, 1891b): $50 \mathrm{~g}$ potato starch in $1 \mathrm{~L}$ of water at $100{ }^{\circ} \mathrm{C}$ subsequently seeded with Bacillus amylobacter and incubated for several days in an oven at $40^{\circ} \mathrm{C}$. Villiers presented his results to the French "Académie des Sciences" in February 1891. At that time, the dextrins, previously discovered in 1821, were the degradation products and/or the intermediate decomposition products of starch through heating. For Villiers, his dextrins were degradation products of starch. When purified by fractional precipitation, the crystals presented very different optical rotation properties and were difficult to hydrolyze any further. Iodine stains red those dextrins that had a high optical activity, the intensity of the stain decreased with the optical activity. The butyric ferment caused the transformation of the starch directly into dextrin without the involvement of intermediates such as diastases secreted by the ferment. Later, Villiers considered his dextrins as the intermediate decomposition products of starch (Villiers 1891b). Villiers also obtained "un curieux sous-produit", i.e., a curious by-product, in small quantities after several weeks of incubation: $3 \mathrm{~g}$ of this carbohydrate was obtained as crystals after bacterial digestion of $1000 \mathrm{~g}$ of starch. This new substance was found in the alcohol that was used for the precipitation of dextrins (Villiers 1891b).

In a second proceedings of the French "Académie des Sciences" of June 1891, Villiers described the chemical composition of the novel highly crystalline dextrin having a composition between that of starch and that of dextrin 
(Villiers 1891c). In air, the crystals, containing water and alcohol of crystallization (the proportion of the latter is rather small, about 4\%), became opaque. They lose alcohol and absorbed water without any change in weight. After purification in large amount of hot water, Villiers obtained small brilliant crystals, most probably $\beta$-cyclodextrin and determined the chemical composition of this crystalline carbohydrate. He gave the first empirical formula: $\left[\left(\mathrm{C}_{6} \mathrm{H}_{10} \mathrm{O}_{5}\right)_{2}+3 \mathrm{H}_{2} \mathrm{O}\right]$. Its solubility in water at room temperature was low but raised with temperature. The white crystals with a very slight sweetness showed extremely high optical activity, much higher than those of certain dextrins formed under the action of the butyric ferment. Villiers then considered this novel substance as an isomer of starch (Villiers 1891c, d). By manipulating the experimental conditions, Villiers obtained two distinct crystalline dextrins, most probably $\alpha$-cyclodextrin and $\beta$-cyclodextrin, having a composition represented by a multiple of the formula $\left[\left(\mathrm{C}_{6} \mathrm{H}_{10} \mathrm{O}_{5}\right)+3 \mathrm{H}_{2} \mathrm{O}\right]$. Villiers noted again that the white crystals with a very slight sweetness showed extremely high optical activity. Pursuing his experiments, he observed that the two dextrins, always considered as isomers of starch, were almost insoluble in water, soluble in alcohol, non-fermentable, acid resistant, and they could also be converted into ethers under the action of acid chlorides. Villiers finally concluded that the properties of these two particular dextrins were very clearly different from those of the various saccharides and polysaccharides known at the time and proposed the name of "cellulosines" due to the similarities with cellulose, e.g., with "regard to difficulty of acid hydrolysis" (Villiers 1891c, d).

At the beginning of the 1900s, Heinrich Robert Koch, a famous German physician and microbiologist, Nobel Prize in 1905, remained unconvinced by Villiers' conclusions (Crini 2014). In Koch's opinion, Villiers used "primitive bacteriological techniques and probably impure cultures." This was also pointed out by Schardinger (1904). Later, French (1957a) indicated that "Villiers used impure cultures but his digests contained sufficient Bacillus macerans to account for the small amount of crystalline dextrin obtained."

The recognition to cyclodextrins is attributed to Franz Schardinger, an Austrian chemist and bacteriologist. Schardinger is the first Great Scientist who has left its mark on the history of these oligosaccharides. He is considered the "Founding Father" of cyclodextrin (Szejtli 1982a; Crini 2014, 2020a). At the beginning of the last century, Schardinger also observed the formation of dextrins during his investigations of resistant micro-organisms that can lead to food poisoning. Like other researchers at that time, Schardinger studied these dextrins with the expectation that they would shed some light on the synthesis and degradation of starch. In 1903, Schardinger discovered that a type of extremely heat-resistant microorganism was able to dissolve starch and form crystalline by-products (Schardinger 1903a), remarkably similar to cellulosines reported by Villiers. Using the iodine test, Schardinger distinguished two types of "krystallisiertes dextrins" which he called crystallized dextrin A and crystallized dextrin B. The B form resembled Villiers' cellulosine. Indeed, the chemical behavior and the physical constants given by Schardinger for his substance agree very well with those of the dextrin previously described by Villiers. Schardinger found that it was possible to isolate pure fractions with a maximum yield of $30 \%$ crystallized dextrins from starch, the main form obtained being always dextrin B. "Krystallisiertes dextrins" were first considered as the degradation products of starch through heating (Schardinger 1903a). Schardinger also managed to isolate the strain of bacteria responsible for the degradation of starch-he called it strain II (Schardinger 1903b). He observed that this heat-resistant organism had considerable starch-fermenting power. When sub-cultured on starch, strain II broke down starch, giving an alcohol-insoluble "soluble starch" together with crystallized dextrin A (fine hexagonal plates) and crystallized dextrin B (stout prismatic crystals). Schardinger also observed that with time, the activity of the strain II microorganism decreased. Indeed, he was unsuccessful in maintaining a culture of strain II which had the characteristic starch-degrading activity.

In 1904, Schardinger isolated a new microorganism, considered as "an accidental contaminant," which he first called Rottebacillus I owing to its action on potato starch, i.e., it produced acetone and ethyl alcohol by fermentation of carbohydrate media (Schardinger 1904). The name Rottebacillus I was used to express the fact the microorganism was able to form both acetone and ethyl alcohol. Several months later, Schardinger used the Latin term Bacillus macerans to name his microbe, i.e., macerare, to rot. This bacillus was able to give the same crystalline dextrins as before, which he designated as "krystallisiertes polysaccharides," i.e., crystallized polysaccharides, considered then as the intermediate decomposition products of starch (Schardinger 1904). Using the characteristic reaction that starch derivatives show with iodine, Schardinger proposed a distinction between a "crystallized amylose" and a "crystallized amylodextrin." The yields obtained were tenfold those reported by Villiers. To explain this result, Schardinger suggested that, in the conditions of sterilization described by Villiers, the bacillus used was "probably not pure" (Schardinger 1904). One year later, Schardinger was also the first to observe that different starchy substrates differed in their behavior with Bacillus macerans, especially in the yields obtained (Schardinger 1905). 


\section{The foundation of the cyclodextrin chemistry}

Between 1905 and 1911, Schardinger made several important observations (Schardinger 1903a, b, 1904, 1905, 1909, 1911). He observed that cellulosines were often formed in starch-based media containing putrefying micro-organisms. The formation of the two crystallized dextrins depended on the type of bacteria digesting starch. The distinction between the two forms was always made through their ability to form complexes of different colors with iodine. Schardinger also studied the chemistry of the two dextrins, pointing out their lack of reducing power and hydrolysis to reducing sugar. Dextrins were non-reducing to copper reagents and non-fermentable by yeast. Schardinger also reported their behavior in the presence of alcohols, chloroform, ether, and iodine solution. He used the complexes with these solvents as a means of precipitation of dextrins. This was the first indication of the ability of dextrins to form "inclusion" complexes (French 1957a; Thoma and Stewart 1965; Szejtli 1998; Crini 2014, 2020a). Finally, Schardinger proposed empirical formulae of dextrins. However, he did not propose a structure for his crystallized dextrins and also did not attempt their molecular-weight determinations. It will take another twenty years before the cyclic nature of Schardinger's dextrins was recognized. Professor Schardinger decided to stop his research into dextrins in 1911, and as a conclusion he wrote: "I realize that still very many questions remain unsolved; the answer to these I must leave to another, who, owing to more favorable external conditions, can deal with the subject more intensively."

In the 24 years following Schardinger's final paper (Schardinger 1911), the field of research on crystallized dextrins was dominated by the groups of Pringsheim and Karrer. Pringsheim is recognized as the first researcher to have published prolifically on dextrins. However, the works were repetitive, marred by frequently contradictory results and by even hot debate between the two groups (French 1957a; Szejtli 1998; Crini 2014, 2020a, b; Morin-Crini et al. 2015).

\section{Historical landmarks in the exploration of cyclodextrins: from 1911 to 1970}

\section{Nomenclature}

In 1891, cyclodextrin was initially called "cellulosine" by Villiers because he assumed that the novel crystalline substance, obtained from digests of Bacillus amylobacter, was a kind of cellulose (Crini 2014, 2020a).

In 1903, Schardinger reported the formation of two "krystallisiertes dextrins" during his investigations of food spoilage, which he called crystallized dextrin A and crystallized dextrin $\mathrm{B}$, because most of their properties were similar to the already know partial degradation products of starch, i.e., the dextrins (Schardinger 1903a, b). One year later, the "krystallisiertes dextrins," considered as the intermediate crystallized decomposition products/byproducts of starch, were designated by the term "krystallisiertes polysaccharides," i.e., crystallized polysaccharides (Schardinger 1904). Pursuing his investigations on the structure of starch, Schardinger then introduced a distinction between a "crystallized amylose" for dextrin A and a "crystallized amylodextrin" for dextrin B, because, for him, there was an analogy between his dextrins and amylose and amylodextrin, especially with respect to their iodine colorreactions (Schardinger 1905, 1907). Finally, Schardinger considered that these names were inappropriate and thus decided to rename it "crystallized dextrin- $\alpha$ " and "crystallized dextrin- $\beta$ " (Schardinger 1911).

In the mid-1910s, the German chemist and biochemist Hans Pringsheim used the name of "krystallisiertes polyamylosen," i.e., crystallized polyamyloses, distinguishing two series, the $\alpha$-series of dextrins contained $2 \mathrm{n}$ D-glucose units per molecule and the $\beta$-series containing $3 \mathrm{n}$ D-glucose units per molecule. Four substances, i.e., $\alpha$-diamylose, $\alpha$-tetraamylose, $\alpha$-hexaamylose, and $\alpha$-octaamylose, were included in the $\alpha$-series of dextrins, while the $\beta$-series only contained two substances, i.e., $\beta$-triamylose and $\beta$-hexaamylose. Indeed, for Pringsheim, the Schardinger dextrins arose through the bacterial depolymerization of starch to the fundamental units: the amylose fraction being broken down into the $\alpha$-series of dextrins, i.e., polyamyloses, and the amylopectin fraction being degraded to the $\beta$-series (French 1957a; Thoma and Stewart 1965; Caesar 1968; Szejtli 1998; Morin-Crini et al. 2015; Crini 2020b). Pringsheim also used the terms of $\alpha$-amylosan, $\alpha$-allo-amylosan and $\alpha$-iso-amylosan, and $\beta$-amylosan, $\beta$-allo-amylosan and $\beta$-isoamylosan for $\alpha$-dextrin and $\beta$-dextrin, respectively (Crini 2014). At the same time, the Swiss chemist Paul Karrer also introduced the notion of series of crystallized dextrins. Like Pringsheim, Karrer was convinced that the $\alpha$-series of dextrins was composed of at least four distinct substances differing in molecular size. However, he disagreed with the subdivision of the $\beta$-series into triamylose and hexaamylose. For Karrer, these two products were identical. In addition, Karrer regarded maltose as the fundamental unit of the whole of the starch molecule while Pringsheim considered the polyamyloses as the basic units of the starch molecule (French 1957a; Thoma and Stewart 1965; Caesar 1968; Szejtli 1998; Morin-Crini et al. 2015). Like Pringsheim, Karrer also used the amylosan-based terminology (Crini 2014).

In the 1920s, as a tribute of the pioneering work of Schardinger, the German chemist Karl Johann Freudenberg called them "Schardinger dextrins" and referred to these compounds as $\alpha$-dextrin and $\beta$-dextrin (French 1957a; Thoma and Stewart 1965; Caesar 1968; Szejtli 
1998; Loftsson and Duchêne 2007; Kurkov and Loftsson 2013; Morin-Crini et al. 2015), and later as pentaosan and hexaosan, respectively (Crini 2014). For many years, cyclodextrins were called "Schardinger dextrins" in his honor, almost up to the 1970 s, or also sometimes simply as dextrins (Szejtli 1998). Schardinger dextrins were subsequently named "cycloamyloses" by the American chemist Dexter French in 1942 (French and Rundle 1942), "cycloglucanes" by Freudenberg in 1943 (Freudenberg 1943), and finally "cyclodextrins" in 1949 by the German chemist Friedrich Cramer, a pupil of Freudenberg (Cramer 1949). The model of "cycloamyloses" was constructed from glucopyranose units in the boat conformation. For French, $\alpha$-dextrin, $\beta$-dextrin and $\gamma$-dextrin must be called cyclohexaamylose, cycloheptaamylose, and cyclooctaamylose, respectively, the Greek prefix to the "amylose" corresponding to the degree of polymerization, i.e., indicating the number of glucose units in the ring (French and Rundle 1942). However, at that time, Freudenberg claimed that "this new nomenclature was inappropriate and ambiguous" (Freudenberg 1943). Again, in 1947, Freudenberg wrote: "It appears to be premature to rename the $\alpha$-dextrin cyclohexa-amylose and the $\beta$-dextrin cyclohepta-amylose” (Freudenberg et al. 1947a, b). In 1943, Freudenberg proposed the cycloglucane-based nomenclature, e.g., cyclohexaglucane $\alpha(1 \rightarrow 4)$, cycloheptaglucane $\alpha(1 \rightarrow 4)$ and cyclooctaglucane $\alpha(1 \rightarrow 4)$ for $\alpha$-dextrin, $\beta$-dextrin, and for $\gamma$-dextrin, respectively (Freudenberg 1943). During the mid-1940s, there was another system in current use (Crini 2014). In the alternate system, the number of residues in the cyclic polymer was indicated by prefixing a Greek letter to the series name. Since the smallest known cycloamylose was a hexamer, it was assigned the prefix $\alpha$. The cyclic heptatose, octaose, etc., were referred to, respectively, as $\beta, \gamma$, etc. The first system introduced by French was, however, preferred because it was more descriptive of the structures.

At the end of the 1940s, Cramer first proposed the cyclobased nomenclature for the nomenclature of the Schardinger dextrins, e.g., (6-ose)-cyclo, (7-ose)-cyclo and (8-ose)-cyclo for $\alpha$-, $\beta$ - and $\gamma$-dextrins, respectively. For the first time in 1949, Cramer introduced the term cyclodextrin. This name was included in the title of his Ph.D. dissertation entitled "Die Cyclodextrine aus Stärke" (Cramer 1949). For Cramer, the term of cyclodextrin must be used to refer to cyclic oligosaccharides made up of 6,7 , or 8 units of D-glucose joined by $\alpha-(1 \rightarrow 4)$ linkages termed $\alpha$-, $\beta$-, and $\gamma$-cyclodextrin, respectively. Because of its relative brevity, the term cyclodextrin was soon accepted, but the nomenclature of cyclodextrins remained a subject of debate until the end of the 1990s (Szejtli 1998; Loftsson and Duchêne 2007; Kurkov and Loftsson 2013; Crini 2014; Morin-Crini et al. 2015). Indeed, at that time, several laboratories proposed clarifications of the nomenclature of cyclodextrins because the term cyclodextrin only specified the nature of the sugars but did not give any information on the bonding between them. Thus, the name cyclomaltohexaose was suggested in 1997. This name is composed of first the term cyclo followed by a term indicating the type of linkage, i.e., malto for glucose units bounds by $\alpha-(1 \rightarrow 4)$ linkages, the number of sugar units with the ending ose, i.e., hexa for 6 or hepta for 7 . This final term, present in cyclomaltohexaose, implies a free anomeric center, which is not present in cyclodextrins. Both the terms cyclodextrins and cyclomalto-oligosaccharides were used (Crini 2014).

Other nomenclatures have also been proposed. For instance, $\alpha$-cyclodextrin was named cyclohexakis- $(1 \rightarrow 4)-\alpha$-D-glycosyl or cyclo- $\alpha-(1 \rightarrow 4)$-glucohexaoside. The name of the glycosyl residue is preceded by the type of linkage between brackets, in turn preceded by the term cyclo plus an indication of the number, i.e., cyclohexakis, etc. The literature uses all of these nomenclatures. Nevertheless, the cyclodextrin-based nomenclature is still the most widely used in literature today. The nomenclature for large-ring cyclodextrins, i.e., LR-CDs with a degree of polymerization between 9 and $>100$, is more simply: each molecule is designated by an abbreviation CDn where $n$ indicates the number of glucose units in the macrocycle, e.g., CD14 (boat-like structure) composed of 14 glucose units (Morin-Crini et al. 2015; Assaf et al. 2016; Sonnendecker and Zimmermann 2019a, b; Sonnendecker et al. 2018, 2019).

\section{Native cyclodextrins}

Schardinger recognized only dextrin- $\alpha$ and dextrin- $\beta$, while Freudenberg obtained $\gamma$-dextrin in 1948, although previously regarded by him as a cyclic heptasaccharide (Freudenberg and Cramer 1948). Two years later, Freudenberg elucidated the structure of $\gamma$-dextrin (Freudenberg and Cramer 1950). The same year, using partial acid hydrolysis and enzyme digestion followed by X-ray measurements and paper chromatography, French also elucidated the structure of $\gamma$-dextrin, first named "cycloöctaamylose," and later cyclooctaamylose (French et al. 1950b). This dextrin was composed of eight glucose residues symmetrically arranged in a ring and linked together by $\alpha-1,4$-glucosidic bonds. In the late $50 \mathrm{~s}$, French and co-workers had established the molecular weight, the exact chemical structure, the dimensions and the types of bonding in the three cycloamyloses, cyclohexaamylose, cycloheptaamylose, and cyclooctaamylose, i.e., $\alpha$-dextrin, $\beta$-dextrin and $\gamma$-dextrin, respectively (French and McIntire 1950; Norberg and French 1950; French et al. 1950a, 1950b).

In 1948, the first indications of the existence of higher homologues of dextrins were published by Freudenberg and his young student Cramer (Freudenberg and Cramer 
1948). Two years later, French also suggested the possible existence of cycloamyloses containing more than 8 glycosyl units (Norberg and French 1950; French et al. 1950b). The same year, Akiya and co-workers claimed the "discovery of new series of cyclic oligosaccharides" similar to the Schardinger dextrins, containing more than 8 glucose units (Akiya and Watanabe 1950a, b, c; Akiya and Okui 1951). Later, Caesar (1968) reported that these "new" compounds were the $\alpha$ - and $\beta$-dextrins. In fact, the existence of larger homologues of cycloamyloses was clearly demonstrated a decade later by French. In 1957, French discovered deltadextrin or $\delta$-dextrin and epsilon-dextrin or $\varepsilon$-dextrin, containing 9 and 10 units of glucose, respectively (French $1957 \mathrm{a}, \mathrm{b})$. He proved their existence using radioautography and chromatography measurements. However, French elucidated their structures only in 1965 (French et al. 1965). At that time, French also wrote: "there is no obvious reason why the series should stop here" (French 1957a), suggesting the existence of cycloamyloses with 11 and 12 units of glucose, i.e., $\xi$-dextrin or zeta-dextrin and $\eta$-dextrin or etadextrin, respectively. In the beginning of the 1960s, French continued to study cycloamyloses with a larger ring. His objective was to develop a fractionation method for isolation of larger homologs of cycloamyloses after extensive $\beta$-amylase digestion to hydrolyze maltooligosaccharides. In 1961, the existence of cycloamyloses with 11 and 12 units of glucose is confirmed using radioautography (Pulley and French 1961), and four years later, he was the first to propose a fractionation method for their isolation (French et al. 1965). The structure and the dimensions of $\xi$-dextrin and $\eta$-dextrin are reported. French finally introduced the notion of Schardinger dextrin series, "a Schardinger dextrin family" (French et al. 1965). The same year, Thoma and Stewart (1965) also published similar results and the discovery of $\xi$-dextrin and $\eta$-dextrin is attributed to them (Caesar 1968; Szejtli 1998; Loftsson and Duchêne 2007).

French's results had for many years been regarded as dubious since they were not able to experimentally distinguish the large cyclodextrins from branched derivatives. As late as 1988, Szejtli expressed his doubts, in his monograph "Cyclodextrin Technology," to whether cyclodextrins larger than $\gamma$-cyclodextrin exist (Szejtli 1988). In fact, higher cyclic cyclodextrins than the three native cyclodextrins, reported in the period 1960s, were probably so-called branched derivatives such as branched diglucosyl-cyclodextrins. When a section of the amylopectin molecule containing a branching point was incorporated into a cyclic structure, one or two glucosyl or maltosyl side chains were attached by $\alpha-(1 \rightarrow 6)$ linkages to the ring formed (Frömming and Szejtli 1994). During the production of native cyclodextrins, these branched cyclodextrins were also produced. It was only during the mid-1990s that the existence of the large cyclodextrins has been fully proven (Miyazawa et al. 1995;
Endo et al. 1997, 1999; Larsen 2002; Qi et al. 2004; Taira et al. 2006; Crini 2014).

\section{Cyclodextrin chemistry}

For over 20 years, Pringsheim and his various collaborators penned an abundant literature on dextrins (Crini 2020b). However, these studies suffered from numerous errors due to the use of dextrins that were not pure and to problems arising from separation of the fractions and from the use of unsuitable analytical methods, e.g., determination of the masses by cryoscopy (Freudenberg and Jacobi 1935; Samec and Blinc 1941; French 1957a; Thoma and Stewart 1965; Caesar 1968). In 1935, Freudenberg dismissed the work of Pringsheim as practically valueless, since "most of it was based upon work with dextrin mixtures and upon serious misconceptions relating to the structural principles of high polymers" (Freudenberg and Jacobi 1935). French (1957a) also wrote: "Pringsheim's literature was voluminous but much of it was repetitive, controversial, or based on erroneous concepts."

From 1910, Pringsheim repeated Schardinger's experiments. He reported higher yields of $\beta$-dextrin from glycogen crude preparations of amylopectin, and this is the reason why he postulated that amylose was polymerized $\alpha$-diamylose, and amylopectin and glycogen were polymerized $\beta$-triamylose. Like Schardinger, Pringsheim observed that the relative proportions of $\alpha$ - and $\beta$-dextrins depended on the different substrates used (Pringsheim and Langhans 1912). Pringsheim described the chemical behavior of dextrins and their properties, in agreement with the previous results published by Schardinger. The dextrins were soluble in water but insoluble in alcohol, ether and chloroform. They do not reduce Fehling's solution. To precipitate the dextrins, different solvents including benzene, toluene, xylene, bromobenzene, nitrobenzene, and petroleum ether were proposed (Pringsheim and Eissler 1913, 1914; Pringsheim 1915; Pringsheim and Lichtenstein 1916). Pringsheim confirmed that the simplest means to distinguish between the $\alpha$ - and $\beta$-dextrins were the iodine reaction (Pringsheim 1922; Pringsheim and Dernikos 1922). Pringsheim was the first to study the halogen complexes of dextrins (Pringsheim and Wolfsohn 1924; Pringsheim and Schapiro 1926). The first methylated $\beta$-dextrin was also obtained by his group: $43.6 \%$ of degree of methylation as against $45.6 \%$ required by theory. Several data can also be found referring to the preparation of dextrin derivatives including acetates, nitrates, and ethers (Pringsheim 1927, 1928a, b, 1931b; Pringsheim and Meyersohn 1927; Irvine et al. 1929; Pringsheim et al. 1930, 1931a, b; Pringsheim and Beiser 1932). However, all Pringsheim's data are essentially of historic interest (Samec and Blinc 1941; French 1957a; Thoma and Stewart 1965; Caesar 1968; Szejtli 1982a; Crini 2014). From 1920 
to 1925 , Karrer also contributed greatly to the knowledge of the chemistry of the Schardinger dextrins (Thoma and Stewart 1965; Caesar 1968; Szejtli 1998; Crini 2014). Karrer published several important works on dextrins (Karrer 1920, 1921, 1922, 1923, 1925; Karrer and Nägeli 1921a, b; Karrer et al. 1921, 1922; Karrer and Bürkin 1922). Like Schardinger and Pringsheim, Karrer studied the crystallized dextrins with the expectation that they would shed some light on the features of starch. In 1921, Karrer published the first conclusions on the acetolysis of $\alpha$-dextrin and $\beta$-dextrins. He demonstrated that this reaction gave essentially the same excellent yield of maltose as starch or maltose itself give, when treated similarly (Karrer 1921; Karrer and Nägeli 1921a, b; Karrer et al. 1921). Karrer also investigated the interactions between dextrins and ions such as barium, sodium, and potassium (Karrer 1922; Karrer and Bürkin 1922; Karrer et al. 1922). In 1925, Karrer summarized the whole of his works and conclusions on dextrins in a famous comprehensive book (Karrer 1925).

Between 1911 and 1935, epoch called by Crini (2014) the "period of doubt," other researchers have also published interesting works on the chemistry of the Schardinger dextrins (Biltz 1913; Biltz and Truthe 1913; Freudenberg and Ivers 1922; Miekeley 1930, 1932; Ulmann 1932, Ulmann et al. 1932; Hess et al. 1933). Miekeley $(1930,1932)$ published experimental data on the chemical composition of dextrins, which complemented those of Pringsheim. In 1933, Ulmann's group observed that the $\alpha$-dextrin-ethanol complex had two different crystal modifications which could be interconverted. This was the first observation that a same guest may form different crystal structures with the same dextrin (Hess et al. 1933). However, this period did nothing to stimulate the development of Schardinger dextrins, considered as by-products of starch degradation, and the work on cyclodextrins reported before 1935 was little consequence (Samec and Blinc 1941; Thoma and Stewart 1965; Caesar 1968; Szejtli 1998; Crini 2014). This can be explained by the fact that researchers used incompletely separated fractions and based too much reliance on cryoscopic measurements of molecular weights, which led to many anomalous results.

From 1935 to 1950, epoch called by French (1957a) the "maturation period," the works of Freudenberg on the chemistry of the Schardinger dextrins were acknowledged to have made an important contribution to the cyclodextrin science (Freudenberg and Jacobi 1935; Freudenberg and Rapp 1936; Freudenberg et al. 1936, 1938, 1939, 1947a, b; Freudenberg and Meyer-Delius 1938, 1939; Freudenberg 1939, 1943; Freudenberg and Cramer 1948, 1950). Indeed, Freudenberg is recognized as a pioneer in this domain (Thoma and Stewart 1965; Caesar 1968). As far back as 1922, Freudenberg was the first researcher to focus on the chemical modification of dextrins, in particular of tosylated residues (Freudenberg and Ivers 1922). Later, the Schardinger dextrins were oxidized by iodite, "probably by a glycol-cleavage reaction" (Freudenberg 1934). Enzymic hydrolysis gave no trace of a sugar unit other than $D$-glucose (Freudenberg and Jacobi 1935). During the hydrolysis of dextrins, Freudenberg also observed an increase in rotation due to hydrolysis of the $\beta$-linkage. During acetolysis, the dextrins were shown to be more nearly similar to starch than to compounds of the levoglucosan type. Using a cryoscopic method for the determination of molecular weights, Freudenberg reported (erroneously) the number of glucose units that the Schardinger dextrins contained: five for $\alpha$-dextrin and six for $\beta$-dextrin (Freudenberg and Jacobi 1935). In 1936, Freudenberg confirmed that enzymatic hydrolysis gave no trace of a sugar unit other than D-glucose. He also reported that methylation studies failed to reveal the presence of any $D$-glucose units, concluding that glucose was the only product of acid hydrolysis of dextrins (Freudenberg and Rapp 1936). The following pieces of experimental evidence were also published: (i) the rate of hydrolysis of dextrins in $51 \%$ sulfuric acid was too low for there to be any labile $\beta$-linkages present; (ii) the Schardinger dextrins were non-reducing, that was, they did not have a reducing chain-termination; and (iii) methylation studies on dextrins gave no products than 2,3,6-O-methyl$D$-glucose (Freudenberg and Rapp 1936). The same year, Freudenberg prepared fully methylated $\alpha$ - and $\beta$-dextrins, and finally demonstrated that 2,3,6-tri-methylglucose was the only product of methylation of dextrins followed by hydrolysis (Freudenberg et al. 1936). Later, acetate derivatives of the dextrins were proposed and characterized for the first time (Freudenberg et al. 1947a, 1947b). In 1955, Freudenberg published a detailed description of the chemistry of the three main cyclodextrins (Freudenberg 1955), and in 1962, he summarized all his results (Freudenberg 1962).

Between 1942 and 1950, French published numerous important contributions on the chemistry of the Schardinger dextrins (French and Rundle 1942; Rundle and French 1943; Bates et al. 1943; French et al. 1948, 1949a, b, 1950a, b, 1954; French and McIntire 1950; Norberg and French 1950). Very quickly, like Freudenberg, French became a pioneer in the understanding of their chemistry (Thoma and Stewart 1965; Caesar 1968; Szejtli 1998; Crini 2014). French showed that the Schardinger dextrins, being cyclic, had no non-reducing end group and they were extremely resistant to alpha-type amylases. Using data from periodate oxidation and methylation reactions, he demonstrated that Schardinger dextrins could not be open-chain compounds. Periodate oxidation was slow with Schardinger dextrins in comparison with that of straight-chain amylodextrin. French also published solubility data on cycloamyloses, especially in the presence of organic liquids. Solubility data of dextrins in water at room temperature were as follows: $\alpha$-dextrin $14.5 \mathrm{~g} / 100 \mathrm{~mL}, \beta$-dextrin $1.8 \mathrm{~g} / 100 \mathrm{~mL}$, and $\gamma$-dextrin $23.2 \mathrm{~g} / 100 \mathrm{~mL}$ (French et al. 1949a). Using data 
from periodate oxidation and methylation reactions, French definitively demonstrated that Schardinger dextrins could not be open-chain compounds and they were regarded as conical cylinders (French and McIntire 1950; Norberg and French 1950; French et al. 1950a, b). At that time, Schardinger dextrins were also found to be rather anomalous structures with interesting complexing properties when compared with the linear oligosaccharides. French indeed suggested for the first time the fact that cycloamyloses were capable of forming particular complexes. The nature of the complexes between halogen and Schardinger dextrins, particularly the iodine complexes, depended much on the amount of the halides added. However, the cavity of dextrins was referred to as hydrocarbon in nature by French. This result has been definitively abandoned in 1965 with the advent of the modern conformational theory.

\section{Molecular structure of Schardinger dextrins}

Schardinger was the first to hypothesize that the crystalline substances were "cyclic polysaccharides" (Schardinger 1907, 1909, 1911). However, he never managed to elucidate their structure.

Karrer (1920) was the first to suggest that the dextrins were made up of several components, and one year later, he proved it using detailed acetolysis data (Karrer 1921; Karrer and Nägeli 1921a, b; Karrer et al. 1921). In 1923, Karrer was also the first to propose that dextrins are composed of maltose units only joined by $\alpha-(1 \rightarrow 4)$ glucosidic linkages (Karrer 1923, 1925), although Pringsheim (1922, 1924) remained unconvinced by Karrer's conclusions. Later, Miekeley $(1930,1932)$ also came to the same conclusions as Karrer. In 1926, Pringsheim is finally convinced by Karrer's conclusions (Pringsheim 1926) although he continued to regard the polyamyloses as the basic units of the starch "molecule" (Pringsheim 1928a, 1931a). However, just like Schardinger, Karrer and Miekeley, Pringsheim failed to elucidate the cyclic structure of the dextrins.

From 1934 for a period of approximately 25 years, the main contributions toward the molecular structure and size of the Schardinger dextrins were developed by Freudenberg (Freudenberg 1934, 1939, 1943, 1955, 1957a, 1957b; Freudenberg and Jacobi 1935; Freudenberg and Rapp 1936; Freudenberg et al. 1936, 1938, 1939, 1947a, b, 1953; Freudenberg and Meyer-Delius 1938, 1939; Freudenberg and Cramer 1948, 1950). From 1922, Freudenberg was attracted by Schardinger dextrins since he wanted to obtain information on the degradation products of starch to be able to elucidate its structure (Freudenberg and Ivers 1922). For Freudenberg, Schardinger dextrins were first laboratory curiosities and/or unwanted by-products of starch degradation (Freudenberg 1934), and their chain molecules were intermediate between maltose and starch with non-reducing end-groups. Indeed, it is only at the end of the 1930s that Freudenberg concluded that the dextrin- $\alpha$ and dextrin- $\beta$ molecules were cyclic. In 1935, $\alpha$-dextrin was considered as a mixture of chain molecules containing 4-5 D-glucose units (Freudenberg and Jacobi 1935). Using results of constructing molecular models with the monomer units in a boat rather than a chain conformation, the dextrins were lined with a hydrocarbon interior. One year later, studying the nature of the glycosidic bonds, Freudenberg showed that the dextrins gave rotation-time curves closely parallel to those given by starch and the rigid models such as Kekule model did not allow free rotation about the individual bonds (Freudenberg and Rapp 1936). The presence of a "Konstellation," i.e., a ring conformation, is suggested, and in 1936, Freudenberg hypothesized that $\alpha$-dextrin and $\beta$-dextrin have a cyclic structure (Freudenberg et al. 1936). During 2 years, he tried to prove it. On the basis of results obtained from methylation reactions and enzymatic hydrolysis of the dextrins, Freudenberg came, in 1938, to the "same conclusion" as Schardinger, Karrer, Pringsheim and Miekeley, concerning the cyclic chemical structure of $\alpha$-dextrin and $\beta$-dextrin (Freudenberg and Meyer-Delius 1938; Freudenberg et al. 1938). Ten years later, Freudenberg and his doctoral student Cramer finally demonstrated his conclusion using optical activity data (Freudenberg and Cramer 1948). Schardinger dextrins had a cyclic structure composed of maltose units bound together by $\alpha-(1 \rightarrow 4)$ glycosidic linkages. At that time, both French and Borchert also confirmed the cyclic structure of dextrins by X-ray crystallography (French et al. 1948; Borchert 1948). However, although Freudenberg had determined for the first time the correct chemical structure for the Schardinger dextrins, the number of D-glucosyl residues that he gave for the $\alpha$ - and $\beta$ - dextrin rings, i.e., five and six, respectively, using a cryoscopic method was incorrect. The correct values were determined by French using both $\mathrm{X}$-ray diffraction and crystal density measurements.

Between 1942 and 1965, French also contributed greatly to the molecular structural knowledge of the Schardinger dextrins, or, as he preferred to call them, cycloamyloses (Caesar 1968; Szejtli 1998; Crini 2014). Very quickly, French became a pioneer in the understanding of their structure, publishing an impressive number of results on cycloamyloses which are still used as references today (French and Rundle 1942; Rundle and French 1943; Bates et al. 1943; French et al. 1948, 1949a, 1949b, 1950a, 1950b, 1954; French and McIntire 1950; Norberg and French 1950; French 1957a, b, 1960, 1962; Bailey and French 1957; Thoma and French 1958, 1959, 1960, 1961; James et al. 1959; Thoma et al. 1959; Whelan et al. 1960; Pulley and French 1961; Robyt and French 1964; French and Abdullah 1965; French et al. 1963, 1965). French's first work concerned the molecular weights of the Schardinger dextrins, considered as cyclic molecules in agreement with the previous results published 
by Freudenberg (Freudenberg and Meyer-Delius 1938; Freudenberg et al. 1938). French and Rundle (1942), using the X-ray diffraction technique and crystal density measurements, determined the molecular weights of $\alpha$-dextrin and $\beta$-dextrins and discovered the correct number of glucose units per dextrin, i.e., six and seven, respectively, in disagreement with the results published by Freudenberg and Jacobi (1935). French and Rundle concluded that the X-ray diffraction technique was better suited to the determination of the molecular weights of high molecular weight crystalline substances since impurities, such as solvent of crystallization and inorganic ash, were of minor importance (French and Rundle 1942). In this paper, French also suggested that Schardinger dextrins were cyclic "macromolecules," formed from starch polysaccharide (French and Rundle 1942). They were non-reducing "D-glucopyranosyl polymers" containing 6,7 or 8 units linked by $\alpha-D-(1 \rightarrow 4)$ bonds, in agreement with the results published by Karrer (1923) and Miekeley (1932). In each cycloamylose "macromolecule," the $D$-glucose units were in the $\mathrm{C} 1$ conformation. Schardinger dextrins were then regarded as cylinders (French and Rundle 1942). However, Freudenberg did not agree with this point of view (Freudenberg 1943).

French pointed out three interesting features: (1) as a consequence of the $\mathrm{C}-1$ conformation of the glucopyranose units, all the secondary hydroxyl groups were located on one side of the cylinder, whereas all the primary hydroxyl groups were located on the opposite side of the cylinder; (2) the interior of the cylinder consisted only of a ring of $\mathrm{C}-\mathrm{H}$ groups, a ring of glucosidic oxygens and another ring of $\mathrm{C}-\mathrm{H}$ groups; and (3) the interior of the cavity was relatively apolar compared to water (French and Rundle 1942; Rundle and French 1943; Bates et al. 1943; French et al. 1948, 1949a, b). Freudenberg claimed again that all the structural and conformational conclusions of French were ambiguous due to "the use of products that were not pure" (Freudenberg et al. 1947a, b). One year later, Freudenberg and Cramer concurred with French's results, after studying the X-ray measurements of Borchert (1948) and also his optical rotation data, publishing similar interpretations (Freudenberg and Cramer 1948; Cramer 1949). In 1950, French, studying the periodate oxidation of the three cycloamyloses, finally concluded that all three molecules had a cyclic structure in which each $D$-glucose unit was linked to the next by an $\alpha-D$-(1 $\rightarrow 4)$-glucosidic bond, and the interior of the cavity was apolar (French and McIntire 1950; Norberg and French 1950; French et al. 1950b). Schardinger dextrins were then regarded rather as conical cylinders than cylinders, in agreement with Cramer's suggestion. Another interesting feature is made by French: $\gamma$-dextrin was "a noncoplanar, more flexible structure," and therefore, it was the "most soluble of the three dextrins." Later, cycloamyloses were finally regarded as truncated cones or "capsules" by French (French 1957a), in agreement with the results published by Cramer (Cramer 1952, 1953, 1956; Dietrich and Cramer 1954).

Cramer also contributed greatly to the molecular structural knowledge of the Schardinger dextrins. In 1948, the young student Cramer published his first result on Schardinger dextrins (Freudenberg and Cramer 1948). Using optical activity, Cramer demonstrated the cyclic nature of $\alpha$ and $\beta$-dextrins. The same year, he discovered $\gamma$-dextrin and suggested that the three dextrins possessed an apolar cavity. One year later, Cramer received his Ph.D. at Heidelberg University, under the supervision of Freudenberg (Cramer 1949). He introduced the cyclodextrin-based nomenclature, demonstrated the cyclic nature of cyclodextrins using optical activity data and showed that the three cyclodextrins had different internal diameters and each cavity was filled with water molecules (Cramer 1949). His doctoral work was then published between 1951 and 1952 (Cramer 1951a, b, c, 1952), adding to the previous results of Freudenberg but mostly "confirming those of French" on the physical (cavity size) and chemical (reactivity) properties, the structure and chemistry of cyclodextrins. For instance, investigating the configuration at the anomeric centers by hydrolytic methods, Cramer came to the same conclusions as Karrer (1923), Miekeley (1932), and French and Rundle (1942) as to the existence of $\alpha-(1 \rightarrow 4)$ glucosidic/glycosidic linkages. Cramer also published for the first time a variety of other interesting features. Studying the molecular size of the three dextrins, he showed that a same dextrin could exist in different crystal forms. Cramer then discovered the toroidal form of the cyclodextrin molecules, considering cyclodextrins as truncated cones or "capsules" rather than cylinders, like previously reported by French et al. (1948, 1949a, b). He schematized his conclusions on the chemical structure of $\alpha-, \beta$ - and $\gamma$-cyclodextrins by the two schemes reported in Fig. 2. Cramer finally concluded that cyclodextrins were non-reducing oligosaccharides containing 6,7 or 8 units linked by $\alpha-D-(1 \rightarrow 4)$ bonds, having both hydrophobic and hydrophilic regions. On the side where the secondary hydroxyl groups were situated, the diameter of the cavity was larger than on the side with the primary hydroxyls, since free rotation of the latter reduced the effective diameter of the cavity (Cramer 1953, 1956; Dietrich and Cramer 1954).

In 1965, both Casu et al. (1965) and Hybl et al. (1965) confirmed the conclusions published by French and Cramer on the cyclic structure of cyclodextrin and its features, using NMR spectra in dimethylsulfoxide solution and using $\mathrm{X}$-ray crystallography of the $\alpha$-cyclodextrin-potassium acetate complex, respectively. Their results clearly demonstrated that i) all the glucose residues of cyclodextrins were in the ${ }^{4} \mathrm{C} 1$ chair conformation; ii) the cavity was lined by the hydrogen atoms and the glycosidic oxygen bridges, respectively; and iii) the nonbonding electron pairs of the glycosidic oxygen bridges were directed toward the inside 
Fig. 2 (a) The general chemical structure for cyclodextrins ( $\mathrm{n}=$ number of glucose units; $\mathrm{n}=6,7$ and 8 for $\alpha-, \beta$ - and $\gamma$-cyclodextrin, respectively, and (b) their particular structure showing the apolar cavity of a cyclodextrin "capsule" or torus (a)

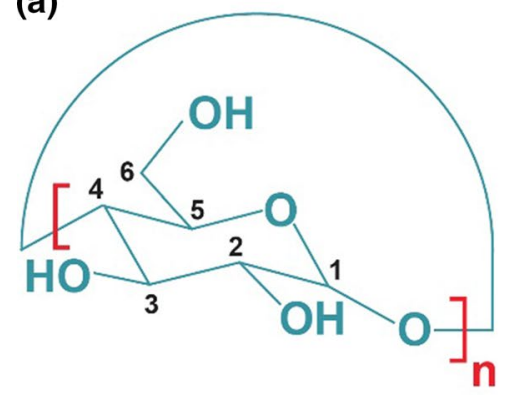

(b)

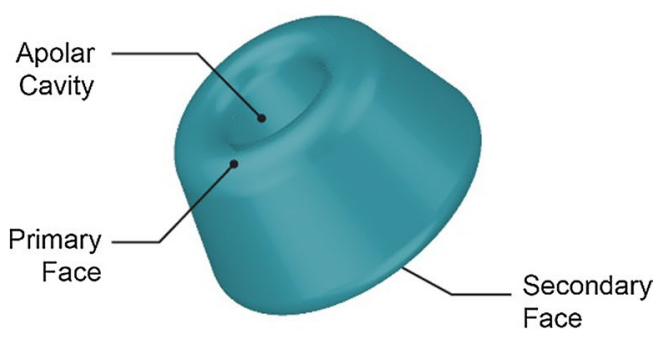

of the cavity, producing a high electron density. The schematic representations of the chemical tridimensional structure and dimensions (Fig. 3) for $\alpha$-, $\beta$ - and $\gamma$-cyclodextrin are finally accepted at the mid-1960s. Later, a more precise study of the conformation of $\alpha$-cyclodextrin in solution was made by Saenger' group using NMR spectroscopy (Wood et al. 1977). All six glucose units had identical conformations and the molecule had hexagonal symmetry. The secondary hydroxyl groups, which were located in one side of the torus of cyclodextrins, formed hydrogen bond with the secondary hydroxyl groups of contiguous glucose units, in agreement with the previous conclusions published by Casu et al. (1965) and by Hybl et al. (1965). In the cyclodextrin molecule, a complete secondary belt was formed by hydrogen bonds, making it a rigid structure. This was proposed to explain the fact that, among the three native cyclodextrins, $\beta$-cyclodextrin had the lowest solubility (Wood et al. 1977). The hydrogen belt was incomplete in the $\alpha$-cyclodextrin molecule and $\gamma$-cyclodextrin was a noncoplanar, more flexible structure, confirming the results published by French and McIntire (1950). At the beginning of the 1960s, French indicated the possible existence of "a Schardinger dextrin family," describing the structure of $\delta$-dextrin, $\varepsilon$-dextrin, $\xi$-dextrin, and $\eta$-dextrin containing 9, 10, 11, and 12 glucose units, called larger homologues of cycloamyloses (Pulley and French 1961; French et al. 1965). These larger dextrins
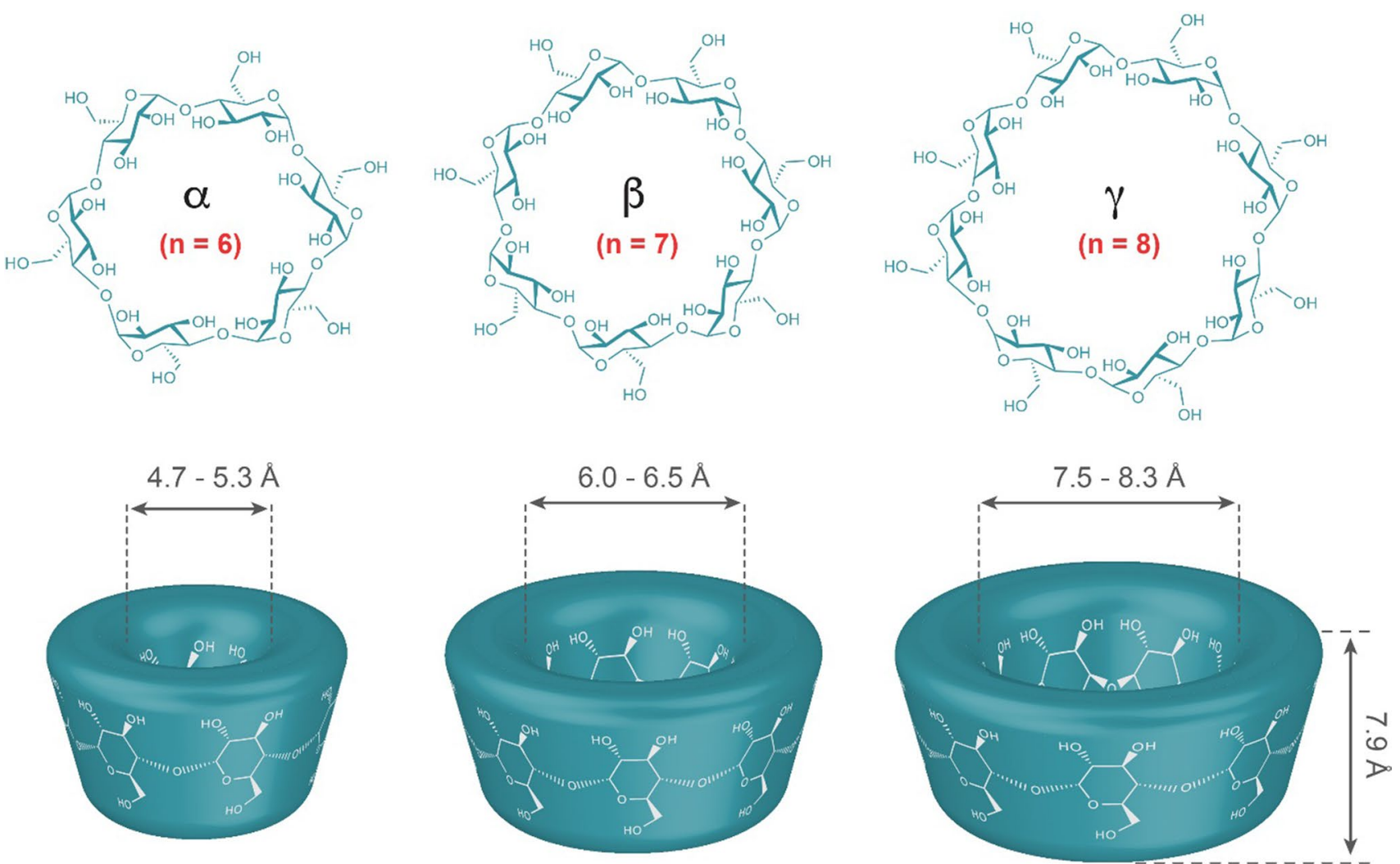

Fig. 3 Chemical tridimensional structure and dimensions for $\alpha$-, $\beta$ - and $\gamma$-cyclodextrins $(n=6,7$ and 8, respectively) accepted in the 1960 s 
were not regular cylinder-shaped structures. Indeed, they were collapsed and their real cavity was even smaller than the $\gamma$-dextrin.

\section{Preparation and separation of Schardinger dextrins}

Between 1905 and 1911, Schardinger studied the first preparation, fractionation/separation, and purification of the two cellulosines (Schardinger 1905, 1907, 1909, 1911). In 1911, he published the first fractionation and purification scheme of the dextrins. Later, both Freudenberg, French and Cramer published other important schemes: see the references French (1957a) and Thoma and Stewart (1965).

The dextrins were synthesized from several sources of starch, e.g., potatoes, rice and wheat, and bacteria, e.g., the formation of dextrins depended on the type of bacteria digesting starch. About $25-30 \%$ of the starch was converted to crystalline dextrins depending on these parameters. The yield were tenfold those reported by Villiers (Schardinger 1907). Schardinger also based his method of separation on the ease of crystallization of the $\beta$-dextrin from water and its low solubility, about $1.5 \%$ at room temperature, followed by precipitation of the $\alpha$-dextrin from the mother liquor by the addition of alcohol. Schardinger' protocol was modified by Lange in 1925 who introduced trichloroethylene as a precipitating agent for the crystalline dextrins (Lange 1925). This protocol is described in detail in Pringsheim's book (Pringsheim 1932).

In 1935, Freudenberg and his student Jacobi described a method for the synthesis of Schardinger dextrins with high purity (Freudenberg and Jacobi 1935). Freudenberg is indeed recognized as the first to prepare almost pure dextrins with high yields (Thoma and Stewart 1965; Caesar 1968; Clarke et al. 1988; Szejtli 1998; Crini 2014). Freudenberg improved the separation of dextrins and produced a scheme based not only on solubility differences of the dextrins themselves, as initially proposed by Schardinger, but also on the differences in solubilities and rates of crystallization of their acetates (Freudenberg and Jacobi 1935). However, the protocol was difficult since it involved many acetylation and saponification reactions. During more than 10 years, this protocol was studied and modified, and in 1947, Freudenberg's group described the first scheme for the isolation of pure fractions of dextrins using bromobenzene as precipitant: $\alpha$-dextrin did not precipitate, while $\beta$-dextrin and $\gamma$-dextrin were readily precipitated (Freudenberg et al. 1947a, b).

French was also among the early researchers, along with Freudenberg, to focus on improving the production of dextrins. French became a pioneer in the preparation of the compounds in a very pure state. Knowing the works of the group of Hudson on the enzymolysis conditions which affected the yield and proportion of the dextrins (Tilden and Hudson 1939, 1942; Tilden et al. 1942; McClenahan et al.
1942; Wilson et al. 1943) and using his own results on the solubilities of Schardinger dextrins (French et al. 1949a), French proposed in 1949 a new protocol for the separation and purification of dextrins (French et al. 1949b), which did not require the acetylation and saponification steps used by Freudenberg. Treatment of starch with the amylase of Bacillus macerans gave crude starch digests containing the three cycloamyloses, i.e., $\sim 60 \% \alpha$-dextrin, $\sim 20 \% \beta$-dextrin, and $\sim 20 \% \gamma$-dextrin, together with small amounts of higher cycloamyloses. Moreover, the protocol permitted the facile separation of pure dextrins by differential precipitation using specific precipitants such as bromobenzene and propan1-ol (French et al. 1949b). Later, French showed that high temperature cellulose column chromatography was one of the most effective methods for the quantitative analysis of mixtures of cycloamyloses (Pulley and French 1961; French et al. 1965). This method was required in connection with the production of cycloamyloses since these products were simultaneously produced from starch together with the higher series of cycloamyloses.

In the mid-1950s, Cramer also investigated the enzymatic production of cyclodextrins, their separation and purification, and characterization (Cramer 1955, 1956; Cramer and Steinle 1955; Cramer and Henglein 1957a, b). Cramer described an easy protocol to separate $\alpha-, \beta$ - and $\gamma$-cyclodextrins from the digest by selective precipitation using appropriate organic compounds and optimize parameters, e.g., $\mathrm{pH}=6$ and temperature $=40^{\circ} \mathrm{C}$ (Cramer 1956). The three cyclodextrins are precipitated by addition of a tetrachloroethylene-tetrachloroethane mixture, followed by the addition of $p$-cumene. $\alpha$-Cyclodextrin was isolated by selective precipitation with cyclohexane, $\beta$-cyclodextrin with fluorobenzene, and $\gamma$-cyclodextrin with anthracene. Cramer explained his results by the difference in the sizes of cavities of the three cyclodextrins and concluded that the superiority of his method over previous procedures, particularly those of French, resided in the technical ease and the completeness of precipitation.

To summarize, during the periods of reaching maturity from 1935 to 1950 and of exploration from 1950 to 1970 , the separation and the purification of the mixture were difficult (Crini 2014; Crini et al. 2018). The period of reaching maturity was also marked by several contradictory results, due, at least in part to differences in the protocols used for the preparation of Schardinger dextrins and dubious purity of the samples (Thoma and Stewart 1965; Caesar 1968; Szejtli 1998). The work during these periods was even marred by hot debate between the different laboratories, especially those of Freudenberg and Cramer and of French. In addition, in the early $50 \mathrm{~s}$, researchers had not fully realized the potential of cycloamyloses and had little faith in their complexation properties (Szejtli 1998). The three main cyclodextrins were considered just laboratory curiosities 
difficult to produce. In 1963, French was the first to propose the preparation of cycloamyloses on a larger-than-laboratory scale (French et al. 1963). However, at the end of the 1960s, French concluded that "cycloamyloses were very promising molecules although they remained very expensive products, available only in small amounts as fine chemicals, and also toxic."

\section{The first Schardinger dextrin-related patents}

The first patent on Schardinger dextrins was registered in 1925 by the German Fritz Lange for IG Farbenindustrie. This patent entitled "Verfahren zur gewinnung von polyamylosen" focused on the isolation of polyamyloses (Lange 1925). Freudenberg, Cramer and Plieninger filed the first industrial cyclodextrin-related patent in 1953, called "Method for preparation of inclusion compounds of physiologically active organic compound" (Freudenberg et al. 1953). The patent described the most important aspects of the applications of cyclodextrins in drug formulations. The authors detailed specific effects that could be achieved by complexation of drugs with cyclodextrin complexation such as enhancement of solubility of poorly soluble drugs, protection of easily oxidizable substances against atmospheric oxidation, reduction in the loss of highly volatile substances, etc. In 1987, Cramer wrote: "At that time, I saw the first possibilities for a technology transfer and I took a patent. This, unfortunately, never found any industrial application" (Cramer 1987). The potential use of cyclodextrins in pharmaceuticals had been launched. It was not till the $70 \mathrm{~s}$ and $80 \mathrm{~s}$ though that the first industrial scale applications in pharmacy appeared (Szejtli 1998; Loftsson and Duchêne 2007; Morin-Crini et al. 2015).

\section{Cyclodextrins as models}

Cramer knew everything about cyclodextrins, publishing an impressive number of results over a period of 25 years on their preparation, separation, characterization, structure, properties, chemistry, biochemistry, and their potential application in pharmacy, catalysis and enzymology (Freudenberg and Cramer 1948, 1950; Cramer 1949, 1951a, b, c, 1952, 1953, 1954, 1956, 1961; Freudenberg et al. 1953; Cramer and Steinle 1955; Cramer and Henglein 1956; 1957a, b; Cramer and Dietsche 1958, 1959a, b; Lüttringhaus et al. 1958; Cramer and Kampe 1962, 1965; Cramer and Hettler 1967; Cramer et al. 1967, 1969).

In 1953, Cramer was the first to show the catalytic role that cyclodextrins could play in chemical reactions through a key-lock interaction similar to that of an enzyme-substrate complex (Cramer 1953). Later, Cramer gave the basis for supramolecular catalysis involving cyclodextrins (Cramer and Dietsche 1958, 1959a; Cramer 1961; Cramer and Kampe 1962, 1965). For instance, he reported a cyclodextrin-accelerated reaction studying the hydrolysis of ethyl $p$-chloromandelate in the presence of $\alpha$-cyclodextrin (Cramer and Dietsche 1958). Cyclodextrins can also be used as an asymmetric agent (Cramer 1961; Cramer and Kampe 1962, 1965). The potential use of cyclodextrins in catalysis and supramolecular chemistry had been launched. The first reports of their potential use as enzyme models were also attributed to Cramer. Enzyme-substrate interactions can be established either by non-covalent bond such as hydrogen bonding or van der Waals forces or by a covalent bond. When a covalent bond is formed, the cyclodextrin established a covalent bond with some entering of leaving component, e.g., in the case of ester hydrolysis. This process was called covalent catalysis. The model of non-covalent catalysis was inclusion complex catalysis, introduced by Cramer (1953) and later studied in detail by Bender (van Etten et al. 1967a, b; Griffiths and Bender 1973). An interesting example is given in Fig. 4. The hydrolysis of 3,3-disubstituted phenyl-glutarate proceeded via intramolecular catalysis. This was suppressed by cyclodextrin inclusion complex formation. The stabilizing effect depended on the cyclodextrin concentration according to the hyperbolic curve of the Michaelis-Menten enzyme kinetics. The reaction rate reached a minimum value when all the ester molecules were complexed. The hydrolysis was also independent of the $\mathrm{pH}$; consequently, cyclodextrin was only a binding site and was not involved directly in the reaction mechanism.

At the end of the 1950s, the numerous fundamental studies of French also led to growth in the interest in cycloamyloses not only as model enzymes but also as aroma stabilizing agents for the food industry (Thoma and French 1958; Thoma et al. 1959; French et al. 1963), even though at the

Fig. 4 Mechanism proposed during the hydrolysis of 3,3-disubstituted phenyl-glutarate via intramolecular catalysis; the presence of cyclodextrin suppressed this intramolecular catalysis
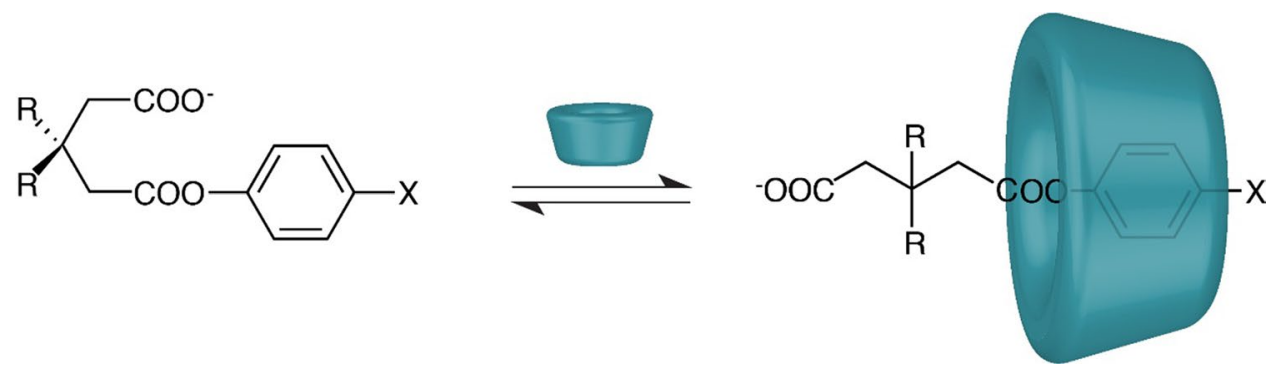
time, industrial application of cycloamyloses was still not considered feasible. This last point was only clarified in the 1970's. In the 1960s, Bender reported that cycloamyloses had a great potential for acid-base catalysis similar to that of naturally occurring enzymes. His numerous works made the creation of artificial enzymes possible. Bender, studying cycloamyloses-catalyzed reactions, showed that cycloamyloses can accelerate or decelerate various kinds of reactions including oxidation, hydrolysis, decarboxylation, nitrosation, and isomerization. The reaction rates depended on the cycloamylose used and the kind and stability of the inclusion compound formed. The first review on the phenomenon of cycloamylose catalysis has been published in 1973 by Bender (Griffiths and Bender 1973). This comprehensive review also summarized the developments in the chemistry of cycloamyloses and its derivatives used as enzyme models. It was updated by Bender in 1978 (Bender and Komiyama 1978). Cycloamylose-catalyzed reactions were classified in two categories: (i) covalent catalysis in which cycloamyloses catalyze reactions via the formation of covalent intermediates and (ii) non-covalent catalysis in which cycloamyloses provide their cavities as apolar or sterically restricted reaction fields without the formation of any covalent intermediates. Bender pointed out that non-covalent catalysis by cycloamyloses might be the result of either a solvent effect or of a conformational effect, e.g., in decarboxylation and stereoselective reactions. Bender is recognized as the initiator of the era of biomimetic chemistry, including artificial enzymes, molecular recognition and bio-inspired reactivity (Bender and Komiyama 1978).

\section{Complex formation and inclusion compounds}

In 1938, Freudenberg suggested, for the first time, the hydrophobicity of the inner surface of the dextrin and noted how dextrins had the ability to form complexes due to their cyclic structure (Freudenberg and Meyer-Delius 1938; Freudenberg et al. 1938). The dextrins exhibited a complexing capacity which was discussed in connection with the blue starch/iodine complex. For the first time, the ability of Schardinger dextrins to form complexes was suggested. To explain these complexes, Freudenberg was the first to show the involvement of hydrophobic forces in the formation of the complexes (Freudenberg 1939; Freudenberg and Meyer-Delius 1939; Freudenberg et al. 1939). Originally, however, Freudenberg was convinced that the dextrins and the amylose helix were lined with a hydrocarbon interior, and thus the cavity of the dextrins has been referred to as hydrocarbon in nature (Thoma and Stewart 1965; Caesar 1968; Clarke et al. 1988; Szejtli 1998; Crini 2014; MorinCrini et al. 2015; Crini et al. 2018).

Cramer was recognized not only for having introduced the cyclodextrin-based nomenclature but mostly for his important work on inclusion complexes, although they were only fully acknowledged at the end of the $70 \mathrm{~s}$ (Crini 2014). In 1949, in his Ph.D. dissertation entitled "Die cyclodextrine aus Stärke," Cramer evoked for the first time the fact that the three native cyclodextrins, considered as cylinders with different internal diameters, were able to accommodate molecules of different sizes: this was the first indication on their ability to form "inclusion" complexes (Cramer 1949). Two years later, Cramer published his first results on the complexes (Cramer 1951a, b, c, 1952). For instance, he observed that a number of dyes showed characteristic changes in their absorption spectra in aqueous solutions of the cyclodextrins (Cramer 1952). Between 1952 and 1954, Cramer discovered that the toroidal form of the cyclodextrin molecules, regarded as truncated cones, enabled them to accept various molecules inside their cavity (Cramer 1952, 1953; Dietrich and Cramer 1954). He was the first to demonstrate the hypotheses Schardinger put forward at the beginning of the nineteenth century on their ability to form complexes. In 1952, Cramer adopted the term "einschlussverbindungen," i.e., inclusion compound, to characterize a complex (Cramer 1952), and later he also used the terms of "occlusion compound" and "molecular encapsulation" (Cramer and Dietsche 1959a). In 1953, he registered his first patent where he highlighted the fact that "the formation of an inclusion complex could modify the physical, chemical and biological characteristics of a guest molecule such as a drug" (Freudenberg et al. 1953). The inclusion phenomena and the term "einschlussverbindungen" were, however, used by Schlenk in 1950 for the first time (Schlenk et al. 1955; French 1957a; Szejtli 1982a; Crini 2014). The term "inclusion compound" has been coined to describe the positional relationship of two components which form certain types of crystals. These components were designated as host and guest, again in reference to the solid state (Schlenk et al. 1955; Schlenk and Sand 1961).

In 1956, Cramer introduced the notion of "inclusion complex" (Cramer 1956). He considered the interior of the cavity as a lipophilic microenvironment into which a nonpolar hydrophobic molecule can "slide" (Fig. 5). The guest was maintained within the cavity by non-covalent forces, which were thus weak and enable the whole system to be reversible. Cramer showed that formation of an inclusion complex was the result of an association/dissociation equilibrium between the free guest and the free host and the complex. This was governed by a constant, denoted formation constant. $\mathrm{K}_{\mathrm{f}}$. The higher its value, the more stable the inclusion is, and the less dissociation that occurred. Cramer then conducted important research between 1955 and 1965 on the inclusion phenomena (Cramer 1956, 1961; Cramer and Henglein 1956; Cramer and Dietsche 1959a, b; Cramer and Kampe 1962,1965). He studied in detail the molecular dispositions of numerous guest organic compounds in the 
Fig. 5 Inclusion phenomena between a cyclodextrin molecule (the host) and an organic molecule (the guest) to form inclusion complexes; $\mathrm{K}_{\mathrm{f}}$ is the formation constant (a)

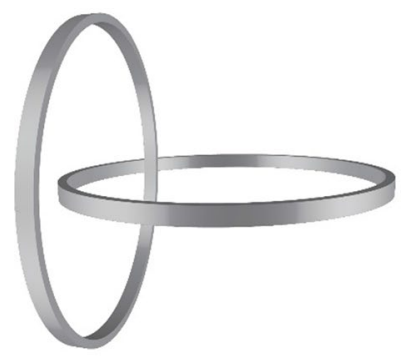

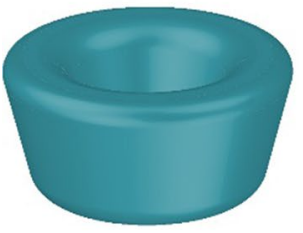

Host

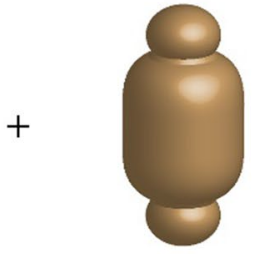

Guest

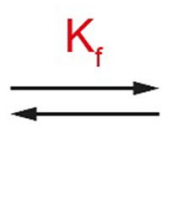

(b)

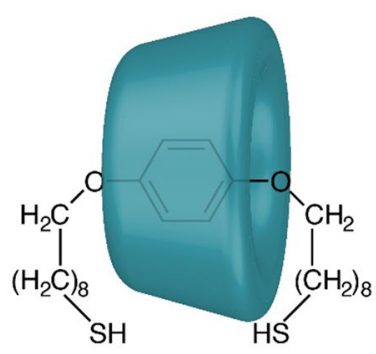
Cramer et al. 1967).
Fig. 6 (a) Structural scheme of catenanes and (b) principle of their attempted preparation adapted from Lüttringhaus et al. (1958)

cyclodextrin cavity in solution by the use of UV-visible and circular dichroism experiments, in order to demonstrate the formation of inclusion complexes. These experiments also permitted to calculate the formation constant or dissociation constant of the different complexes.

The preferred position for the guest compound inside the cavity depended on steric interactions, due to the chemical structure and geometry of each guest compound. The complex was strong when there was size complementarity between the guest and the cyclodextrin cavity. In solution, two main components of the driving forces of the process are suggested, the first was the presence of repulsive forces between the included water molecules and the apolar cavity, and the second the presence of repulsive forces between the bulk water and the apolar organic guest. Cramer also indicated that hydrogen bonding between the guest and the cyclodextrin was of only minor importance as a driving force for complex formation (Cramer 1956). The stability of cyclodextrin inclusion complexes was due to a favorable change in enthalpy during the inclusion process. However, later, Cramer also considered that a complex was stabilized not only by van der Waals forces but also by hydrogen bonds (Cramer and Kampe 1965;

In 1958, Cramer was the first to propose a scheme for the preparation of so-called catenanes, compounds consisting of two rings connected to each other without chemical bond, by using cyclodextrin complexes (Lüttringhaus et al. 1958). Figure 6 shows the structural scheme of catenanes and the principle of their attempted preparation. Incorporating a dithiol with sufficiently long chain into cyclodextrin, and oxidizing the two protruding terminal SH groups to give an -S-S- bridge, a catenane was formed. These molecules were studied in the 1990s and proposed for the synthesis of supramolecular materials, scaffolds and templates, and in biomimetism (Nepogodiev and Stoddart 1998). In 1959, Cramer observed that, in the case of guest molecules that cannot be totally included by a single molecule, a second cyclodextrin molecule may bind: this was the first observation of a 2:1 complexes in solution (Cramer and Dietsche 1959a, b). Figure 7 illustrates the association of free cyclodextrin and substrate to form various substrate-cyclodextrin complexes. Depending on the respective size of the guest and host molecules, one guest molecule can interact with one or two (or more) cyclodextrin, i.e., host:guest complexes 1:1 and 2:1, or two (or

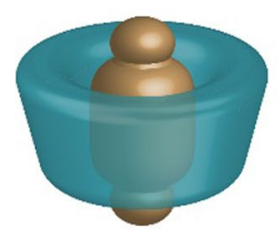

$1: 1$

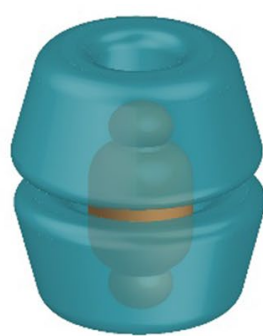

$2: 1$

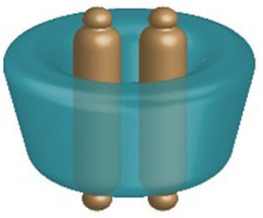

$1: 2$

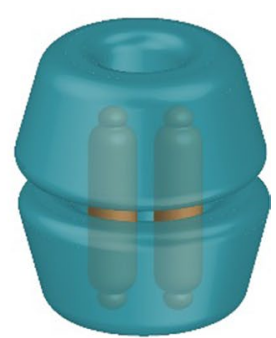

$2: 2$

Fig. 7 Association of free cyclodextrin and substrate to form various substrate-cyclodextrin complexes 
more) guest molecules can interact with one cyclodextrin or two (or more), i.e., host:guest complexes 1:2 and 2:2.

In 1967, Cramer comprehensively discussed all the possible penetration pathways and the effect of substituents on the stability of the inclusion complexes (Cramer and Hettler 1967). The same year, he gave the first scientific explanation to explain the mechanism of formation of an inclusion complex between a substrate and a cyclodextrin molecule both in solution and solid state (Cramer et al. 1967). To explain the formation of an inclusion complex, Cramer introduced five elementary steps: (1) the substrate approaches the cyclodextrin molecule; water molecules escape from the cyclodextrin cavity and acquire a new energy level, corresponding to that of the gaseous state; the van der Waals interactions and the number of hydrogen bonds decreases, whereas the degrees of freedom of translation and rotation of the freed water molecules increase; (2) the guest molecule becomes released from the layer of water that envelops it and also acquires a different state; the layer of water becomes dispersed and rearranges; (3) the guest molecule, considered to be in a perfect gas state, enters the cavity and the complex formed is stabilized by van der Waals forces and/or hydrogen bonds; (4) the expelled water molecules are rearranged and form hydrogen bonds between each other; and (5) the structure of the water is restored around the part of the substrate that remains in contact with the solvent and that is integrated into the hydration shell around the CD. Cramer finally concluded that the most important property of cyclodextrins was the ability to establish specific interactions, i.e., molecular encapsulation, with various types of molecules through the formation of non-covalently bonded entities such as hydrophobic interactions, van der Waals forces, and hydrogen bonding (Cramer and Hettler 1967; Cramer et al. 1967). Cramer's work on inclusion complexes established much of our modern understanding of the behavior of cyclodextrins during complexation and remains a commonly cited source to this day.

At the same time as Cramer, French also studied the formation of inclusion complexes and showed that evidence for a guest inclusion into the cycloamylose cavity may be proved by analytical techniques such as UV-visible absorption spectrophotometry, optical rotatory dispersion, circular dichroism, and X-ray measurements (Thoma and French 1958, 1959, 1960, 1961; James et al. 1959; Thoma et al. 1959). The guests studied were the same as that of Cramer such as phenol, benzoic acids or iodine. For instance, in 1958, French showed that absorption spectroscopy was an interesting method to determine the dissociation constant of the inclusion complex between cycloamylose and iodine (Thoma and French 1958). The values of dissociation constant could be easily obtained from the observed change in absorbance and the concentration of cycloamylose added according the Benesi-Hildebrand method. For French, the driving forces for complex formation included solvent effects, van der Waals forces, and hydrogen bonds. One year later, French demonstrated that X-ray diffraction was also a powerful method to study the inclusion complexes between iodine and cycloamyloses (James et al. 1959). French also observed that, because of their structure, some guests can be included in one or two cycloamylose molecules, and depending on the cavity size, it was a different part of the guest molecule that can be included. This was clearly demonstrated in the 1970s by NMR spectroscopy (Szejtli 1982a).

Later, Lichtenthaler and Immel (1996) demonstrated, using molecular modeling, the need for compliance between hydrophobic host surfaces and hydrophobic domains in the cyclodextrin cavity. This striking tendency to optimize the reciprocal concurrence of lipophilic as well as hydrophilic domains at the guest-host interface may accordingly be concluded to be an important, if not the decisive element in orienting the guest into the cavity and in determining the stability of the complex, particularly in cases where the guest is devoid of polar groups. This was the first study showing the importance of the reciprocal interplay of such interactions.

\section{Toxicological considerations}

Pringsheim was the first to conduct several biological tests to determine whether the dextrins were physiologically available either to plants or animals (Pringsheim and Müller 1922; Hoesslin and Pringsheim 1923; Pringsheim 1928b, 1931a). Pringsheim studied the absorption and metabolism of dextrins in rats, pigs and humans. Polyamylose, probably $\alpha$-cyclodextrin, administered in a dose of $50 \mathrm{~g}$ to diabetic persons, did not cause any change in the urinary glucose level, and no polyamylose was found in the feces (Pringsheim and Müller 1922). Hoesslin and Pringsheim (1923) fed polyamylose to starved rabbits and guinea-pigs. No glycogen synthesis was detected in the liver $3 \mathrm{~h}$ after administration. Pringsheim suggested that polyamylose was metabolized in the rat. His experiments also showed that the Schardinger dextrins were not fermentable and hence not utilized by yeast (Pringsheim 1928b). In 1931, for the treatment of diabetes, Pringsheim concluded: " $\alpha$-dextrin directly utilized would be a suitable source of energy for diabetics since it only occasionally cause nausea and there is no noticeable increase in urine sugar" (Pringsheim 1931a).

However, in 1957, French wrote: "It would appear that the Schardinger dextrins exhibit a toxic effect, possibly by virtue of their remarkable complexing ability, and in any case, the suggestion of Professor Pringsheim that they be used as an energy source by diabetics looks risky" (French 1957a). Indeed, the first studies carried out by him in the rat led to the conclusion that Schardinger dextrins presented a certain toxicity (French 1957a). In the same paper, it is noted that "In unpublished attempts to investigate the ability of 
animals to utilize Schardinger dextrins, B.H. Thomas and D. French fed rats a diet in which a part of the carbohydrate was supplied by higher purified $\beta$-dextrin. The animals refused to eat the test diet except in very small quantities and within a week all animals on the ration were dead. Postmortem examination did not reveal the cause of death" (French 1957a). Their experiments indeed showed that the rats refused to eat food containing highly refined dextrins except in very small quantities. In spite of the small doses, rat mortality was $100 \%$ within a week of introducing "highly purified" $\beta$-dextrin into the diet (French 1957a). However, in these studies, experimental conditions, such as the purity of dextrins, the number of rats treated or the existence of a control group, were not mentioned. Later, Szejtli suggested that one of the hypotheses was traces of solvent remaining in the dextrins which the rats could have smelt (Szejtli 1982a, 1988; Frömming and Szejtli 1994). This was the only result of French's that posed a problem and which led to extensive debate was that of the toxicity of the cycloamyloses (French 1957a), and most importantly this result deterred many scientists from developing cycloamylose-containing products for human use. The observations and conclusions drawn by French were only refuted much later following studies with the same animal model (Andersen et al. 1963; Lach and Cohen 1963; Lach and Chin 1964; Szejtli et al. 1980a; Chow and Karara 1986).

\section{Historical landmarks in the development of cyclodextrins: from 1970 until now}

\section{Production of cyclodextrins}

At the mid-1970s, industrial scale production really started (Horikoshi 1979). Indeed, several manufacturers started to produce and to market cyclodextrins, e.g., Nihon Shokohin Kako Japan, Sanraku Ocean Co. Ltd Japan, Toyo Joso Japan, and Chinoin Hungary. The first pilot plant at Nihon Shokohin Kako firm, Japan, started up in 1978 with a production capacity of about 20 tons per year (Sicard and Saniez 1987). However, cyclodextrins were expensive.

The first to believe in the possibilities of industrial production and the multiple applications of cyclodextrins was probably Szejtli, a Hungarian carbohydrate chemist who organized the cyclodextrin technology in Hungary in the 1970s (Szejtli 1988, 1998). Among the list of prestigious researchers who have contributed to the development of cyclodextrins, Szejtli played a fundamental role as eminent scientist, visionary, and entrepreneur, creating in 1989, a private company, CycloLab Ltd., totally devoted to cyclodextrins. Without Szejtli, the feasible production of cyclodextrins on an industrial scale probably would not be as advanced as it is today.
In the mid-1980s, advancements in biotechnology led to drastic improvements in the production and purification of cyclodextrins. Cyclodextrins were then produced in large quantities with high purity and marketed at a reasonable price, and as a result, more industrial applications have become possible. In addition, this period from 1970 to 1980 was also marked by another important event: the first toxicological studies had established that $\beta$-cyclodextrin administrated orally was a harmless substance. Pharmaceutical, food, chromatographic, and cosmetic applications started to appear and rapidly gained ground. Since then, an increasing interest in cyclodextrins as raw materials and their possible applications has existed (Szejtli 1982a, 1988; Duchêne 1987, 1991).

\section{Mechanism of inclusion complexes}

In the mids-1970s, several researchers such as Saenger, a pupil of Cramer, Bender and Szejtli pursued and reformulated the interpretations made by Cramer on the mechanisms of formation of inclusion complexes.

On the basis of the mechanism proposed in 1967 by Cramer, Saenger gave in 1976 three important explanations for the formation of an inclusion complex with $\alpha$-cyclodextrin in aqueous solution (Saenger et al. 1976): (1) the guest molecule directly replaces the water molecules in the cavity; (2) the cyclodextrin molecules absorb the energy of the water molecules retained in the cavity and take on a relaxed conformation; in this state, the water molecules can be easily substituted by another guest; and (3) the guest becomes associated with the outer surface of the cyclodextrin and only enters the cavity once it has absorbed the activation energy, i.e., transfer of the conformation from a state of high energy of the cyclodextrin-water complex to a state of lower energy of the cyclodextrin-guest molecule complex. Saenger introduced the notion of the release of the tension energy within the $\alpha$-cyclodextrin molecule upon formation of the complex. This relief of strain in the cyclodextrin ring contributed to the enthalpy of association and to the stabilization of the inclusion complex. In water, the $\alpha$-cyclodextrin was in a strained, high-energy conformation, and that, when another guest molecules displaced the water, thus forming an inclusion complex, a conformational change of the cyclodextrin molecule occurred, transforming the $\alpha$-cyclodextrin structures into an unstrained, relaxed state. This was demonstrated using detailed X-ray diffraction studies. A scheme of inclusion-complex formation involving relief of strain energy and release of high-energy water is proposed (Fig. 8). This scheme shows the possible pathways of $\alpha$-cyclodextrin inclusion complex formation in aqueous solution. Owing to the inclusion of water, the ring of cyclodextrin is distorted, only four of the six possible 
Fig. 8 Saenger's theory of formation of $\alpha$-cyclodextrincomplexes in aqueous solution: $\mathrm{G}=$ guest, $\mathrm{H}_{2} \mathrm{O}^{*}=$ activated water. Hydrogen bonds are marked by dashed lines adapted from Saenger et al. (1976)

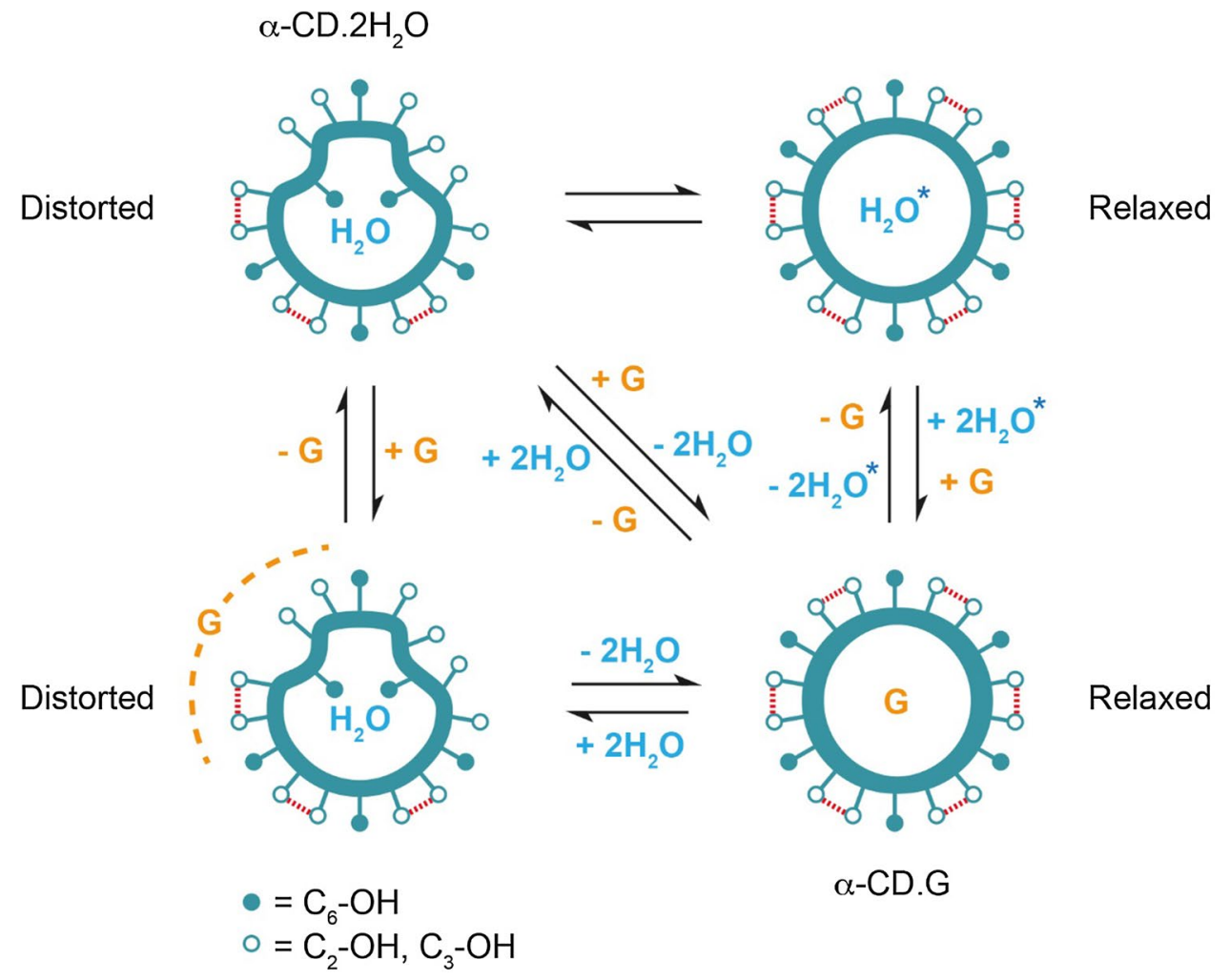

hydrogen bonds are formed, and introducing a suitable guest molecule, the ring is relaxed. Later, Saenger showed that, in the cases of $\beta$ - and $\gamma$-cyclodextrins, the strainenergy relief-mechanism did not seem to be operative, and the cyclodextrin-water adducts were not strained (Lindner and Saenger 1978). Saenger (1980) published a thorough state-of-the-art of inclusion complexes, including his own interpretations.

In 1978, Bender elucidated the mechanism of formation of the complexes developed by Saenger. He pointed out that the complexation involved hydrophobic interactions, like that of Saenger 2 years before. The driving force of inclusion is "an example of an atypical hydrophobic interaction" (Bender and Komiyama 1978). Bender proposed the fact that the complexation reaction involved a gain in enthalpy and a loss of entropy. The further the guest molecule penetrated into the cyclodextrin cavity, the greater was the change in enthalpy, and the higher was the stability of the complex. Moreover, the greater was the apolarity of the guest, and the more this phenomenon was marked. The previous explanation that Bender offered to explain the favorable enthalpy change was that the empty cyclodextrin contained water molecules that were unable to form their full complement of hydrogen bonds to adjacent water molecules and thus might be considered to enthalpy rich (Griffiths and Bender 1973). The inclusion of a guest "would then displace this high energy water from the cyclodextrin cavity, leading to a net increase in solvent-solvent hydrogen bonds and a favorable enthalpy of association."

In 1982, in his first book on cyclodextrins, Szejtli pursued and reformulated all the interpretations made by Cramer, Saenger and Bender on the mechanism of formation of inclusion complexes (Szejtli 1982a). The gain in enthalpy is then explained by the spontaneous arrival of the guest, displacing active water molecules retained in the non-polar cavity of the cyclodextrin in aqueous solution. Szejtli illustrated his conclusions using a schematic representation of cyclodextrin inclusion complex formation (Fig. 9). In this famous figure, $p$-xylene is the guest molecule, and the small circles represent the water molecules which are repulsed both by the hydrophobic potential guest and the hydrophobic cavity of the truncated cyclodextrin cylinder (Szejtli 1978; Szejtli et al. 1979). The three main conclusions were: (1) the guest molecule, less polar than water, directly replaced the water molecules in the cavity; these water molecules were in an unfavorable energy state owing to the polar-apolar interactions and were thus easily displaced by more suitable molecules; (2) the cyclodextrin molecules absorbed the energy of the water molecules retained in the cavity; and (3) the organic guest dissolved in water entered in the cavity because it had a preference for hydrophobic environment.

Szejtli supported the idea that, although van der Waals interactions and hydrogen bonding played an important role, the main force behind the formation of the complexes was the stabilizing reduction in the whole system's energy on 


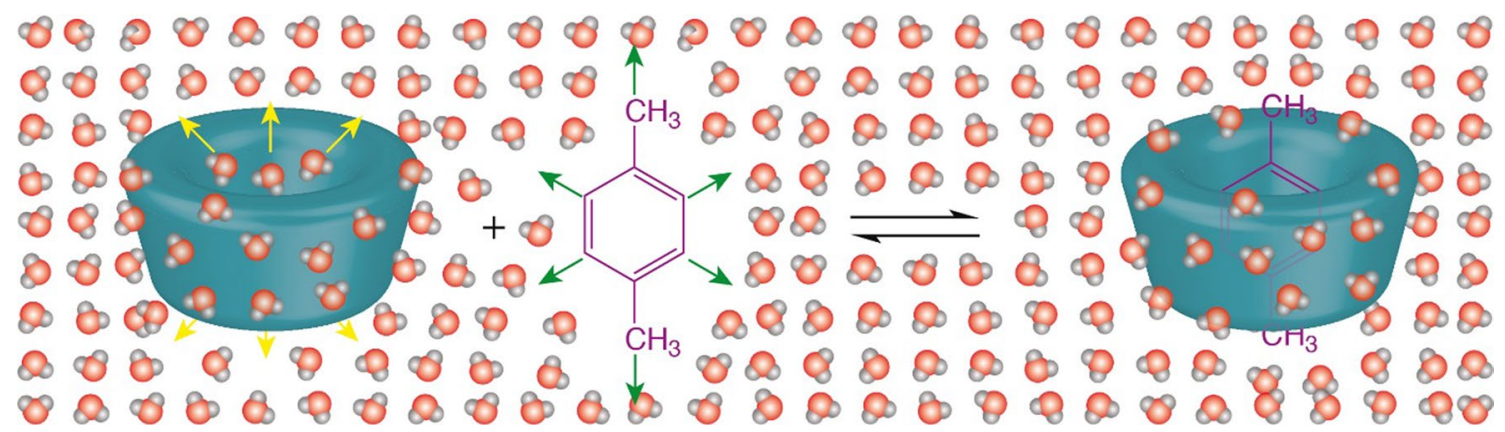

Fig. 9 Formation of an inclusion complex between $p$-xylene, the guest, and a cyclodextrin molecule; water molecules are repulsed by the hydrophobic potential guest adapted from Szejtli (1978) and Szejtli et al. (1979)

the replacement of the high enthalpy water molecules in the cavity, by hydrophobic molecules leading to apolar-apolar bonding. He proposed that this bonding was too weak to be alone responsible for the higher stability of the complex and showed the parallel occurrence of steric interactions. Indeed, Szejtli demonstrated in various publications that the preferred position for the guest compound inside the cavity also depended on steric interactions. He concluded that the complexation phenomenon results from a multitude of interactions between the three components of the system cyclodextrin-substrate-solvent leading to a state that is more thermodynamically stable overall (Szejtli 1995). In the 1990 s, there was a general agreement in the literature that during the formation of an inclusion complex a whole set of intermolecular interactions come into play and that each one has its own role in the overall process.

\section{Inclusion phenomena and its effects}

Since Cramer's discovery of inclusion phenomena, effort was devoted to physical and chemical properties of inclusion complexes and their consequences. Indeed, his results were not only of fundamental interest but also of industrial interest, and in the 1970s, this interest has grown considerably. Numerous works showed that inclusion of a guest active ingredient molecule in a host cyclodextrin molecule was a real molecular encapsulation, and the resulting inclusion complex superstructure had new physicochemical properties, stability, solubility and also better therapeutic efficacy. So, several technological characteristics used in pharmacy could also be advantageously modified.

Rapidly, the pharmaceutical industry understood the advantages of using cyclodextrins. Szejtli (1982a, 1988) summarized them in six points: (1) the modification of the physicochemical properties of the guest molecule: e.g., liquid compounds can be transformed into crystalline, compressible forms; substances with low solubility in water become more soluble after complexation; the rate of dissolution of poorly soluble substances can also be increased; certain unpleasant tastes can be eliminated; smell can also be covered by complex forming; the color of certain substances can be altered since inclusion can change the spectral properties of the guest, etc.; (2) the modification of the chemical activity of the guest: e.g., reactive substances can be protected by inclusion reducing the risks when they are mixed with other substances; chemical reactions can be carried out selectively, the cyclodextrins playing the role of catalysts, etc.; (3) the stabilization of substances sensitive to light or to oxygen, etc.; e.g., protection of active ingredients against oxidation, heat promoted decomposition, or light induced reactions; (4) the uptake of volatile substances: e.g., volatile drug can be stabilized without losses through evaporation; storage and handling of certain toxic substances such as pesticides can be improved; savings can be made on the quantity of substance required owing to reduced evaporation, etc.; (5) the complexation, extraction, and transport of pollutants; and (6) several technological advantages: e.g., stable, standardized compositions, simple dosage and handling of dry powders, reduced packing and storage costs, and also saving of energy and manpower.

\section{Large cyclodextrins}

Although the existence of cyclodextrins with over 8 glucose units is described and studied for the first time in the 1950s by Freudenberg, French, and Cramer, it was only in the middle of the 1990s that the cyclodextrins containing $9,10,11$, and 12 units of glucose, called large ring cyclodextrins, were studied in any depth (Miyazawa et al. 1995; Endo et al. 1997, 1999; Larsen 2002; Taira et al. 2006). The difficulties to purify them and the low yields prevented their study until then. Using specific enzymes and/or particular experimental conditions, some works also reported the existence of cyclodextrins of over 100 glucose units (Terada et al. 1997; Koizumi et al. 1999; Qi et al. 2004). Larsen (2002) published the first interesting review on large cyclodextrins. 


\section{Cyclodextrin derivatives}

The underivatized or native $\beta$-cyclodextrin's low water solubility as showed by French in the 1940s restricted its advantage. For this reason, a number of derivatives such as hydrophilic methylated derivatives have been synthesized. Whereas the first methylated derivatives of $\beta$-cyclodextrins were studied as early as 1924 by Pringsheim and collaborators (Irvine et al. 1924), it was, however, not until 1969 that the alkylated cyclodextrins were comprehensively described by Gramera (1969). Indeed, in the older literature, particularly in the works of Pringsheim and Freudenberg, several methods were proposed referring to the preparation of such derivatives, but these are essentially of historic interest.

The literature on the preparation and investigation of cyclodextrin derivatives only proliferated in the 1960s. Since, numerous cyclodextrin derivatives and polymers were described, including alkylated and acylated derivatives, nitrogen- and sulfur-containing derivatives, halogenated products, and 6-deoxy derivatives. The derivatives of practical importance were the methylated and hydroxypropyl cyclodextrin derivatives in the 1980s, and ten years later the sulfobutyl ether derivatives. Casu was the first to prepare cyclodextrin derivatives such as methylated (Casu et al. 1968a, 1968c) and acetylated (Casu et al. 1970) products. The experimental protocols were repeated in the 1980s by Szejtli (Szejtli 1982a, 1983, 1984). His work, particularly on methylated cyclodextrins, showed great promise for both human and animal use (Szejtli 1982a). Methylation could be either partial, i.e., esterification in positions 2 and 6 giving dimethyl-cyclodextrins or complete giving trimethyl-cyclodextrins. The randomized derivative called RAMEB was often used. These derivatives were much more soluble than the parent cyclodextrins, but their solubility was temperature-dependent. For this reason, hydroxypropylcyclodextrins with high water solubility were more advantageous. However, hydroxypropylation occurring randomly, products obtained were not pure chemical entities but amorphous complicate mixtures.

Croft and Bartsch (1983) were the first to publish a review on all the different chemically modified cyclodextrins which had been synthetized up to late 1982. In 1987, Sébille showed that cyclodextrin chemistry offered various possibilities to synthetize derivatives with different functions for various industrial uses, e.g., sulfur- and nitrogen-, imidazole or histamine-containing derivatives, alkylated and acyl derivatives, halogenated products, polymers from cyclodextrins, etc. (Sébille 1987). By working in carefully controlled conditions, mono-, di- and polysubstitution were possible and opened the way to several functional derivatives with catalytic or biological activity for instance. One of the most popular derivatives was mono-substituted 6-O-p-toluenesulfonyl-cyclodextrin, used as starting material to prepare modified cyclodextrins (Saenger 1980; Szejtli 1982a; Sébille 1987). Jicsinsky et al. (1996) published a comprehensive chapter (137 pages, 865 references) on cyclodextrin derivatives. In 1998, Khan et al. (1998) proposed a global schema for the modification of cyclodextrins. These two last publications are still reference today.

Thousands derivatives containing cyclodextrin have been proposed in the literature, particularly for pharmaceutical uses. Szejtli (2004) estimated that over 15,000 derivatives had been studied. In reality, most of these derivatives will never find applications, especially for reasons of production costs, essentially lengthy and difficult synthesis involving complicated steps. Among industrially produced, standardized and available derivatives, the most important ones are the methylated $\beta$-cyclodextrins such as RAMEB (randomly methylated- $\beta$-cyclodextrin, considered as a mixture) and DIMEB (a particular methylated cyclodextrin: heptakis(2,6di-O-methyl- $\beta$-cyclodextrin), considered a single isomer; its solubility decreases with an increase in temperature), the 2 -hydroxypropylated $\beta$-cyclodextrins or HPBCD (the real advantage of this derivative over the methylated derivatives is the lower affinity for cholesterol binding), and the sulfobutylether- $\beta$-cyclodextrins or SBEBCD.

Brauns and Müller (1983) and Pitha (1984) registered the first patents on 2-hydroxypropyl- $\beta$-cyclodextrin. This compound called hydroxypropylbetadex was the first commonly applied cyclodextrin derivative, used as pharmaceutical excipient in drug formulations in the 1990s (Szente and Strattan 1991). Rapidly, a monograph for this substance has been published in both the U.S. Pharmacopeia and European Pharmacopeia (Brewster and Loftsson 2002, 2007; Brewster et al. 2004). Nowadays, 2-hydroxypropyl- $\beta$-cyclodextrin is the most versatile excipient among the cyclic oligosaccharides (Malanga et al. 2016). It can be used in oral, rectal, dermal, ocular and parenteral formulations and several pharmaceutical products are marketed, e.g., Indocid ${ }^{\circledR}$ (eye drop), Vorzu $^{\circledR}$ (tablet for fungal infection), Strepfen ${ }^{\circledR}$ (oromucosal spray with flurbiprofen), Vibativ ${ }^{\circledR}$ (i.v. infusion with televancin), Lubion ${ }^{\circledR}$ (injection with progesterone as active ingredient). This substance is used as excipient and/or as active component, e.g., at the end of 2000s, it was discovered that it had beneficial effects for patients in Niemann Pick type C disease (Liu et al. 2009). Stella and Rajewski (1992) patented the sulfobutylether- $\beta$-cyclodextrin product as a potential alternate solubilizing excipient to 2-hydroxypropyl$\beta$-cyclodextrin. This derivative, developed by Cydex under the brand name Captisol ${ }^{\circledR}$, was found a more efficient complex forming host than parent cyclodextrins with no apparent toxicity and very high water solubility. Captisol ${ }^{\circledR}$ became generic worldwide in 2011, e.g., Dexolve ${ }^{\circledR}$ developed by Cyclolab, Ltd. (Hungary). It is used not only as a solubilizing agent but also as an osmotic agent (Puskás et al. 2015). 
In the last four decades, numerous cyclodextrin-based materials have also been synthetized. The list includes modified polymers obtained using grafting reactions (Crini and Morcellet 2002; Kozlowski and Sliwa 2010), cross-linked materials using reticulation or polymerization reaction, e.g., soluble or insoluble polymers (gels/hydrogels, beads, sponges) and fibers (Fenyvesi 1988; Armspach et al. 1999; Mocanu et al. 2001; Crini and Morcellet 2002; Crini 2005; Li 2009; Yang and Yang 2013; Aytac and Uyar 2017), functionalized materials prepared through coating or grafting such as silica beads, e.g., Cyclobond ${ }^{\circledR}$ columns, or resins (Crini and Morcellet 2002; Landy et al. 2012), and nanoporous frameworks containing cyclodextrins (Mahmud and Wilson 2016; Morin-Crini et al. 2018). These materials have been proposed for potential applications in pharmacy (Fenyvesi 1988; Van de Manakker et al. 2009; Muankaew and Loftsson 2018), chromatography (Ward and Armstrong 1988; Schneiderman and Stalcup 2000; Szejtli 2002; Vetter and Bester 2006; Xiao et al. 2012), electrophoresis (Fanali 1993; Chankvetadze 2004; Escuder-Gilabert et al. 2014), textile (Buschmann et al. 1998; Szejtli 2003; Buschmann and Schollmeyer 2004; Ammayappan and Moses 2009; Andreaus et al. 2010; Voncina 2011), supramolecular chemistry (Wenz 1994; Nepogodiev and Stoddart 1998; Schneider and Yatsimirsky 2000; Wenz et al. 2006; Schneider 2012; Zhang and Ma 2013), enzymology (Komiyama 1996; Villalonga et al. 2007; Sonnendecker and Zimmermann 2019a), food industry (Han 2005; Fenyvesi et al. 2016), cosmetics (Buschmann and Schollmeyer 2002, 2004; Bilensoy 2011), and for environmental purposes (Gruiz et al. 2011; MorinCrini et al. 2018; Crini et al. 2018).

\section{The first applications of cyclodextrins}

Since the 1990s, a large number of generalist reviews and book chapters have been published on practically all the aspects of cyclodextrins, so many that it would not be feasible to cite them all. In this section, we chose to highlight selected works on the first applications of cyclodextrins. A recent review on this topic can be found in the review by Crini et al. (2018) who summarized the literature published in the last four decades. Readers interested in cyclodextrin applications should also refer to the library database "Cyclodextrin News" from CycloLab Ltd., Hungary.

Cyclodextrins have been used in pharmaceutical industry since the 1970s (Szejtli 1977; Uekama and Hirayama 1978; Uekama and Otagiri 1987; Frömming and Szejtli 1994). With a more accurate picture of their toxicity and better understanding of molecular encapsulation, several inclusion complexes appeared on the market (Davis and Brewster 2004; Brewster and Loftsson 2007). In 1976, the first product, i.e., prostaglandin E2/ $\beta$-cyclodextrin Prostarmon $\mathrm{E}^{\mathrm{TM}}$ sublingual tablet, was marketed in Japan (Ono Co.)
(Uekama and Hirayama 1978; Hirayama et al. 1980). Prostaglandin E2, a substance with potent oxytocin-like effects, was of interest as a possible agent for the induction of labor in childbirth (Davis and Brewster 2004). However, this substance was highly unstable, and this feature complicated its formulation and development. The solution was to encapsulate it using $\beta$-cyclodextrin, resulting in a significant increase in its solid-state stability. This led to spectacular progress in pharmaceutical domain. The second prostaglandin marketed was Prostavasin ${ }^{\circledR}$, a complex between prostaglandin E1 and $\alpha$-cyclodextrin. In 1979, this product was approved for the treatment of peripheral vascular complications. Uekama's group studied the molecular motions of prostaglandin $\mathrm{F}_{2 \alpha}$-cyclodextrin inclusion compounds (Uekama and Hirayama 1978; Hirayama et al. 1980; Uekama et al. 1984). As a consequence of the inclusion, the internal motion of the $\varpi$-side alkyl chain of the prostaglandin is selectively reduced by $\alpha$-cyclodextrin, while the internal motion around the fivemembered ring, as well as the overall motion, are decreased by $\beta$-cyclodextrin. In the case of the $\gamma$-cyclodextrin inclusion compound, total motion of the prostaglandin is reduced. The inclusion of prostaglandin $E_{1}$ in $\gamma$-cyclodextrin increased its heat stability and slowed down its conversion to prostanglandin $\mathrm{A}_{1}$ (Uekama et al. 1984). The structures proposed by Uekama's group and illustrated in Fig. 10 were demonstrated using NMR data (Uekama and Hirayama 1978; Hirayama et al. 1980).

Another interesting formulation was the complex $\beta$-cyclodextrin/piroxicam, used, e.g., in the treatment of acute pain of rheumatic disease. In 1988, Chiesi Farmaceutici Italy has put on the market this complex Brexin ${ }^{\circledR}$ or Cycladol $^{\circledR}$. Nine years later, the first US-approved product, 2-hydroxypropyl- $\beta$-cyclodextrin/itraconazole oral solution (Sporanox ${ }^{\circledR}$ Janssen) was introduced. Itraconazole is an orally active triazole antifungal agent to inhibit most human fungal pathogens but is practically insoluble in water at physiological pH. In 2002, two formulations containing sulfobutylether $\beta$-cyclodextrin were introduced by Pfizer in the U.S. and Europe: an intravenous formulation of the antifungal agent voriconazole $\left(V_{\text {fend }}{ }^{\circledR}\right.$ ) and an intramuscular dosage form for the antipsychotic agent ziprasidone (Geodon ${ }^{\circledR}$ ). All these formulations are preformed prior to be administrated. There are also some cases when the complexes are formed within the body. The best-known example is the one containing the active compound sugammadex (Bridion ${ }^{\circledR}$ ): it is a modified $\gamma$-CD used as an antidote to certain curare-like muscle relaxants in anesthesia since 2008. After intravenous administration, it neutralizes steroid curare-like agents such as rocuronium and vecuronium by forming an inactive complex in the plasma which is then eliminated in the urine.

Actually, more than 80 pharmaceutical products can be found (CycloLab Ltd., Hungary). In these formulations, native cyclodextrins and their derivatives such as the 

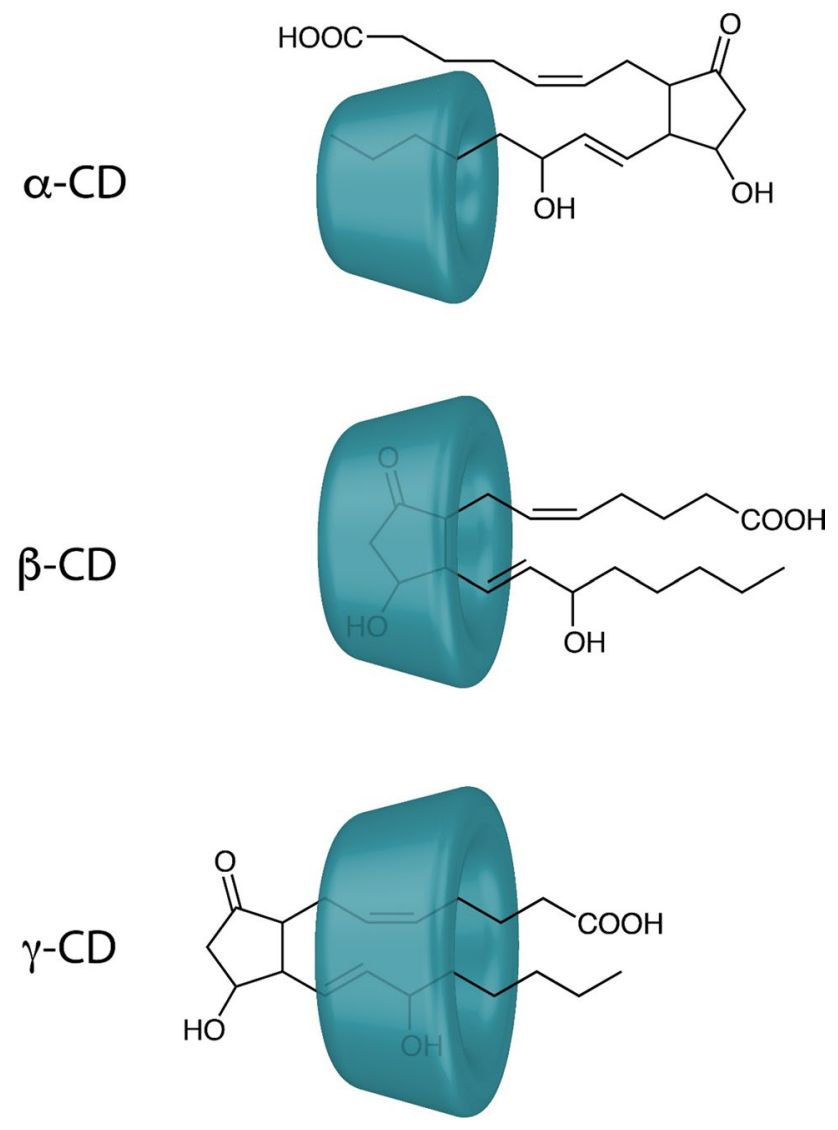

Fig. 10 Inclusion mode of cyclodextrin-prostaglandin $\mathrm{F}_{2 \alpha}$ inclusion compounds in aqueous solution adapted from Uekama and Hirayama (1978) and Hirayama et al. (1980)

hydroxypropyl derivatives of $\beta$ - and $\gamma$-cyclodextrins, sulfobutylether $\beta$-cyclodextrin, and maltosyl- $\beta$-cyclodextrin (this derivative might be a component of several drugs marketed in Japan but information are scarce) are mainly used as complexing agents to increase the aqueous solubility of poorly water-soluble drugs, to increase their stability and bioavailability. Cyclodextrins are also used to replace organic solvents in parenteral and topical formulations, to reduce gastrointestinal irritation and to increase dermal availability of drugs. Initially, cyclodextrins were mainly used in solid dosage forms for oral administration but rapidly, other administration routes were proposed such as ocular, nasal, parenteral, rectal or dermal route. For instance, RAMEB is included in Clorocil $^{\circledR}$ eye drop (Oftalder, Portugal) and Aerodiol ${ }^{\circledR}$ nasal spray (Servier, France). Both are non-parenteral, and the latter was withdrawn from the market because of economic reasons.

Food applications also started to appear in the mid-1970s. Japan authorized the use of cyclodextrin as a food additive in 1976 (Szejtli 1982a, 1998; Vaution et al. 1987; Hedges et al. 1995; Hashimoto 1996; Hedges 1998). Powdered flavors, e.g., apple and citrus fruits, spices, e.g., horseradish Wasabi and mustard, and herbs such as peppermint were marketed. Other marketed food products containing cyclodextrins or made by cyclodextrin-aided technology included chocolate (Choco Bar ${ }^{\mathrm{TM}}$ ), chewing-gum (Flavono ${ }^{\mathrm{TM}}$ ), powdered green tea (Stick Lemon ${ }^{\mathrm{TM}}$ ), and dietary fibers (Hedges 1998; Hashimoto 2002). In 1992, low-cholesterol butter, prepared by mixing cyclodextrin with the melted butter, under the tradename of Balade ${ }^{\mathrm{TM}}$ was marketed in Belgium (Comini and Mentink 1991). Other low-cholesterol milk products such as cheese (Natual ${ }^{\mathrm{TM}}$ France), cream and egg (Simply eggs $^{\text {TM }}$ USA) were produced. Other examples include bubbling coffee (Nescafé ${ }^{\circledR}$ Nestlé), beer (Flavor Aktiv ${ }^{\mathrm{TM}}$ Great Britain), and supplements. In the 2000s, the three native cyclodextrins were introduced into the generally regarded safe list of the U.S. Food and Drug Administration for use as a food additive (Hashimoto 2002). Now, the food industry, along with the pharmaceutical domain, is one of the sectors that consumes the most cyclodextrins, at least in Japan.

Hinze (1981) was the first to describe the application of cyclodextrins in analytical chemistry, focusing on their use in chromatography and purification methods. At that time, the first studies had established that cyclodextrins were interesting complexing agents, chiral selectors and/or additives in chromatography (Smolková-Keulemansová and Krysl 1980; Hinze 1981; Smolková-Keulemansová 1982; Sybilska and Smolková-Keulemansová 1984; Krysl and Smolková-Keulemansová 1985; Li and Purdy 1992). Cyclodextrins were first proposed for thin-layer chromatography, gel electrophoresis, gas chromatography, and liquid chromatography, later for capillary electrophoresis, electrokinetic chromatography and dialysis (Armstrong 1980, 1984; Smolková-Keulemansová and Krysl 1980; Smolková-Keulemansová 1982; Hinze 1981; Cserhati et al. 1983; Ward and Armstrong 1986; Li and Purdy 1992; Fanali 1993; Fanali et al. 1994; Schneiderman and Stalcup 2000). The first cyclodextrin-based chiral gas chromatography was published by Smolková-Keulemansová (1982).

At the beginning of the 1980s, Armstrong laid down the fundamentals of cyclodextrin-assisted separation science. In 10 years (1980-1988), Armstrong and his collaborators pioneered the development and optimization of analytical methods suitable for cyclodextrin-based isomer separation. In 1984, the first chromatographic columns were marketed (Advanced Separation Technologies Inc., Whippany, NJ) and this led to spectacular progress in chromatography (Armstrong 1980, 1984; Hinze 1981; Ward and Armstrong 1986, 1988; Armstrong and Jin 1989; Han and Armstrong 1989; Menges and Armstrong 1991). These chromatographic packings consisted of cyclodextrin molecules linked to silica gel via a 6-10-atom spacer. Both the linkage and the cyclodextrin were hydrolytically stable under high performance liquid chromatography. Easily the most popular cyclodextrin-based stationary phases were based on $\beta$-cyclodextrin, e.g., they 
have been shown to be very effective at resolving the enantiomers of many compounds. Subsequently, other stationary phases were developed, based on other native cyclodextrins, e.g., $\alpha$ - and $\gamma$-cyclodextrin, or derivatized cyclodextrins such as naphthyl-ethyl-carbamate derivative. The $\alpha$-cyclodextrin and $\gamma$-cyclodextrin columns, while less broadly applicable in the reversed-phase mode than the $\beta$-cyclodextrin columns, were useful for specific applications such as the separation of enantiomers of underivatized aromatic amino acids and substituted analogs or of polycyclic aromatic compounds and steroid stereoisomers. The aromatic-derivatized cyclodextrin phases were used to separate the enantiomers of many classes of compounds including pesticides, biological compounds, drugs and amino acids (Menges and Armstrong 1991; Mitchell and Armstrong (2004). The chiral recognition mechanisms in analytical separation sciences were reviewed by Scriba (2012). Li and Purdy (1992) and later Szente and Szemán (2013) comprehensively reviewed the application of cyclodextrins in diverse fields of analytical chemistry and covered the structural aspects of cyclodextrins that enabled the improvement of different chromatographic separations.

The first comprehensive review on potential applications in cosmetology, toiletry and hygiene has been published by Szejtli (1982b). This topic was later updated by Vaution et al. (1987), Hashimoto (1996, 2006), Citernesi and Sciacchitano (1995), Buschmann and Schollmeyer (2002), and Duchêne et al. (2009). In the mid-1980s, some products appear in the market although the cyclodextrins were often used without any indication of their precise role: Epicutin ${ }^{\circledR}$ TT Chemishes Laboratorium Dr Kurt Richter, a complex between cyclodextrin and Melaleuca alternifolia leaf oil, is used in skin care applications; Vivace ${ }^{\circledR}$ Shiseifo Co., a powder cologne; Klorane ${ }^{\circledR}$ Klorane laboratories, a dry shampoo; Novoflex ${ }^{\circledR}$ Revlon, a vitamin shampoo; Eucerin ${ }^{\circledR}$ Vital Active Beiersdorf, a vitamin A cream, etc. In the cosmetic industry, cyclodextrin complexes were useful for modifying solubility, improving stabilization, transforming liquids into solids, preserving color, decreasing an unpleasant smell, or diminishing the odor of mercaptan used in permanent hair preparations. Cyclodextrins were used as empty capsules in dry-shampoos to eliminate fatty substances such as sebum, or in tooth paste and mouth wash to remove undesirable odors (Duchêne et al. 2009).

In the 1980s, applications were found in textiles including textile finishing and functional textiles (Szejtli 1985; Hashimoto 1996; Buschmann and Schollmeyer 2002). The permanent fixation of cyclodextrin molecules offered textiles with interesting properties, e.g., the formation of body odor was reduced by the complexation, the release of perfumes from cyclodextrins was possible, etc. The first cellulose-cyclodextrin copolymer was described in 1980 by Szejtli's group. Alkali-swollen cellulose fibers were reacted with epichlorohydrin. The chemically bound cyclodextrin retained its complex forming ability and could be loaded with chemically and/or biologically active guests such as perfumes to prepare perfumed textiles or drugs to prepare medical bandages (Szejtli et al. 1980b). For instance, Fig. 11 illustrates a guest exchange by a cellulose fiber containing cyclodextrin. The process consists to load the fixed cyclodextrin molecules with perfume molecules. During wearing and by sweat humidity excreted short chain fatty acids displace and release the perfume molecules and will be in turn entrapped (Szejtli 2003). Procter \& Gamble recognized that similar effects can be achieved without chemical fixation by simple spraying hydroxypropyl- $\beta$-cyclodextrin solution on the fabric. This odor-eliminating spray (Febreze ${ }^{\circledR}$ ) has become a great success in the US marketed since 1998 ensuring a continuous demand for cyclodextrin production. Actually, cyclodextrins play an important role in the textile industry as a tool to remove odors, e.g., encapsulation of sweat or cigarette smoke components permit to reduce the intensity of odors of clothing or furniture textiles, as showed in Fig. 12. The mechanism of drug release is similar from medical textiles such as antimicrobial textiles for wound dressing (Aubert-Viard et al. 2019), intraperitoneal meshes (Chai et al. 2019) and other implants (Vermet et al. 2017). CycloMesh $^{\mathrm{TM}}$, a polyester visceral implant soaked in ropivacaine hydrochloride developed for slow anesthetic release and in situ activity after inguinal hernia surgery, will be soon subjected to clinical trials in France.

During the period from 1980 to 1990 , manufactured products using cyclodextrins have emerged such as pesticide formulations, reproduction processes, e.g., photography and inks, tobaccos, corrosion inhibitors, industrial detergents, sterilizing agents, anti-foam agents, glues, wood treatment, etc. (Szejtli 1982a, 1984, 1988; Vaution et al. 1987). In the agricultural sector, cyclodextrin complexation has assisted pesticide formulation in many ways, e.g., by enhancing water solubility, biological activity, through stabilization of labile substances, by enabling easier handling of hazardous substance, and also through the formation of crystalline substances from volatile liquids. An important feature of the cyclodextrin-formulated pesticides is the water-triggered release of the active compounds. A large number of patents concerning the use of cyclodextrins in agrochemistry was filled (Szejtli 1982a, 1984; Szente and Szejtli 1996; Morillo 2006).

\section{Cyclodextrins: trends and outlook}

Although an important number of works, patents and products have been realized, the sector of cyclodextrin-based pharmacy continues to interest the scientific community. Cyclodextrins are still regarded as "novel" excipients, active ingredients, drug delivery vehicles and anti-aggregation 
Fig. 11 Guest exchange by a cellulose fiber containing cyclodextrin: the process consists to load the fixed cyclodextrin molecules with perfume molecules; then during wearing and by sweat humidity excreted short chain fatty acids displace and release the perfume molecules and will be in turn entrapped adapted from Szejtli (2003) (a)

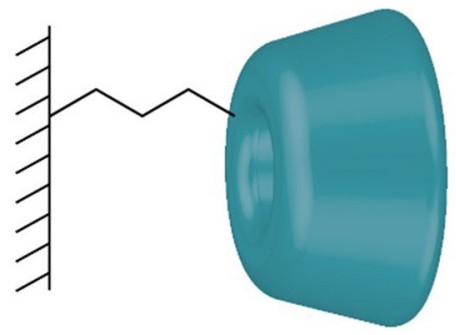

$+$

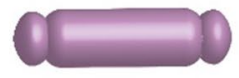

Perfume Molecule

(b)

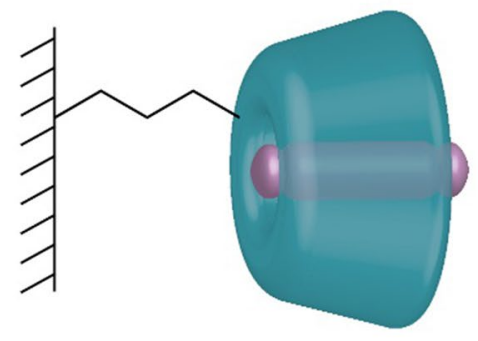

$+$

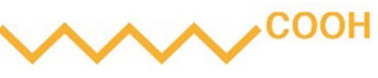

Fatty Acid Molecule

(c)
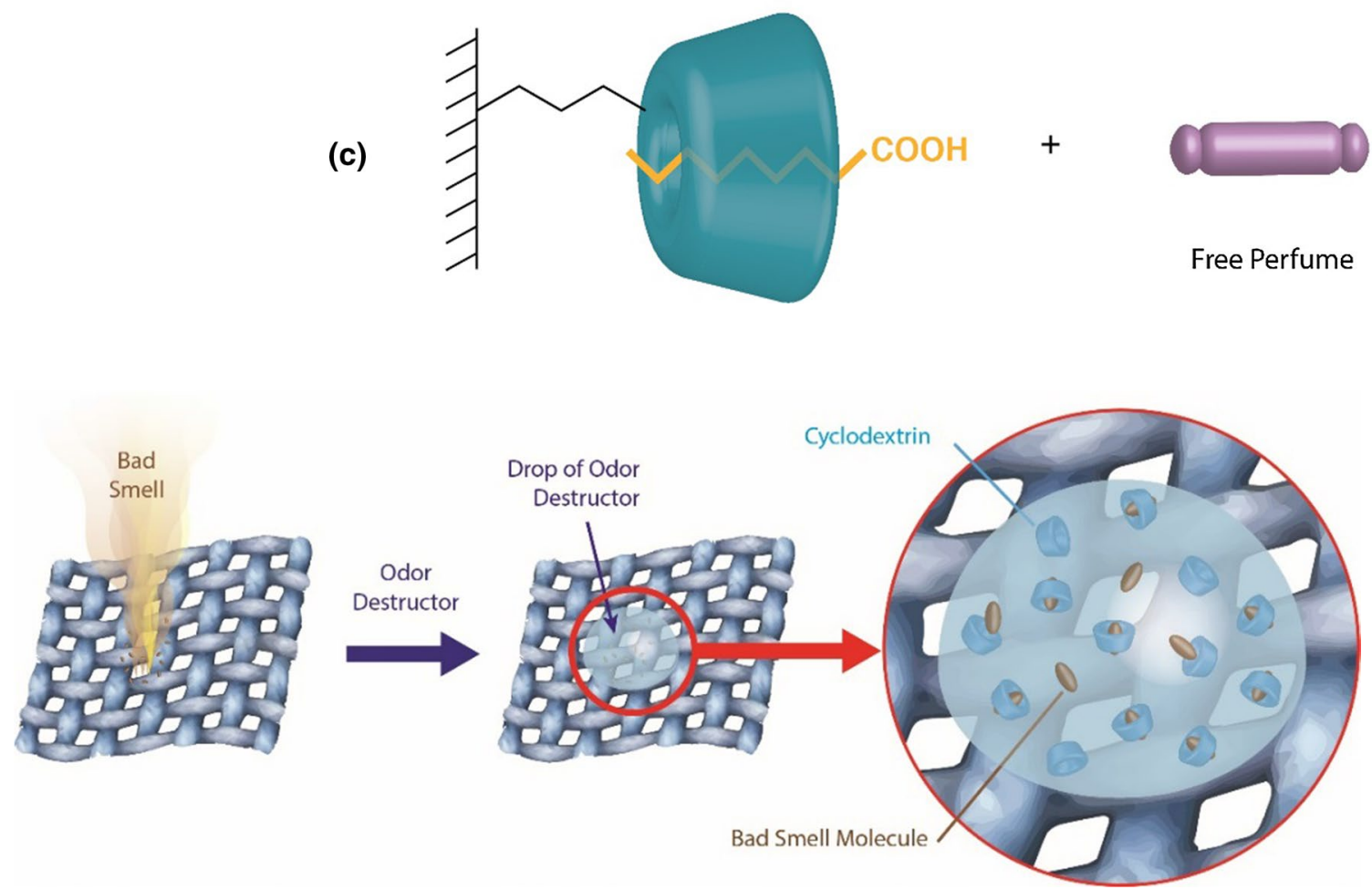

Fig. 12 Elimination of odors by a textile fiber containing cyclodextrin molecules either permanently fixed by chemicals bonds or just adsorbed on the fibers

agents (Conceição et al. 2018). New formulations continue to be reported, generating new interests in medicine and biomedicine (Higashi et al. 2018; Higashi 2019; Menezes et al.
2019; Pawar and Shende 2019). The 18 ongoing clinical trials in 2019 give the promise of new marketed formulations (Cyclodextrin News, CycloLab Ltd., Hungary). 
The recent research has clearly revealed that cyclodextrins cannot be considered inactive excipients any more (Arima et al. 2017). Hydroxylpropyl- $\beta$-cyclodextrin was found by serendipity to be useful for slowing down the progression of Niemann Pick type $\mathrm{C}$ disease, the fatal genetic disorder. Based on the promising results of the clinical trials, this cyclodextrin received orphan drug status both from Food and Drug Administration and European Drug Agency. The mechanism of action which was thought first to be based on cholesterol complexation is still under debait.

Yokoo et al. (2015) demonstrated that hydroxypropyl- $\beta$ cyclodextrin was a potential anticancer agent in leukemia. This derivative was found effective in inhibition of leukemic cell proliferation at various leukemic cell lines. It was proved to influence autophagy, a catabolic process with an essential function in the maintenance of cellular and tissue homeostasis. As solubilizing agent to increase cholesterol solubility, hydroxypropyl- $\beta$-cyclodextrin is used for prevention and treatment of atherosclerosis, a chronic inflammatory disease driven primarily by a continuous retention of cholesterol within the subendothelial space to hinder its precipitation in the form of cholesterol crystals (Zimmer et al. 2016).

Several research groups are developing special cyclodextrin derivatives with various functions, for instance, for targeted drug delivery. Folate appended cyclodextrins are recognized by folate-receptor-expressing tumor cells; therefore, they can be utilized as potent anticancer agents (Motoyama et al. 2015). Lactosyl- $\beta$-cyclodextrin was found effective for hepatomegaly in Niemann Pick type C disease (Maeda et al. 2019). Cyclodextrins decorated with a photosensitizer group can be used for drug delivery in phototherapy where the release of active ingredients is controlled by light (Benkovics et al. 2017). Multifunctional cyclodextrin derivatives having nitric oxide-releasing moiety in addition to the photosensitizer are efficient antimicrobial and antitumor agents in photodynamic therapy (Malanga et al. 2019). Many bacteria display mannose-binding lectins on their surfaces, and so mannosylated cyclodextrins are target-specific antimicrobial delivery systems to be used in fighting against antimicrobial resistance (Cutrone et al. 2018).

Another direction of recent cyclodextrin research is the design and synthesis of specific cyclodextrins tailored to the guest molecules to be entrapped. Encouraged by the extreme success of sugammadex tailored for encapturing rocuronium muscle relaxant, further cyclodextrin-based detoxicants were prepared: e.g., a cyclodextrin dimer as antidote for cyanide poisoning (Yamagiwa et al. 2014), another dimer designed for binding and removal of bisretinoid lipofuscins from eye to prevent aging-related blindness (Nociari et al. 2014), specially substituted cyclodextrins to catalyze the decomposition of organophosphorous chemical weapons getting importance in view of increasing terrorist threat (Müller et al. 2013). Even the social media shared the news on methyl- and hydroxypropyl- $\beta$-cyclodextrins as possible antidotes to box jellyfish venom (Lau et al. 2019). Similarly, quaternary amino $\beta$-cyclodextrin was found to bind ochratoxin A, a widely spread nephrotoxic contaminant mycotoxin, with an association constant more than 200 fold higher than that of $\beta$-cyclodextrin, making this derivative useful for decontamination of ochratoxin A-contaminated drinks (Poór et al. 2015).

Actually, fundamental research is also focusing on cyclodextrin-based nanoparticles/nanomaterials for pharmaceutical and biomedical applications and nanomedicine, e.g., molecular diagnosis, medical imaging, antifungal treatment, antimicrobial therapy, gene therapy or tissue engineering, and on self-association of cyclodextrins for applications not only for formulation and drug delivery, and medicine, but also for materials science, supramolecular chemistry and asymmetric catalysis (Hirakawa and Tomita 2013; Morohoshi et al. 2013; Zhang and Ma 2013; Chilajwar et al. 2014; Melotti et al. 2014; Simoes et al. 2014; Dong et al. 2015; Macaev and Boldescu 2015; Mavridis and Yannakopoulou 2015; Miller et al. 2015; Perez-Anes et al. 2015; Wu et al. 2015; Brackman et al. 2016; Junthip et al. 2016; Okano et al. 2016; Oliveri and Vecchio 2016; Ryzhakov et al. 2016; Sharma and Baldi 2016; Silva et al. 2016; Yuan and Zhang 2016; Saokham and Loftsson 2017; Egele et al. 2019; Fenyvesi et al. 2019; Hammoud et al. 2019; Kumar and Rao 2019; Neva et al. 2019; Pawar and Shende 2019; Topuz and Uyar 2019; Zhang et al. 2019a).

Nanoparticles of various compositions have been engineered in ever smaller sizes to function in both diagnostic and therapeutic capacities. They are available on a scale similar to many biological molecules and infectious agents, thereby opening the possibility of biological intervention on the molecular level (Gilmore and Colson 2011). Nanoparticle-based systems can improve bioavailability, reduce immunogenicity, modify drug metabolism, reduce toxicity, and increase the biological half-life of drugs after systemic administration. The use of cyclodextrin-based nanoaggregates both in oral and ophthalmic drug delivery could be a promising strategy to improve the bioavailability of poorly soluble drugs (Loftsson and Stefánsson 2017; Kumar and Rao 2019). Nanomaterials are also interesting because they can be formulated as oral, parenteral, topical or inhalation dosage forms (Chilajwar et al. 2014). They can be targeted by using specific components and/or moieties, e.g., antibody targeted cyclodextrin-based nanoparticles were developed for siRNA delivery in the treatment of myeloid leukemia (Guo et al. 2017). Various innovative ideas for the purposeoriented design of such systems have been published, e.g., "ship-in-a-bottle" (Xu et al. 2019), modern Trojan horse (Gilmore and Colson 2011) and molecular Lego approach for the diversity-oriented synthesis of cyclodextrin analogs as scaffolds for multivalent systems (Lepage et al. 2015). 
Promising developments for nanoparticles are under way in emerging domains such as nutraceuticals and cosmeceuticals (Fenyvesi et al. 2016; Adeoye et al. 2017). Further contributions are also expected in the near future in bacterial resistance and chemotherapy (Carneiro et al. 2019; Zhang et al. 2019b).

Recently, Higashi et al. (2018) introduced a new concept in pharmaceutical sciences termed "supramolecular pharmaceutical sciences" which combines pharmacy domain and supramolecular chemistry. This concept is focused on the development of cyclodextrin-based supermolecules, such as polyspeudorotaxanes, polyrotaxanes, polycatenanes, and daisy chains, as active pharmaceutical ingredients used, for instance, against Niemann Pick disease type C, leukemia, Alzheimer's disease, chronic renal failure, or sterility. These biodegradable polyrotaxanes ensure longer residence time and slow release of the cyclodextrin-mostly hydroxypropyl- $\beta$-cyclodextrin-as active ingredient. The low local concentrations result in reduced toxicity even in the case of the methylated derivatives.

The number of publications on the use of nanofibers containing cyclodextrins, e.g., prepared by electrospinning, is also growing (Celebioglu and Uyar 2012, 2013; Aytac et al. 2015, 2016; Topuz and Uyar 2019). These nanofibers are proposed as innovative products for medicine, biomedicine, and nanomedicine applications, e.g., for medical devices, tissue engineering scaffolds, stents, prosthesis, and bone implants. Most of these studies are in the proof-of-concept stage, and only a few therapeutic nanosystems/nanomaterials have been comprehensively investigated. Nanofibers are also proposed for textile and environmental applications (Celebioglu et al. 2016), e.g., innovative clothing, filtration media, and membranes.

The use of cyclodextrins for veterinary use seems to be a promising domain (Chiu et al. 2016) and new formulations continue to be reported, e.g., Itrafungol ${ }^{\mathrm{TM}}$, Voriconazole Dexolve ${ }^{\mathrm{TM}}$, Nexterone ${ }^{\mathrm{TM}}$, Cereni ${ }^{\mathrm{TM}}$, Vetmedin ${ }^{\mathrm{TM}}$, Suvaxyn ${ }^{\mathrm{TM}}$, etc. Itrafungol ${ }^{\mathrm{TM}}$ is an antifungal containing 2-hydroxypropyl- $\beta$-cyclodextrin used as antimycotic drug in oral form in cats. Another example is Voriconazole Dexolve ${ }^{\mathrm{TM}}$, a commercial formulation containing sulfobutylether- $\beta$-cyclodextrin as an excipient, used as an antimycotic drug for veterinary and human use. Suvaxyn ${ }^{\mathrm{TM}}$ containing a sulfolipo-cyclodextrin as adjuvant is used as vaccine for the active immunization of pigs.

The global market of cyclodextrins used in food industries is continuously increasing (Fenyvesi and Szente 2016; Fenyvesi et al. 2016). The main application is the stabilization of flavors and aromas. $\alpha$-Cyclodextrin, being non-digestible, is recognized a dietary fiber with beneficial effects on digestion of fat and carbohydrates (Artiss et al. 2006). It has been marketed for body weight control in several countries. Further studies and industrial developments are expected in the near future in the following domains: functional food, nutritional supplements, nutraceuticals, wrapping materials, and packaging. One of the most promising functional food groups is those enriched in antioxidant compounds of a lipophilic nature (Fenyvesi and Szente 2016; Kfoury et al. 2016; Zarzycki et al. 2016).

Other applications have been reported in sectors such as supramolecular catalysis (Hapiot et al. 2014; Chen et al. 2019; Fernandez et al. 2019), asymmetric and stereospecific synthesis (Macaev and Boldescu 2015), click chemistry (Celebioglu et al. 2016; Hou et al. 2016), metal-organic frameworks (Rajkumar et al. 2019), agrochemistry (Campos et al. 2015; Yusoff et al. 2016), supercritical fluid chromatography (Xiao et al. 2012; West 2014), imprinting techniques (Lay et al. 2016), nanofibers (Topuz and Uyar 2019), and environment (Taka et al. 2017; Crini et al. 2018).

Research on cyclodextrins is also very active in fields such as the formulation of detergents and sugar-based surfactants (Valente and Söderman 2014), glues and adhesives (Osaki 2019), silicon industry (Grachev et al. 2019), flame retardant formulation (Luda and Zanetti 2019), the sector of plastics for packaging or automotive (Szente and Fenyvesi 2018), the industry of fibers and paper, soil remediation (Atteia et al. 2013; Lau et al. 2014; Madrid et al. 2019; Gruiz et al. 2019), materials for wastewater treatment (Cova et al. 2018; Morin-Crini et al. 2018; Barbosa et al. 2019), biodiesel production (Zhang et al. 2018), and hydrogen storage (Han et al. 2018).

The slide ring gels (polyrotaxane gels) found their application in the car industry and telecommunication (Ito 2017; Kashiwagi et al. 2018; Jiang et al. 2018). There are also many possibilities for the development of new textiles and cosmetic products, called cosmetotextiles (Singh et al. 2011), with advanced properties (Shende and Trotta 2019; Yao et al. 2019). Their applications seem promising.

Cosmeceuticals containing cyclodextrins also seem to be a promising domain for medicine, dermatology, and aromatherapy (Adeoye et al. 2017; Kaur et al. 2018). These products are cosmetics with pharmaceutical and therapeutic benefits.

\section{Conclusion}

In this review, we described historical landmarks of the discovery, exploration, and utilization of cyclodextrins, cyclic oligosaccharides obtained from the enzymatic degradation of starch and discovered serendipitously in 1891 by Villiers. Of course, this historical paper cannot hope to be exhaustive, but it highlighted the work of those researchers who have contributed to the knowledge of cyclodextrins throughout the 130 years of history. 
Expensive to produce, the three main native cyclodextrins, i.e., $\alpha$-, $\beta$ - and $\gamma$-cyclodextrins, were long considered just laboratory curiosities. Until the mid-1970s, the main obstacles were the lack of sufficient knowledge of these molecules, their high price, and also their presumed toxicity. In addition, very few researchers were convinced of the industrial potential of cyclodextrins. As reported in this comprehensive review, since Villiers' discovery, several great scientists, including Schardinger, Freudenberg, Cramer, French and Szejtli, have left their mark on the history, characterization, properties, and potential applications of these molecules over a period of 85 years, from 1903 , i.e., the first paper on cyclodextrin chemistry published by Schardinger, to 1989, i.e., the creation by Szejtli of the first company totally devoted to cyclodextrins. Since the 1980s, cyclodextrins have considerably attracted the interest of scientists and industries in different disciplines including health science, agriculture, chemistry, biochemistry, and environment. The main reason for this growing interest was their ability to form inclusion complexes with various molecules through host-guest interactions.

Today, cyclodextrins continue to offer new horizons to scientists and industrials with a wide range of possible modifications and forms for multiple classical, e.g., pharmacy, food industry, chromatography, cosmetology and biotechnology, and emerging, e.g., biomedicine, agrochemistry and nanomaterials, applications.

\section{References}

Adeoye O, Figueiredo A, CabralMarques H (2017) Chapter 13: cyclodextrins and skin disorders: therapeutic and cosmetic applications. In: Ascenso A, Ribeiro H, Simões S (eds) Carrier-mediated dermal delivery. Jenny Stanford Publishing, New York. https://doi.org/10.4324/9781315364476

Akiya S, Okui S (1951) Studies of the degeneration process of sugars. 3. Reactions of periodic acid on 2 hexasaccharides. J Pharm Soc Jpn 71:865-869

Akiya S, Watanabe T (1950a) A crystalline decomposition product of starch by a bacillus. 3. A new strain of Bacillus macerans. J Pharm Soc Jpn 70:572-576

Akiya S, Watanabe T (1950b) A crystalline decomposition product of starch by a bacillus. 4. A new hexasaccharide. J Pharm Soc Jpn 70:576-578

Akiya S, Watanabe T (1950c) A crystalline decomposition product of starch by a bacillus. 5. Structure of the new hexasaccharide. J Pharm Soc Jpn 70:579-582

Ammayappan L, Moses JJ (2009) An overview on application of cyclodextrins in textile product enhancement. J Text Assoc 70:9-18

Andersen GH, Robbins FM, Domingues FJ, Moores RG, Long CL (1963) The utilization of Schardinger dextrins by the rat. Toxicol Appl Pharmacol 5:257-266

Andreaus J, Dalmolin MC, De Oliveira IB, Barcellos IO (2010) Application of cyclodextrins in textile processes. Quim Nova 33:929937. https://doi.org/10.1590/S0100-40422010000400031
Arima H, Motoyama K, Higashi T (2017) Potential use of cyclodextrins as drug carriers and active pharmaceutical ingredients. Chem Pharm Bull 65:341-348. https://doi.org/10.1248/cpb. c16-00779

Armspach D, Gattuso G, Koeniger R, Stoddart JF (1999) Cyclodextrins. In: Hecht SM (ed) Bioorganic chemistry: carbohydrates. Oxford University Press Inc, New York, pp 458-488

Armstrong DW (1980) Pseudophase liquid chromatography: applications to TLC. J Liq Chromatogr 3:895-900

Armstrong DW (1984) Chiral stationary phases for high performance liquid chromatographic separation of enantiomers: a mini-review. J Liq Chromatogr 2:353-376

Armstrong DW, Jin HL (1989) Liquid-chromatographic separation of anomeric forms of saccharides with cyclodextrin bonded phases. Chirality 1:27-37. https://doi.org/10.1002/chir.530010108

Arora D, Saneja A, Jaglan S (2019) Cyclodextrin-based delivery systems for dietary pharmaceuticals. Environ Chem Lett 17:12631270. https://doi.org/10.1007/s10311-019-00878-w

Artiss JD, Brogan K, Brucal M, Moghaddam M, Jen KL (2006) The effects of a new soluble dietary fiber on weight gain and selected blood parameters in rats. Metabolism 55:195-202

Assaf KI, Gabela D, Zimmermann W, Nau WM (2016) High-affinity host-guest chemistry of large-ring cyclodextrins. Org Biomol Chem 14:7702-7706. https://doi.org/10.1039/c6ob01161f

Astray G, Mejuto JC, Simal-Gandara J (2020) Latest developments in the application of cyclodextrin host-guest complexes in beverage technology processes. Food Hydrocoll 106:105882. https://doi. org/10.1016/j.foodhyd.2020.105882

Atteia O, Estrada ED, Bertin H (2013) Soil flushing: a review of the origin of efficiency variability. Rev Environ Sci Bio-Technol 12:379-389. https://doi.org/10.1007/s11157-013-9316-0

Aubert-Viard F, Mogrovejo-Valdivia A, Tabary N, Maton M, Chai F, Neut C, Martel B, Blanchemain N (2019) Evaluation of antibacterial textile covered by layer-by-layer coating and loaded with chlorhexidine for wound dressing application. Mater Sci Eng C 100:554-563. https://doi.org/10.1016/j.msec.2019.03.044

Aytac Z, Uyar T (2017) Core-shell nanofibers of curcumin/cyclodextrin inclusion complex and polylactic acid: enhanced water solubility and slow release of curcumin. Int J Pharm 518:177-184. https:// doi.org/10.1016/j.ijpharm.2016.12.061

Aytac Z, Sen HS, Durgun E, Uyar T (2015) Sulfisoxazole/cyclodextrin inclusion complex incorporated in electrospun hydroxypropyl cellulose nanofibers as drug delivery system. Colloids Surf B Biointerfaces 128:331-338. https://doi.org/10.1016/j.colsu rfb.2015.02.019

Aytac Z, Yildiz ZI, Kayaci F, San NO, Kusku SI, Durgun E, Tekinay T, Uyar T (2016) Fast-dissolving, prolonged release and antibacterial cyclodextrin/limonene-inclusion complex nanofibrous webs via polymer-free electrospinning. J Agric Food Chem 64:73257334. https://doi.org/10.1021/acs.jafc.6b02632

Bailey JM, French D (1957) The significance of multiple reactions in enzyme-polymer systems. J Biol Chem 226:1-14

Barbosa PFP, Cumba LR, Andrade RDA, do Carmo DR (2019) Chemical modifications of cyclodextrin and chitosan for biological and environmental applications: metals and organic pollutants adsorption and removal. J Polym Environ 27:1352-1366. https ://doi.org/10.1007/s10924-019-01434-x

Bates FL, French D, Rundle RE (1943) Amylose and amylopectin content of starches determined by their iodine complex formation. $\mathrm{J}$ Am Chem Soc 65:142-148. https://doi.org/10.1021/ja01242a003

Bender ML, Komiyama M (1978) Cyclodextrin chemistry. Reactivity and structure: concepts in organic chemistry, vol 6. Springer, Berlin

Benkovics G, Afonso D, Darcsi A, Béni S, Conoci S, Fenyvesi É, Szente L, Malanga M, Sortino S (2017) Novel $\beta$-cyclodextrin-eosin 
conjugates. Beilstein J Org Chem 13:543-551. https://doi. org/10.3762/bjoc. 13.52

Bezerra FM, Lis MJ, Firmino HB, da Silva JGD, Valle RDSC, Valle JAB, Scacchetti FAP, Tessaro AL (2020) The role of beta-cyclodextrin in the textile industry-review. Molecules 25:3624. https://doi.org/10.3390/molecules25163624

Bilensoy E (ed) (2011) Cyclodextrins in pharmaceutics, cosmetics and biomedicine. Current and future industrial applications. Hoboken, Wiley, p 395. https://doi.org/10.1002/9780470926 819

Biltz W (1913) Über den osmotischen druck der kolloide. Fünfte mitteilung: zur kolloidchemie der dextrine. Z Phys Chem 83:683-707. https://doi.org/10.1515/zpch-1913-8348

Biltz W, Truthe W (1913) Über die molekulargrösse von dextrin $\beta$. Ber Dtsch Chem Ges 46:1377-1380. https://doi.org/10.1002/ cber.19130460217

Borchert W (1948) Röntgenographische untersuchungen an Shardinger-dextrinen. Z Naturforsch B 3:464-465

Brackman G, Garcia-Fernandez MJ, Lenoir J, De Meyer L, Remon JP, De Beer T, Concheiro A, Alvarez-Lorenzo C, Coenye T (2016) Dressings loaded with cyclodextrin-hamamelitannin complexes increase Staphylococcus aureus susceptibility toward antibiotics both in single as well as in mixed biofilm communities. Macromol Biosc 16:859-869. https://doi.org/10.1002/mabi.201500437

Braga SS (2019) Cyclodextrins: emerging medicines of the new millennium. Biomolecules 9:801. https://doi.org/10.3390/biom9120801

Brauns U, Müller BW (1983) Pharmaceutical compositions drugs which are unstable or sparingly soluble in water, and methods for their preparation. European Patent No. 149197, 21 March 1990, with priority from German Patent DE No. 3346123, 21 December 1983

Breslow R (1979) Biomimetic chemistry in oriented systems. Israel J Chem 18:187-191

Breslow R, Dong SD (1998) Biomimetic reactions catalyzed by cyclodextrins and their derivatives. Chem Rev 98:1997-2012. https:// doi.org/10.1021/cr970011j

Brewster ME, Loftsson T (2002) The use of chemically modified cyclodextrins in the development of formulations for chemical delivery systems. Pharmazie 57:94-101

Brewster ME, Loftsson T (2007) Cyclodextrins as pharmaceutical solubilizers. Adv Drug Deliv Rev 59:645-666. https://doi. org/10.1016/j.addr.2007.05.012

Brewster ME, Loftsson T, Bodor N (2004) Applications of chemicallymodified cyclodextrins: use of hydroxypropyl-beta-cyclodextrin as an enabling excipient for brain targeting, redox-based derivatives of estradiol a review of preclinical and clinical findings. J Drug Del Sci Technol 14:32-34

Buschmann HJ, Schollmeyer EJ (2002) Applications of cyclodextrins in cosmetic products: a review. J Cosmetic Sci 53:185-191

Buschmann HJ, Schollmeyer E (2004) Cosmetic textiles: a new functionality of clothes. Cosmet Toiletries 11:105-112

Buschmann HJ, Denter U, Knittel D, Schollmeyer E (1998) The use of cyclodextrins in textile processes-an overview. J Text Inst 89:554-561. https://doi.org/10.1080/00405009808658641

Caesar GV (1968) The Schardinger dextrins. In: Radley JA (ed) Starch and its derivatives, chapter X, 4th edn. Chapman and Hall Ltd., EC4, London, pp 290-305

Campos EVR, de Oliveira JL, Fraceto LF, Singh B (2015) Polysaccharides as safer release systems for agrochemicals. Agron Sustain Dev 35:47-66. https://doi.org/10.1007/s13593-014-0263-0

Carneiro SB, Duarte FIC, Heimfarth L, Quintans JDS, Quintans LJ, da Veiga VF, de Lima AAN (2019) Cyclodextrin-drug inclusion complexes: in vivo and in vitro approaches. Int J Mol Sci 20:642. https://doi.org/10.3390/ijms20030642
Casu B, Reggiani M, Gallo GG, Vigevani A (1965) NMR spectra and conformation of glucose and some related carbohydrates in dimethylsulphoxide solution. Tetrahedron Lett 27:2253-2259

Casu B, Gallo GG, Reggiani M, Vigevani A (1968a) Applications of magnetic resonance spectroscopy of hydroxyl protons to analysis of starch-derived products. Starch/Stärke 20:387-391. https://doi. org/10.1002/star.19680201202

Casu B, Reggiani M, Gallo GG, Vigevani A (1968b) Applications of magnetic resonance spectroscopy of the hydroxyl protons to the analysis of starch-derived products. X Congress of the Italian Chemical Society, Padova, Italy

Casu B, Reggiani M, Gallo GG, Vigevani A (1968c) Conformation of O-methylated amylose and cyclodextrins. Tetrahedron 24:803821. https://doi.org/10.1016/0040-4020(68)88030-5

Casu B, Reggiani M, Gallo GG, Vigevani A (1970) Conformation of acetylated cyclodextrins Celebioglu A, Demirci S, Uyar T (2014) Cyclodextrin-grafted electrospun cellulose acetate nanofibers via click reaction for removal of phenanthrene. Appl Surf Sci 305:581-588. https://doi.org/10.1016/j.apsusc.2014.03.138

Celebioglu A, Uyar T (2012) Electrospinning of nanofibers from nonpolymeric systems: polymer-free nanofibers from cyclodextrin derivatives. Nanoscale 4:621-631. https://doi.org/10.1039/c1nr1 $1364 \mathrm{j}$

Celebioglu A, Uyar T (2013) Electrospinning of nanofibers from nonpolymeric systems: electrospun nanofibers from native cyclodextrins. J Colloid Int Sci 404:1-7. https://doi.org/10.1016/j. jcis.2013.04.034

Celebioglu A, Sen HS, Durgun E, Uyar T (2016) Molecular entrapment of volatile organic compounds (VOCs) by electrospun cyclodextrin nanofibers. Chemosphere 144:736-744. https:// doi.org/10.1016/j.chemosphere.2015.09.029

Chai F, Maton M, Degoutin S, Vermet G, Simon N, Rousseaux C, Martel B, Blanchemain N (2019) In vivo evaluation of postoperative pain reduction on rat model after implantation of intraperitoneal PET meshes functionalized with cyclodextrins and loaded with ropivacaine. Biomaterials 192:260-270. https ://doi.org/10.1016/j.biomaterials.2018.07.032

Chankvetadze B (2004) Combined approach using capillary electrophoresis and NMR spectroscopy for an understanding of enantioselective recognition mechanisms by cyclodextrins. Chem Soc Rev 33(6):337-347. https://doi.org/10.1039/b111412n

Chen YQ, Gui X, Duan ZB, Zhu LJ, Xiang YZ, Xia DH (2019) Transition metal catalyzed organic reaction involving cyclodextrin. Chin J Org Chem 39:1284-1292. https://doi.org/10.6023/cjoc2 01809012

Chilajwar SV, Pednekar PP, Jadhav KR, Gupta GJC, Kadam VJ (2014) Cyclodextrin-based nanosponges: a propitious platform for enhancing drug delivery. Expert Opin Drug Del 11:111-120. https://doi.org/10.1517/17425247.2014.865013

Chiu KW, Robson S, Devi JL, Woodward A, Whittem T (2016) The cardiopulmonary effects and quality of anesthesia after induction with alfaxalone in 2-hydroxypropyl-beta-cyclodextrin in dogs and cats: a systematic review. J Vet Pharm Ther 39:525-538. https://doi.org/10.1111/jvp.12312

Chow DD, Karara AH (1986) Characterization, dissolution and bioavailability in rats of ibuprofen- $\beta$-cyclodextrin complex. Int $\mathbf{J}$ Pharm 28:95-101

Citernesi U, Sciacchitano M (1995) Cyclodextrins in functional dermocosmetics. Cosmet Toilet 110:53-61

Clarke RJ, Coates JH, Lincoln SF (1988) Inclusion complexes of cyclomalto-oligosaccharides (cyclodextrins). Adv Carbohydr Chem Biochem 46:205-249

Comini S, Mentink L (1991) Refining mixtures containing complexes of cyclodextrins with lipophilic compounds such as fatty acids. European Patent 440539 
Conceição J, Adeoye O, Cabral-Marques HM, Sousa Lobo JM (2018) Cyclodextrins as excipients in tablet formulations. Drug Discov Today 23:1274-1284. https://doi.org/10.1016/j.drudi s.2018.04.009

Cova TFGG, Murtinho D, Pais AACC, Valente AJM (2018) Cyclodextrin-based materials for removing micropollutants from wastewater. Curr Org Chem 22:2150-2181. https://doi. org/10.2174/1385272822666181019125315

Cramer F (1949) Die cyclodextrine aus Stärke. Dissertation, Heidelberg

Cramer F (1951a) Einschlussverbindungen von cyclodextrinen und die jod-reaktion der starke. Angew Chem 63:487

Cramer F (1951b) Über Einschlussverbindungen, I. Mitteilung, additionsversbindungen der cycloamylosen. Chem Ber 84:851-854

Cramer F (1951c) Über Einschlussverbindungen, II. Mitteilung, die blauen jodadditionsverbindungen organischer moleküle. Chem Ber 84:855-859

Cramer F (1952) Einschlußverbindungen. Angew Chem 64:437-447

Cramer F (1953) Über einschlussverbindungen. 5. Basenkatalyse durch innermolekulare hohlraume. Chem Ber Recl 86:1576-1581

Cramer F (1954) Einschlussverbindungen. Springer, Berlin. ISBN 978-3-642-49192-4

Cramer F (1955) Umglucosidierung mit einer amylase aus Bacillus macerans. Angew Chem Int Ed 67:714

Cramer F (1956) Einschlu $\beta$ verbindungen. Angew Chem 68(1956): 115-120

Cramer F (1961) Probleme der Chemischen polynucleotide synthese. Angew Chem Int Ed 73:49

Cramer (1987) Introduction. In: cyclodextrins and their industrial uses. Duchêne D (ed), Paris: éditions de santé, pp. 11-18. ISBN: 2-86411-019-9

Cramer F, Dietsche W (1958) Asymetric catalysis by inclusion compounds. Chem Ind 28:892-893

Cramer F, Dietsche W (1959a) Occlusion compounds. 15. Resolution of racemates with cyclodextrins. Chem Ber 92:378-384

Cramer F, Dietsche W (1959b) Uber einschlussverbindungen. 16. Sterospezifische reaktionen mit einschlussverbindungen. Chem Ber 92:1739-1755

Cramer F, Henglein FM (1956) Einschlussverbindungen der cyclodextrine mit gasen. Angew Chem Int Ed 68:649

Cramer F, Henglein FM (1957a) Über einschlussverbindungen. 11. Gesetzmassigkeiten bei der bildung von addukten der cyclodextrine. Chem Ber Rel 90:2561-2571

Cramer F, Henglein FM (1957b) Über einschlussverbindungen. 12. Verbindungen von alpha-cyclodextrin mit gasen. Chem Ber Recl 90:2572-2575

Cramer F, Hettler H (1967) Inclusion compounds of cyclodextrins. Naturwissenschaften 54:625-632

Cramer F, Kampe W (1962) Katalyse der decarboxylierung durch cyclodextrine. Eine modellreaktion fur die wirkungsweise der enzyme. Tetrahedron Lett 8:353-356

Cramer F, Kampe W (1965) Inclusion compounds. 17. Catalysis of decarboxylation by cyclodextrins. A model reaction for mechanism of enzymes. J Am Chem Soc 87:1115-1118

Cramer F, Steinle D (1955) Die wirkungsweise der amylase aus Bacillus macerans. Ann Chem Justus Liebig 595:81-100

Cramer F, Saenger W, Spatz HC (1967) Inclusion compounds. XIX. The formation of inclusion compounds of $\alpha$-cyclodextrin in aqueous solutions. Thermodynamics and kinetics. J Am Chem Soc 89:14-20

Cramer F, MacKensen G, Sensse K (1969) Über einschlussverbindungen, XX ORD-spektren und konformation der glucose-einheiten in cyclodextrin. Chem Ber 102:494-508

Crini G (2005) Recent developments in polysaccharide-based materials used as adsorbents in wastewater treatment. Prog Polym Sci 30:38-70. https://doi.org/10.1016/j.progpolymsci.2004.11.002
Crini G (2014) Review: a history of cyclodextrins. Chem Rev 114:10940-10975. https://doi.org/10.1021/cr500081p

Crini G (2020a) The contribution of Franz Schardinger to cyclodextrins: a tribute on the occasion of the centenary of his death. J Incl Phenom Macrocyclic Chem 97:19-28. https://doi. org/10.1007/s10847-020-00990-3

Crini G (2020b) Twenty years of dextrin research: a tribute to professor Hans Pringsheim (1876-1940). J Incl Phenom Macrocyclic Chem 98:11-27. https://doi.org/10.1007/s10847-020-01013-x

Crini G, Morcellet M (2002) Synthesis and applications of adsorbents containing cyclodextrins. J Sep Sci 25:789-813. https://doi. org/10.1002/1615-9314(20020901)25:13\%3c789:AID-JSSC7 89\%3e3.0.CO;2-J

Crini G, Fourmentin S, Fenyvesi É, Torri G, Fourmentin M, MorinCrini N (2018) Cyclodextrins, from molecules to applications. Environ Chem Lett 16:1361-1375. https://doi.org/10.1007/s1031 1-018-0763-2

Crini G, Fourmentin S, Lichtfouse E (2020). The history of cyclodextrins. Environmental Chemistry for a sustainable World 52. Springer Nature Switzerland, Cham. ISBN: 978-3-030-49307-3

Croft AP, Bartsch RA (1983) Synthesis of chemically modified cyclodextrins. Tetrahedron 9:1417-1474

Cserhati T, Dobrovolszky A, Fenyvesi E, Szejtli J (1983) Beta-cyclodextrin polymer beads as GC packings. J High Res Chromatogr 6:442-443

Cutrone G, Benkovics G, Malanga M, Casas-Solvas JM, Fenyvesi É, Sortino S, García-Fuentes L, Vargas-Berenguel A (2018) Mannoside and 1,2-mannobioside $\beta$-cyclodextrin-scaffolded NO-photodonors for targeting antibiotic resistant bacteria. Carbohydr Polym 199:649-660. https://doi.org/10.1016/j.carbp ol.2018.07.018

Davis ME, Brewster ME (2004) Cyclodextrin-based pharmaceutics: past, present and future. Nat Rev 3:1023-1035. https://doi. org/10.1038/nrd1576

Dhiman P, Bhatia M (2020) Pharmaceutical applications of cyclodextrins and their derivatives. J Incl Phenom Macrocyclic Chem 98:171-186. https://doi.org/10.1007/s10847-020-01029-3

Dietrich HV, Cramer F (1954) Über Einschlussverbindungen, VII. Mitteilung, zür struktur der jodketten in kanal-einschlussverbindungen. Chem Ber 87:806-817

Dong RJ, Zhou YF, Huang XH, Zhu XY, Lu YF, Shen J (2015) Functional supramolecular polymers for biomedical applications. Adv Mater 27:498-526. https://doi.org/10.1002/adma.201402975

Duchêne D (1987) Cyclodextrins and their industrial uses. Éditions de Santé, Paris

Duchêne D (1991) New trends in cyclodextrins and derivatives. Éditions de Santé, Paris

Duchêne D, Bochot A, Loftsson T (2009) Cyclodextrins and their use in pharmacy and cosmetology. STP Pharma Pratiques 19:15-27

Egele K, Samaddar S, Schneider N, Thompson D, Wenz G (2019) Synthesis of the anionic hydroxypropyl- $\beta$-cyclodextrin:poly(de camethylenephosphate) polyrotaxane and evaluation of its cholesterol efflux potential in Niemann-Pick C1 cells. J Mater Chem B 7:528-537. https://doi.org/10.1039/C8TB02950D

Endo T, Nagase H, Ueda H, Kobayashi S, Nagai T (1997) Isolation, purification, and characterization of cyclomaltodecaose (epsilon-cyclodextrin), cyclomaltoundecaose (zeta-cyclodextrin) and cyclomaltotriodecaose (theta-cyclodextrin). Chem Pharm Bull 45:532-536

Endo T, Nagase H, Ueda H, Kobayashi S, Shiro M (1999) Crystal structure of cyclomaltodecaose (epsilon-cyclodextrine) at $203 \mathrm{~K}$. Anal Sci 15:613-614

Escuder-Gilabert L, Martin-Biosca Y, Medina-Hernandez MJ, Sagrado S (2014) Cyclodextrins in capillary electrophoresis: recent developments and new trends. J Chromatogr A 1357:2-23. https://doi. org/10.1016/j.chroma.2014.05.074 
Fanali S (1993) Use of cyclodextrins in capillary electrophoresis. In: capillary electrophoresis Technology. In: Guzman NA (ed) Chromatographic science series. New York: Marcel Dekker Inc. vol 64, part V, pp 731-752. ISBN: 0-8247-9042-1

Fanali S, Cristalli M, Vespalec R, Bocek P (1994) Chiral separations in capillary electrophoresis. In: advances in electrophoresis. In: Chrambach A, Dunn MJ, Radola BJ (eds) Weinheim: VCH Verlagsgesellschaft mbH, chapter 7, pp 1-88

Fenyvesi E (1988) Cyclodextrin polymers in the pharmaceutical industry. J Incl Phenom 6:537-545

Fenyvesi É, Szente (2016) Nanoencapsulation of flavors and aromas by cyclodextrins. In: Grumezescu A (ed) Encapsulations. Nanotechnology in the agri-food industry. 1st edn, vol 2, chapter 18, pp 769-792. ISBN: 978-0-12-804378-3

Fenyvesi É, Vikmon M, Szente L (2016) Cyclodextrins in food technology and human nutrition: benefits and limitations. Crit Rev Food Sci Nutr 56:1981-2004. https://doi.org/10.1080/10408 398.2013.809513

Fenyvesi É, Puskas I, Szente L (2019) Applications of steroid drugs entrapped in cyclodextrins. Environ Chem Lett 17:375-391. https ://doi.org/10.1007/s10311-018-0807-7

Fernandez MA, Fernando OF, Vico RV, de Rossi RH (2019) Complex systems that incorporate cyclodextrins to get materials for some specific applications. Carbohydr Res 480:12-34. https://doi. org/10.1016/j.carres.2019.05.006

Fourmentin S, Crini G, Lichtfouse E (2018a) Cyclodextrins applications in medicine, food, environment and lLiquid crystals. Environmental chemistry for a sustainable world. Springer, Basel. ISBN 978-3-319-76162-6

Fourmentin S, Crini G, Lichtfouse E (2018b) Cyclodextrins fundamentals, reactivity and analysis. Environmental chemistry for a sustainable world. Springer, Basel. ISBN 978-3-319-76159-6

French D (1957a) The Schardinger dextrins. In: Wolfrom ML (ed) Advances in carbohydrate chemistry, vol 12. Academic Press Inc, New York, pp 189-260

French D (1957b) Preparation of Schardinger dextrins. Methods Enzymol 3:17-20. https://doi.org/10.1016/S0076-6879(57)03341-8

French D (1960) Determination of starch structure by enzymes. Bull Soc Chim Biol 42:1677-1689

French D (1962) Cyclodextrin transglycosylase (Bacillus macerans amylase). In: Collowick SP, Kaplan NO (eds) Methods in enzymology. Academic New York, vol 5, pp 148-155. https://doi. org/10.1016/S0076-6879(62)05197-6

French D, Abdullah M (1965) Branched Schardinger dextrins. Feder Proc 24:221-223

French D, McIntire RL (1950) Studies on the Schardinger dextrins. V. Periodate oxidation. J Am Chem Soc 72:5148-5150. https://doi. org/10.1021/ja01167a095

French D, Rundle RE (1942) The molecular weights of the Schardinger alpha and beta dextrins. J Am Chem Soc 64:1651-1653. https:// doi.org/10.1021/ja01259a050

French D, Pazur JH, Levine ML, Norberg E (1948) Reversible action of macerans amylase. J Am Chem Soc 70:3145. https://doi. org/10.1021/ja01189a512

French D, Levine ML, Pazur JH, Norberg E (1949a) Studies on the Schardinger dextrins. The preparation and solubility characteristics of alpha-dextrins, beta-dextrins, and gamma-dextrins. $\mathbf{J}$ Am Chem Soc 71:353-356. https://doi.org/10.1021/ja01169a100

French D, Levine ML, Pazur JH (1949b) Studies on the Schardinger dextrins. II. Preparation and properties of amyloheptaose. J Am Chem Soc 71:356-358. https://doi.org/10.1021/ja01169a101

French D, Levine ML, Pazur JH, Norberg E (1950a) Studies on the Schardinger dextrins. IV. The action of soy bean beta amylase on amyloheptaose. J Am Chem Soc 72:1746-1748. https://doi. org/10.1021/ja01160a093
French D, Knapp D, Pazur JH (1950b) Studies on the Schardinger dextrins. VI. The molecular size and structure of the $\gamma$-dextrin. J Am Chem Soc 72:5150-5152. https://doi.org/10.1021/ja01167a096

French D, Levine ML, Norberg E, Nordin P, Pazur JH, Wild GM (1954) Studies on the Schardinger dextrins. VII. Co-substrate specificity in coupling reactions of Macerans amylase. J Am Chem Soc 76:2387-2390

French D, Pulley AO, Whelan WJ (1963) Preparation of Schardinger dextrins on a larger-than-laboratory scale. Die Stärke 8:280-284

French D, Pulley AO, Effenberger JA, Rougvie MA, Abdullah M (1965) Studies on the Schardinger dextrins. XII. The molecular size and structure of the delta-, epsilon-, zeta-, and etadextrins. Archiv Biochem Biophys 111:153-160. https://doi. org/10.1016/0003-9861(65)90334-6

Freudenberg K (1934) Beiträge zur chemie der stärke und anderer polysaccharide. Angew Chemie 39:675-677

Freudenberg K (1939) Polysaccharides and lignin. Annu Rev Biochem $8: 81-112$

Freudenberg K (1943) Beiträge zur chemie der kohlenhydrate. Ber Dtsch Chem Ges 76:A71-A96

Freudenberg K (1955) Contributions to the chemistry of high molecular natural substances. J Polym Sci 16:155-162

Freudenberg K (1957a) Hydrolysis and optical rotation of cellulose, starch, and cycloglucans. J Polym Sci 23:791-799

Freudenberg K (1957b) Beiträge zur chemie der stärke und der cycloglucane (Schardinger-dextrine). Angew Chemie 69:419-422

Freudenberg K (1962) Beiträge zur chemie der cellulose und der stärke. Starch-Stärke 15:199-208

Freudenberg K, Cramer F (1948) Die constitution der Schardingerdextrine dextrine-alpha, dextrin-beta and dextrin-gamma. Z Naturforsch B 3:464

Freudenberg K, Cramer F (1950) Über die Schardinger-dextrine aus stärke. Chem Ber Recl 83:296-304

Freudenberg K, Ivers O (1922) Synthesen gemischt-acylierter halogen zucker. Ber Dtsch Chem Ges 55:929-941. https://doi. org/10.1002/cber.19220550416

Freudenberg K, Jacobi R (1935) Über Schardingers dextrin aus stärke. Justus Liebigs Ann Chem 518:102-108

Freudenberg K, Meyer-Delius M (1938) Über die Schardinger-dextrine aus stärke. Ber Dtsch Chem Ges 71:1596-1600

Freudenberg K, Meyer-Delius M (1939) Neue ansichten über die stärke. Naturwissenschaften 27:850-853. https://doi.org/10.1007/BF014 89430

Freudenberg K, Rapp W (1936) Zur kenntnis der stärke und der Schardinger-dextrine. Ber Dtsch Chem Ges 69:2041-2045

Freudenberg K, Blomqvist G, Ewald L, Soff K (1936) Hydrolyse und acetolyse der stärke und der Schardinger-dextrine. Ber Dtsch Chem Ges 69:1258-1266

Freudenberg K, Boppel H, Meyer-Delius M (1938) Observations on starch. Naturwissenschaften 26:123-124

Freudenberg K, Schaaf E, Dumpert G, Ploetz T (1939) New aspects of starch. Naturwissenschaften 27:850-853

Freudenberg K, Plankenhorn E, Knauber H (1947a) Uber Schardinger dextrine aus stärke. Ann Chem Justus Liebig 558:1-10

Freudenberg K, Plankenhorn E, Knauber H (1947b) Schardinger's dextrins-Derived from starch. Chem Ind 48:731-735

Freudenberg K, Cramer F, Plieningen H (1953) Verfahren zur Herstellung von Einschlussverbindungen Physiologisch Wirksamer Organischer Verbindungen. Knoll AG, Chemische Fabriken, German Patent DBP 895.769, November 1953

Frömming KH, Szejtli J (1994) Cyclodextrins in pharmacy. Topics in inclusion science, vol 5. Kluwer Academic Publishers, Dordrecht

Gentili A (2020) Cyclodextrin-based sorbents for solid phase extraction. J Chromatogr A 1609:460654. https://doi.org/10.1016/j. chroma.2019.460654 
Gilmore D, Colson YL (2011) Tumor targeted nanoparticles: a modern day Trojan horse. Semin Thorac Cardiovasc Surg 23:10-11. https ://doi.org/10.1053/j.semtcvs.2011.03.004

Grachev MK, Kurochkina GI, Popkov AV (2019) The features of synthesis and chemical behavior of some silicon-containing cyclodextrin derivatives. Russ Chem Bull 68:708-716. https://doi. org/10.1007/s11172-019-2477-4

Gramera R (1969) Cyclodextrin polyethers and their production. US Patent No. 3459731, October 1969

Griffiths DW, Bender ML (1973) Cycloamyloses as catalysts. Adv Catal 23:209-261. https://doi.org/10.1016/S0360-0564(08)60302-8

Gruiz K, Molnar M, Fenyvesi É, Cs Hajdu, Atkari A, Barkacs K (2011) Cyclodextrins in innovative engineering tools for risk-based environmental management. J Incl Phenom Macrocycl Chem 70:299-306. https://doi.org/10.1007/s10847-010-9909-y

Gruiz K, Meggyes T, Fenyvesi É (eds) (2019) Engineering tools for environmental risk management. Volume 4. Risk reduction technologies and case studies. CRC Press, Boca Raton. https://doi. org/10.1201/b20405

Guo J, Russell EG, Darcy R, Cotter TG, McKenna SL, Cahill MR, O’Driscoll CM (2017) Antibody-targeted cyclodextrin-based nanoparticles for siRNA Delivery in the treatment of acute myeloid leukemia: physicochemical characteristics, in vitro mechanistic studies, and ex vivo patient derived therapeutic efficacy. Mol Pharm 14:940-952. https://doi.org/10.1021/acs.molpharmac eut.6b01150

Hamada Y, Nambu N, Nagai T (1975) Pharmaceutical interactions in dosage forms and processing. III. Interactions of $\alpha$ - and $\beta$-cyclodextrin with several nonsteroidal antiinflammatory drugs in aqueous solution. Chem Pharm Bull 23:1205-1211

Hammoud Z, Khreich N, Auezova L, Fourmentin S, Elaissari A, Greige-Gerges H (2019) Cyclodextrin-membrane interaction in drug delivery and membrane structure maintenance. Int J Pharm 564:59-76. https://doi.org/10.1016/j.ijpharm.2019.03.063

Han JH (2005) Innovations in food packaging. Food Science and Technology, International Series. ISBN 0-12-311632-5

Han SM, Armstrong DW (1989) HPLC separation of enantiomers and other isomers with cyclodextrin-bonded phases: rules for chiral recognition. In: Chiral Separations by HPLC. New York: Ellis Horwood Limited, Wiley, New York. Krstulovic AM (ed), chapter 10, pp 208-284

Han YY, Liu WCJ, Huang JW, Qiu SR, Zhong H, Liu D, Liu JQ (2018) Cyclodextrin-based metal-organic frameworks (CD-MOFs) in pharmaceutics and biomedicine. Pharmaceutics 10:271. https:// doi.org/10.3390/pharmaceutics10040271

Hapiot F, Bricout H, Menuel S, Tilloy S, Monflier E (2014) Recent breakthroughs in aqueous cyclodextrin-assisted supramolecular catalysis. Catal Sci Technol 4:1899-1908. https://doi. org/10.1039/C4CY00005F

Hashimoto HJ (1996) Cyclodextrins in foods, cosmetics, and toiletries. In: Szejtli J, Osa T (eds) Comprehensive supramolecular chemistry, vol 3. Pergamon Oxford, London, pp 483-502

Hashimoto HJ (2002) Present status of industrial applications of cyclodextrins in Japan. J Inclu Phenom Macrocycl Chem 44:57-62

Hashimoto H (2006) Cyclodextrin applications in food, cosmetic, toiletry, textile and wrapping materiel fields. In: Dodziuk H (ed) Cyclodextrins and their complexes. Chemistry, analytical methods, applications, chapter 16. Wiley-VCH, Verlag GmbH \& Co. KGaA, Weinheim, pp 452-459. https://doi.org/10.1002/35276 08982.ch16

Hedges AR (1998) Industrial applications of cyclodextrins. Chem Rev 98:2035-2044

Hedges AR, Shieh WJ, Sikorski CT, (1995) Use of cyclodextrins for encapsulation in the use and treatment of food products. In: Risch SJ, Reineccius GA (eds) Encapsulation and controlled release of food ingredients. ACS Sym. Ser. 590. American Chemical Society, Washington, DC, pp 60-71

Hess K, Trogus M, Ulmann M (1933) Information on the modifications of alpha-dextrin by F Schardinger. Z Phys Chem Abt B 21:1-6

Higashi T (2019) Cyclodextrin-based molecular accessories for drug discovery and drug delivery. Chem Pharm Bull 67:289-298. https://doi.org/10.1248/cpb.c18-00735

Higashi T, Iohara D, Motoyama K, Arima H (2018) Supramolecular pharmaceutical sciences: a novel concept combining pharmaceutical sciences and supramolecular chemistry with a focus on cyclodextrin-based supermolecules. Chem Pharm Bull 66:207-216

Hinze WL (1981) Applications of cyclodextrins in chromatographic separations and purification methods. Sep Purif Methods 10:159-237

Hirakawa H, Tomita H (2013) Interference of bacterial cell-to-cell communication: a new concept of antimicrobial chemotherapy breaks antibiotic resistance. Front Microbiol 4:114. https://doi. org/10.3389/fmicb.2013.00114

Hirayama F, Uekama K, Koinuma H (1980) Molecular dynamics of prostaglandin $\mathrm{F}_{2 \alpha}$-cyclodextrin complexes in aqueous solution. Chem Pharm Bull 28:1975-1980

Hoesslin H, Pringsheim H (1923) Physiology of the polyamyloses. II. Glycogen formation and animal combustion. Hoppe-Seiler's Z Physiol Chem 131:168-176

Horikoshi K (1979) Production and industrial applications of betacyclodextrin. Proc Biochem 14:26-30

Hou XS, Ke CF, Stoddart JF (2016) Cooperative capture synthesis: yet another playground for copper-free click chemistry. Chem Soc Rev 45:3766-3780. https://doi.org/10.1039/c6cs00055j

Hussain Asim M, Ijaz M, Rösch AC, Bernkop-Schnürch A (2020) Thiolated cyclodextrins: new perspectives for old excipients. Coord Chem Rev 420:213433. https://doi.org/10.1016/j. ccr.2020.213433

Hybl A, Rundle RE, Williams DE (1965) The crystal and molecular structure of the cyclohexaamylose-potassium acetate complex. J Am Chem Soc 87:2779-2788. https://doi.org/10.1021/ja010 $91 \mathrm{a} 001$

Irvine JC, Pringsheim H, MacDonald J (1924) CXIV_-The constitution of polysaccharides. Part VIII. The molecular structure of $\beta$-hexaamylose. J Chem Soc Trans 125:942-947

Irvine JC, Pringsheim H, Skinner AF (1929) Die methylierung der $\alpha$-tetra-amylose. Ber Dtsch Chem Ges 62:2372-2378. https:// doi.org/10.1002/cber.19290620873

Ito K (2017) Slide-ring materials using cyclodextrin. Chem Pharm Bull 65:326-329. https://doi.org/10.1248/cpb.c16-00874

James WJ, French D, Rundle RE (1959) Studies on the Schardinger dextrins. 9. Structure of the cyclohexaamylose-iodine complex. Acta Crystallogr 12:385-389. https://doi.org/10.1107/S0365 $110 X 59001141$

Jiang L, Liu C, Mayumi K, Kato K, Yokoyama H, Ito K (2018) Highly stretchable and instantly recoverable slide-ring gels consisting of enzymatically synthesized polyrotaxane with low host coverage. Chem Mater 30:5013-5019. https://doi.org/10.1021/acs.chemm ater. $8 \mathrm{~b} 01208$

Jicsinszky L, Fenyvesi É, Hashimoto H, Ueno A (1996) Cyclodextrin derivatives. In: Atwood JL, Davies JE, MacNicol DD, Vögtle F, Szejtli J, Osa T (eds) comprehensive supramolecular chemistry, London, Elsevier Science Ltd. vol 3, chap 4, pp 57-188. ISBN: 978-008-0912-844

Junthip J, Tabary N, Chai F, Leclercq L, Maton M, Cazaux F, Neut C, Paccou L, Guinet Y, Staelens JN, Bria M, Landy D, Hedoux A, Blanchemain N, Martel B (2016) Layer-by-layer coating of textile with two oppositely charged cyclodextrin polyelectrolytes for extended drug delivery. J Biomed Mater Res Part A104:4081424. https://doi.org/10.1002/jbm.a.35674 
Kainuma K (1984) Starch oligosaccharides: linear, branched, and cyclic. In: Whistler RL, BeMiller JN, Paschall EF (eds) Starchchemistry and technology, 2nd edn. Academic Press Ltd., London, chapter V, pp 125-152. https://doi.org/10.1016/B978-0-12746270-7.50011-2

Karrer P (1920) The understanding of polysaccharides I. Methylation of starch. Helv Chim Acta 3:620-625

Karrer P (1921) Polysaccharides XI. The compounds of anhydrosugar with caustic alkali. A method for determining the basic elements of polymeric anhydrosugar. Helv Chim Acta 4:811-816

Karrer P (1922) Untersuchungen über polymere kohlenhydrate. Angew Chem 35:85-90

Karrer P (1923) Polysaccharides XX. Zur kenntniss polymerer kohlenhydrate. Helv Chim Acta 6:402-409

Karrer P (1925) Polymere kohlenhydrate. Akademische Verlagsgesellschaft, Leipzig

Karrer P, Bürkin E (1922) Polysaccharides XIV. On the understanding of amylose. Helv Chim Acta 5:181-187

Karrer P, Nägeli C (1921a) Polysaccharides II. On the constitution of diarrylose. Helv Chim Acta 4:169-172

Karrer P, Nägeli C (1921b) Structure of potato starch. Helv Chim Acta 4:185-202

Karrer P, Nägeli C, Hurwitz O, Wälti A (1921) Polysaccharides VIII. Zur kenntnis der stärke und der amylosen. Helv Chim Acta 4:678-699

Karrer P, Staub M, Wälti A (1922) Polysaccharides XIII. On the understanding of inulin and the alkali hydroxide bonding of anhydrous sugar. Helv Chim Acta 5:129-139

Kashiwagi Y, Katashima T, Nakahata M, Takashima Y, Harada A, Inoue $\mathrm{T}$ (2018) Linear viscoelastic studies on a transient network formed by host-guest interaction. J Polym Sci B Polym Phys 56:1109-1117. https://doi.org/10.1002/polb.24630

Kaur R, Kukkar D, Bhardwaj SK, Kim KH, Deep A (2018) Potential use of polymers and their complexes as media for storage and delivery of fragrances. J Control Release 285:8-95. https://doi. org/10.1016/j.jconrel.2018.07.008

Kfoury M, Hădărugă NG, Hădărugă DI, Fourmentin S (2016) Cyclodextrins as encapsulation material for flavors and aroma. In: Encapsulations. Nanotechnology in the agri-food industry, 1st edn, vol 2, chapter 4, pp. 127-192. ISBN: 978-0-12-804378-3

Kfoury M, Auezova L, Greige-Gerges H, Fourmentin S (2019) Encapsulation in cyclodextrins to widen the applications of essential oils. Environ Chem Lett 17:129-143. https://doi. org/10.1007/s10311-018-0783-y

Khan AR, Forgo P, Stine KJ, D'Souza VT (1998) Methods for selective modifications of cyclodextrins. Chem Rev 98:1977-1996. https://doi.org/10.1021/cr970012b

Koizumi K, Sanbe H, Kubota Y, Terada Y, Takaha T (1999) Isolation and characterization of cyclic alpha- $(1 \rightarrow 4)$-glucans having degrees of polymerization 9-31 and their quantitative analysis by high-performance anion-exchange chromatography with pulsed amperometric detection. J Chromatogr A 852:407-416

Komiyama M (1996) Cyclodextrins as enzyme models. In: Szejtli J, Osa T (eds) Comprehensive supramolecular chemistry, vol 3. Pergamon Oxford, London, pp 401-422

Kozlowski CA, Sliwa W (2010) Use of cyclodextrin polymers in separation of organic species. In: Polymer science and technology series. Nova Science Publishers, Inc., New York

Krysl S, Smolková-Keulemansová E (1985) Cyclodextrins and their utilization in chromatographic methods. Chemické Listy 79:919-942

Kumar S, Rao R (2019) Analytical tools for cyclodextrin nanosponges in pharmaceutical field: a review. J Incl Phenom Macrocycl Chem 94:11-30. https://doi.org/10.1007/s10847-019-00903-Z

Kumari P, Singh P, Singhal A, Alka (2020) Cyclodextrin-based nanostructured materials for sustainable water remediation applications. Environ Sci Pollut Res 27:32432-32448. https:// doi.org/10.1007/s11356-020-09519-0

Kurkov SV, Loftsson T (2013) Cyclodextrins. Int J Pharm 453:167180. https://doi.org/10.1016/j.ijpharm.2012.06.055

Lach JL, Chin TF (1964) Interaction of pharmaceuticals with Schardinger dextrins. III. J Pharm Sci 53:69-73

Lach JL, Cohen J (1963) Interaction of pharmaceuticals with Schardinger dextrins. II. J Pharm Sci 52:137-142

Landy D, Mallard I, Ponchel A, Monflier E, Fourmentin S (2012) Remediation technologies using cyclodextrins: an overview. Environ Chem Lett 10:225-237. https://doi.org/10.1007/s1031 1-011-0351-1

Lange F (1925) Verfahren zur gewinnung von polyamylosen. German Patent, Patentschrift n 442963, I.G. Farbenindustrie Akt.-Ges. In Frankfurt

Larsen KL (2002) Large cyclodextrins. J Incl Phenom 43:1-13. https ://doi.org/10.1023/A:1020494503684

Lau EV, Gan SY, Ng HK, Poh PE (2014) Extraction agents for the removal of polycyclic aromatic hydrocarbons (PAHs) from soil in soil washing technologies. Environ Pollut 184:640-649. https ://doi.org/10.1016/j.envpol.2013.09.010

Lau MT, Manion J, Littleboy JB, Oyston L, Khuong TM, Wang QP, Nguyen DT, Hesselson D, Seymour J, Neely GG (2019) Molecular dissection of box jellyfish venom cytotoxicity highlights an effective venom antidote. Nat Commun 10:1655. https://doi. org/10.1038/s41467-019-09681-1

Lay S, Ni XF, Yu HN, Shen SR (2016) State-of-the-art applications of cyclodextrins as functional monomers in molecular imprinting techniques: a review. J Sep Sci 39:2321-2331. https://doi. org/10.1002/jssc. 201600003

Lepage ML, Schneider JP, Bodlenner A, Compain P (2015) Toward a molecular Lego approach for the diversity-oriented synthesis of cyclodextrin analogues designed as scaffolds for multivalent systems. J Org Chem 80:10719-10733. https://doi.org/10.1021/ acs.joc. 5 b01938

Li J (2009) Cyclodextrin inclusion polymers forming hydrogels. In: Wenz G (ed) Inclusion polymers. Book series: advances in polymer science 222:79-112. https://doi.org/10.1007/12_2008_9

Li S, Purdy WC (1992) Cyclodextrins and their applications in analytical chemistry. Chem Rev 92:1457-1470

Lichtenthaler FW, Immel S (1996) Towards understanding formation and stability of cyclodextrin inclusion complexes: computation and visualization of their molecular lipophilicity patterns. Starch/ Stärke 48:145-154

Lindner K, Saenger W (1978) $\beta$-cyclodextrine dodecahydrate: crowing of water molecules within a hydrophobic cavity. Angew Chem Int Ed 17:694-695

Liu B, Turley SD, Burns DK, Miller AM, Repa JJ, Dietschy JM (2009) Reversal of defective lysosomal transport in NPC disease ameliorates liver dysfunction and neurodegeneration in the npc1/- mouse. Proc Natl Acad Sci USA 106:2377-2382. https://doi. org/10.1073/pnas.0810895106

Liu QM, Zhou Y, Lu J, Zhou YB (2020) Novel cyclodextrin-based adsorbents for removing pollutants from wastewater: a critical review. Chemosphere 241:125043. https://doi.org/10.1016/j. chemosphere.2019.125043

Loftsson T, Duchêne D (2007) Cyclodextrins and their pharmaceutical applications: historical perspectives. Int J Pharm 329:1-11. https ://doi.org/10.1016/j.ijpharm.2006.10.044

Loftsson T, Stefánsson E (2017) Cyclodextrins and topical drug delivery to the anterior and posterior segments of the eye. Int J Pharm 531:413-423. https://doi.org/10.1016/j.ijpharm.2017.04.010

Loftsson T, Jarho P, Másson M, Järvinen T (2005) Cyclodextrins in drug delivery. Expert Opin Drug Deliv 2:335-351. https://doi. org/10.1517/17425247.2.1.335 
Luda MP, Zanetti M (2019) Cyclodextrins and cyclodextrin derivatives as green char promoters in flame retardants formulations for polymeric materials. A review. Polymers 11:664. https://doi. org/10.3390/polym11040664

Lüttringhaus A, Cramer F, Prinzbach H, Henglein FM (1958) Cyclisationen von langkettigen dithiolen. Versuche zur darstellung sich umfassender ringe mit hilfe von einschlußverbindungen. Liebigs Ann Chem 613:185-198. https://doi.org/10.1002/jlac.19586 130120

Macaev F, Boldescu V (2015) Cyclodextrins in asymmetric and stereospecific synthesis. Symmetry Basel 7:1699-1720. https://doi. org/10.3390/sym7041699

Madrid F, Ballesteros R, Lacorte S, Villaverde J, Morillo E (2019) Extraction of PAHS from an aged creosote-polluted soil by cyclodextrins and rhamnolipids. Side effects on removal and availability of potentially toxic elements. Sci Total Environ 635:384-392. https://doi.org/10.1016/j.scitotenv.2018.10.316

Maeda Y, Motoyama K, Nishiyama R, Higashi T, Onodera R, Hakamura H, Takeo T, Nakagata H, Yamada Y, Ishitsuka Y, Kondo Y, Irie T, Era T, Arima H (2019) In vivo efficacy and safety evaluation of lactosyl- $\beta$-cyclodextrin as a therapeutic agent for hepatomegaly in Niemann-pick type $\mathrm{C}$ disease. Nanomaterials 9:802. https://doi.org/10.3390/nano9050802

Mahmud ST, Wilson LD (2016) Synthesis and characterization of surface-modified mesoporous silica materials with beta-cyclodextrin. Cogent Chem 2:1132984. https://doi.org/10.1080/23312 009.2015.1132984

Malanga M, Szemán J, Fenyvesi E, Puskas I, Csabai K, Gyemant G, Fenyvesi F, Szente L (2016) "Back to the future": a new look at hydroxypropyl beta-cyclodextrins. J Pham Sci 105:2921-2931. https://doi.org/10.1016/j.xphs.2016.04.034

Malanga M, Seggio M, Kirejev V, Fraix A, Di Bari I, Fenyvesi É, Ericson MB, Sortino S (2019) A phototherapeutic fluorescent $\beta$-cyclodextrin branched polymer delivering nitric oxide. Biomater Sci 7:2272-2276. https://doi.org/10.1039/C9BM00395A

Matencio A, Navarro-Orcajada S, Garcia-Carmona F, Lopez-Nicolas JM (2020) Applications of cyclodextrins in food science. A review. Trends Food Sci Technol 104:132-143. https://doi. org/10.1016/j.tifs.2020.08.009

Mavridis IM, Yannakopoulou K (2015) Anionic cyclodextrins as versatile hosts for pharmaceutical nanotechnology: synthesis, drug delivery, enantioselectivity, contrast agents for MRI. Int J Pharm 492:275-290. https://doi.org/10.1016/j.ijpharm.2015.06.004

McClenahan WS, Tilden EB, Hudson CS (1942) A study of the products obtained from starch by the action of the amylase of Bacillus macerans. J Am Chem Soc 64:2139-2144

Melotti A, Mas C, Kuciak M, Lorente-Trigos A, Borges I, Ruiz i Altaba A (2014) The river blindness drug ivermectin and related macrocyclic lactones inhibit WNT-TCF pathway responses in human cancer. EMBO Mol Med 6:1263-1278. https://doi.org/10.15252 /emmm.201404084

Menezes PD, Andrade TD, Frank LA, de Souza EPBSS, Trindade GDG, Trindade IAS, Serafini MR, Guterres SS, Araujo AAD (2019) Advances of nanosystems containing cyclodextrins and their applications in pharmaceuticals. Int J Pharm 559:312-328. https://doi.org/10.1016/j.ijpharm.2019.01.041

Menges RA, Armstrong DW (1991) Chiral separations using native and functionalized cyclodextrin-bonded stationary phases in highpressure liquid-chromatography. ACS Symp Ser 471:67-100

Miekeley A (1930) Über die fragliche existenz der sog. $\alpha$-diamylose. Ber Dtsch Chem Ges 63:1957-1961

Miekeley A (1932) Bemerkung zür existenz des $\alpha$-diamylose. Ber Dtsch Chem Ges 65:69

Miller KP, Wang L, Chen YP, Pellechia PJ, Benicewicz BC, Decho AW (2015) Engineering nanoparticles to silence bacterial communication. Frontiers Microbiol 6:189. https://doi. org/10.3389/fmicb.2015.00189

Mitchell CR, Armstrong DW (2004) Cyclodextrin-based chiral stationary phases for liquid chromatography: a twenty-year overview. In: Gübitz G, Schmid MG (eds) Chiral separations-methods and protocols. Methods in molecular biology, vol 243. Humana Press Inc., New Jersey, pp 61-112. ISBN: 1-58829-150-2

Miyazawa I, Ueda H, Nagase H, Endo T, Kobayashi S, Nagai T (1995) Physicochemical properties and inclusion complex formation of 8-cyclodextrin. Eur J Pharm Sci 3:153-162

Mocanu G, Vizitiu D, Carpov A (2001) Cyclodextrin polymers. J Bioact Compat Polym 16:315-342

Morillo E (2006) Application of cyclodextrins in agrochemistry. In: cyclodextrins and their complexes. In: Dodziuk H (ed) Chemistry, analytical methods, applications, chapter 16 . Wiley-VCH, Verlag GmbH \& Co. KGaA, Weinheim, pp 459-467

Morillo E, Lara-Moreno F, Villaverde J (2020) Soil bioremediation by cyclodextrins. A review. Int J Pharm 591:119943. https://doi. org/10.1016/j.ijpharm.2020.119943

Morin-Crini N, Fourmentin S, Crini G (eds) (2015) Cyclodextrines. Besançon: PUFC. 370 p. ISBN: 978-2-84867-520-6

Morin-Crini N, Fourmentin M, Fourmentin S, Torri G, Crini G (2018) Synthesis of silica materials containing cyclodextrin and their applications in wastewater treatment. Environ Chem Lett 16:1361-1375. https://doi.org/10.1007/s10311-018-00818-0

Morin-Crini N, Fourmentin S, Fenyvesi É, Lichtofuse E, Torri G, Fourmentin M, Crini G (2020) History of cyclodextrins. In: Crini G, Fourmentin S, Lichtfouse E (eds) The history of cyclodextrins, Chapter 1. Springer, pp 1-92. https://doi. org/10.1007/978-3-030-49308-1

Morohoshi T, Tokita K, Ito S, Saito Y, Maeda S, Kato K, Ikeda T (2013) Inhibition of quorum sensing in gram-negative bacteria by alkylamine-modified cyclodextrins. J Biosci Bioeng 116:175-179. https://doi.org/10.1016/j.jbiosc.2013.01.022

Motoyama K, Onodera R, Tanaka N, Kameyama K, Higashi T, Kariya R, Okada S, Arima H (2015) Evaluation of antitumor effects of folate-conjugated methyl- $\beta$-cyclodextrin in melanoma. Biol Pharm Bull 38:374-379. https://doi.org/10.1248/ bpb.b14-00531

Muankaew C, Loftsson T (2018) Cyclodextrin-based formulations: a non-invasive platform for targeted drug delivery. Basic Clin Pharm Toxicol 122:46-55. https://doi.org/10.1111/bcpt.12917

Müller S, Estour F, Kalakuntla RK, Le P, Romain LO, Worek F, Thiermann H, Reiter G (2013) New modified beta-cyclodextrin derivatives as detoxifying agents of chemicalwarfare agents (II). In vitro detoxification of cyclosarin (GF): general screening and toxicokineticaspects of OP scavengers. Toxicol Lett 216:206-212

Nepogodiev S, Stoddart FJ (1998) Cyclodextrin-based catenanes and rotaxanes. Chem Rev 98:1959-1976. https://doi.org/10.1021/ cr970049w

Neva T, Mellet CO, Fernandez JMG, Benito JM (2019) Multiply-linked cyclodextrin-aromatic hybrids: caps, hinges and clips. J Carbohydr Chem. https://doi.org/10.1080/07328303.2019.1609020

Nociari MM, Lehmann GL, Perez Bay AE, Radu RA, Jiang Z, Goicochea S, Schreiner R, Warren JD, Shan J, de Beaumais SA, Ménand M, Sollogoub M, Maxfield FR, Rodriguez-Boulan E (2014) Beta cyclodextrins bind, stabilize, and remove lipofuscin bisretinoids from retinal pigment epithelium. Proc Nat Acad Sci USA 111:E1402-E1408. https://doi.org/10.1073/pnas.14005 30111

Norberg E, French D (1950) Studies on the Schardinger dextrins. III. Redistribution reactions of Macerans amylase. J Am Chem Soc 72:1202-1205. https://doi.org/10.1021/ja01159a036

Okano C, Nasuno E, Iimura K, Kato N (2016) Cyclodextrin-immobilized microspheres for uptake of the quorum-sensing signaling 
molecule N-acylhomoserine lactone. J Appl Polym Sci. https:// doi.org/10.1002/app.43198

Oliveri V, Vecchio G (2016) Cyclodextrins as protective agents of protein aggregation: an overview. Chem Asian J 11:1648-1657. https://doi.org/10.1002/asia.201600259

Osaki M (2019) Functionalization of cyclodextrin derivatives to create supramolecular pharmaceutical materials. J Pharm Soc Jpn 139:165-173

Pawar S, Shende P (2019) A comprehensive patent review on betacyclodextrin cross-linked nanosponges for multiple applications. Recent Patents Nanotechnol. https://doi.org/10.2174/1872210513 666190603083930

Perez-Anes A, Gargouri M, Laure W, Van Den Berghe H, Courcot E, Sobocinski J, Tabary N, Chai F, Blach JF, Addad A, Woisel P, Douroumis D, Martel B, Blanchemain N, Lyskawa J (2015) Bioinspired titanium drug eluting platforms based on a poly-beta-cyclodextrin-chitosan layer-by-layer self-assembly targeting infections. ACS Appl Mater Int 7:12882-12893. https ://doi.org/10.1021/acsami.5b02402

Pitha J (1984) Pharmaceutical preparations containing cyclodextrin derivatives. US Patent No. 4277064, 23 February 1988, with priority from US Patent No. 4596795, 25 April 1984

Pitha J, Szente L, Szejtli J (1983) Molecular encapsulation of drugs by cyclodextrins and congeners. In: Bruck SD (ed) Controlled drug delivery, vol I. CRC Press, Boca Raton, pp 125-148

Poór M, Kunsági-Máté S, Szente L, Matisz G, Secenji G, Czibuya Z, Kőszegi T (2015) Interaction of ochratoxin A with quaternary ammonium beta-cyclodextrin. Food Chem 172:143-149. https:// doi.org/10.1016/j.foodchem.2014.09.034

Pringsheim H (1915) Neue ergebnisse der stärkechemie. Naturwissenschaften 3:95-99. https://doi.org/10.1007/BF01546143

Pringsheim H (1922) Problematisches aus der polysaccharide chemie. Angewe Chemie 35:345-349

Pringsheim H (1924) Über die konstitution der stärke, des glykogens und der flechtenstärke (Beiträge zur Chemie der Stärke, XII). Ber Dtsch Chem Ges 57:1581-1598. https://doi.org/10.1002/ cber. 19240570870

Pringsheim H (1926) Abbau und aufbau der polysaccharide. Ber Dtsch Chem Ges 59:3008-3018. https://doi.org/10.1002/cber.19260 591205

Pringsheim H (1927) Über die zusammensetzung des holzgeistöls und acetonöls. Angew Chem 40:1387-1393

Pringsheim H (1928a) A comprehensive survey of starch chemistry. In: Walton RP (ed) Chemical Catalog Co. Inc., New York, p 35

Pringsheim H (1928b) Twenty-five years of biochemistry. Science 68:603-608

Pringsheim H (1931a) Dextrine: charakteristik, gewinnung und eigenschaften. In: Die polysaccharide. Verlag von Julius Springer, Berlin, chapter VII, pp 248-274

Pringsheim H (1931b) Ein umri $\beta$ der heutigen zuckerchemie. Angew Chem 44:677-682

Pringsheim H (1932) The dextrins: characteristics, sources, and properties. In: The chemistry of the monosaccharides and of the polysaccharides, vol 6. McGraw-Hill Book Company, Inc. New York, Cornell University, chapter XV, pp 271-295

Pringsheim H, Beiser A (1932) Diamylose und tetraamylose (Beiträge zur chemie der stärke, XXVII). Ber Dtsch Chem Ges 65:18701873. https://doi.org/10.1002/cber.19320651124

Pringsheim H, Dernikos D (1922) Weiteres über die polyamylosen (Beiträge zur Chemie der Stärke, VI). Ber Dtsch Chem Ges 55:1433-1445. https://doi.org/10.1002/cber.19220550534

Pringsheim H, Eissler F (1913) Über Schardingers krystallisierte dextrin (Beiträge zur chemie der stärke, II.). Ber Dtsch Chem Ges 46:2959-2974. https://doi.org/10.1002/cber.19130460370
Pringsheim H, Eissler F (1914) Über Schardingers krystallisierte dextrin (Beiträge zur chemie der stärke, III.). Ber Dtsch Chem Ges 47:2565-2572. https://doi.org/10.1002/cber.19140470331

Pringsheim H, Langhans A (1912) Über krystallisierte polysaccharides aus stärke. Ber Dtsch Chem Ges 45:2533-2546. https:// doi.org/10.1002/cber.191204502156

Pringsheim H, Lichtenstein S (1916) On crystallized polysaccharides from glycogen. Ber Dtsch Chem Ges 49:364-369. https://doi. org/10.1002/cber.19160490141

Pringsheim H, Meyersohn P (1927) Über die dispergierung der polyamylosen (Beiträge zur Chemie der Stärke, XX). Ber Dtsch Chem Ges 60:1709-1716. https://doi.org/10.1002/cber.19270600743

Pringsheim H, Müller KO (1922) Physiology of the polyamyloses. Hoppe-Seiler's Z Physiol Chem 118:236-240

Pringsheim H, Schapiro E (1926) Über den fermentativen abbau der stärke durch biolase. (Beiträge zur chemie der stärke, XVI). Ber Dtsch Chem Ges 59:996-1000. https://doi.org/10.1002/ cber.19260590524

Pringsheim H, Wolfsohn K (1924) Über den verschiedenen aufbau der beiden stärke-bestandteile (Beiträge zur Chemie der Stärke, X). Ber Dtsch Chem Ges 57:887-891. https://doi.org/10.1002/ cber.19240570537

Pringsheim H, Wiener A, Weidinger A (1930) Über neue polyamylosen. I. (Beiträge zur chemie der stärke, XXIV). Ber Dtsch Chem Ges 63:2628-2636. https://doi.org/10.1002/cber.19300630943

Pringsheim H, Weidinger A, Sallentien H (1931a) Diamylose und tetramylose; triamylose und hexaamylose (Beiträge zur Chemie der Stärke, XXV). Ber Dtsch Chem Ges 64:2117-2125. https://doi. org/10.1002/cber.19310640841

Pringsheim H, Weidinger A, Sallentien H (1931b) Über neue polyamylosen, II. (Beiträge zur Chemie der Stärke, XXVI). Ber Dtsch Chem Ges 64:2125-2130. https://doi.org/10.1002/cber.19310 640842

Pulley AO, French D (1961) Studies on the Schardinger dextrins. 11. Isolation of new Schardinger dextrins. Biochem Biophys Res Commun 5:11-15. https://doi.org/10.1016/0006-291X(61)90071 $-7$

Puskás I, Varga E, Tuza K, Szemán J, Fenyvesi É, Sohajda T, Szente L (2015) Sulfobutylether-cyclodextrins: structure, degree of substitution and functional performance. In: Ramirez FG (ed) Cyclodextrins. Nova Science Publishers, Inc., chapter 10, pp 293-320. ISBN: 978-1-63482-788-1

Qi QS, She XY, Endo T, Zimmermann W (2004) Effect of the reaction temperature on the transglycosylation reactions catalyzed by the cyclodextrin glucanotransférase from Bacillus macerans for the synthesis of large-ring cyclodextrins. Tetrahedron 60:799-806

Rajkumar T, Kukkar D, Kim KH, Sohn JR, Deep A (2019) Cyclodextrin-metal-organic framework (CD-MOF): from synthesis to for applications. J Ind Eng Chem 72:50-66. https://doi. org/10.1016/j.jiec.2018.12.048

Robyt J, French D (1964) Purification and action pattern of an amylase from Bacillus polymyxa. Arch Biochem Biophys 104:338-345. https://doi.org/10.1016/S0003-9861(64)80024-2

Rundle RE, French D (1943) The configuration of starch and the starchiodine complex. II. Optical properties of crystalline starch fractions. J Am Chem Soc 65:558-561. https://doi.org/10.1021/ja012 $44 \mathrm{a} 018$

Ryzhakov A, Thi TD, Stappaerts J, Bertoletti L, Kimpe K, Couto ARS, Saokham P, Van den Mooter G, Augustijns P, Somsen GW, Kurkov S, Inghelbrecht S, Arien A, Jimidar MI, Schrijnemakers K, Loftsson T (2016) Self-assembly of cyclodextrins and their complexes in aqueous solutions. J Pharm Sci 105:2556-2569. https://doi.org/10.1016/j.xphs.2016.01.019

Saenger W (1980) Cyclodextrin inclusion-compounds in research and industry. Angew Chem Int Ed 19:344-362. https://doi. org/10.1002/anie.198003441 
Saenger W, Noltemeyer M, Manor PC, Hingerty B, Klar B (1976) "Induced fit" type complex formation of the model enzyme $\alpha$-cyclodextrin. Bioorg Chem 5:187-195. https://doi. org/10.1016/0045-2068(76)90007-9

Samec M, Blinc M (1941) Die neuere entwicklung der kolloidchemie der stärke. T. Steinkopff, Dresden and Leipzig, p 543

Saokham P, Loftsson T (2017) Gamma-cyclodextrin. Int J Pharm 516:278-292. https://doi.org/10.1016/j.ijpharm.2016.10.062

Schardinger F (1903a) Über thermophile bakterien aus verschiedenen speisen und milch, sowie über einige umsetzungsprodukte derselben in kohlenhydrathaltigen nährlösungen, darunter krystallisierte polysaccharide (dextrine) aus stärke. Zeitschrrift für Untersuchuing von Nahrungs- und Genussmittel 6:865-880

Schardinger F (1903b) Ueber die Zulässigkeit des warmhaltens von zum genu $\beta$ bestimmten nahrungsmitteln mittelst wärme speichernder apparate, sog. thermophore. Wien Klin Wochenschr $16: 468-474$

Schardinger F (1904) Mitteilung aus der staatlichen untersuchungsanstalt für lebensmittel in Wien Azetorgärung. Wien Klin Wochenschr 17:207-209

Schardinger F (1905) Bacillus macerans, ein aceton bildender rottebacillus. Centralblatt für Bakteriologie Parasitenkunde und Infektionskrankheiten 14:772-781

Schardinger F (1907) Zur biochemie des Bacillus macerans. Centralblatt für Bakteriologie Parasitenkunde und Infektionskrankheiten 19:161-163

Schardinger F (1909) Ueber die bildung kristallisierter fehlingsche lösung nicht reduzierender körper (polysaccharide) aus stärke durch mikrobielle tätigkeit. Centralblatt für Bakteriologie und Parasitenkunde 22:98-103

Schardinger F (1911) Bildung kristallisierter polysaccharide (dextrine) aus stärkekleister durch mikrobien. Centrablatt für Bakteriologie, Parasitenkunde und Infektionskrankheiten 29:188-197

Schlenk H, Sand DM (1961) The association of $\alpha$ - and $\beta$-cyclodextrins with organic acids. J Am Chem Soc 83:2312-2320. https://doi. org/10.1021/ja01471a022

Schlenk H, Sand DM, Tillotson JA (1955) Stabilization of autoxidizable materials by means of inclusion. J Am Chem Soc 77:35873590. https://doi.org/10.1021/ja01618a049

Schneider HJ (2012) Applications of supramolecular chemistry. CRC Press, Taylor \& Francis Group, Boca Raton

Schneider HJ, Yatsimirsky AK (2000) Principles and methods in supramolecular chemistry. Wiley, Chichester

Schneiderman E, Stalcup AM (2000) Cyclodextrins: a versatile tool in separation science. J Chromatogr B 745:83-102. https://doi. org/10.1016/S0378-4347(00)00057-8

Scriba GKE (2012) Chiral recognition mechanisms in analytical separation sciences. Chromatographia 75:815-838. https://doi. org/10.1007/s10337-012-2261-1

Sébille B (1987) Cyclodextrin derivatives. In: Duchêne D (ed) cyclodextrins and their industrial uses. Edition de Santé, Paris, pp 351-393

Sharma N, Baldi A (2016) Exploring versatile applications of cyclodextrins: an overview. Drug Deliv 23:739-757. https://doi. org/10.3109/10717544.2014.938839

Shende P, Trotta F (2019) Diversity of beta-cyclodextrin-based nanosponges for transformation of actives. Int J Pharm 565:333-350. https://doi.org/10.1016/j.ijpharm.2019.05.015

Sicard PJ, Saniez MH (1987) Biosynthesis of cycloglycosyltransferase and obtention of its enzymatic reaction products. In: Duchêne D (ed) Cyclodextrins and their industrial uses. Paris: Éditions de Santé, chapter 2, pp 77-103

Silva A, Duarte A, Sousa S, Ramos A, Domingues FC (2016) Characterization and antimicrobial activity of cellulose derivatives films incorporated with a resveratrol inclusion complex. WT Food Sci Technol 73:481-489. https://doi.org/10.1016/j.lwt.2016.06.043
Simoes SMN, Veiga F, Torres-Labandeira JJ, Ribeiro ACF, Concheiro A, Alvarez-Lorenzo C (2014) Syringeable self-assembled cyclodextrin gels for drug delivery. Curr Top Med Chem 14:494-509. https://doi.org/10.2174/1568026613666131219124308

Singh MK, Varun VK, Behera BK (2011) Cosmetotextiles: state of art. Fibres Textiles Eastern Europe 19:27-33

Smolková-Keulemansová E (1982) Cyclodextrins as stationary phases in chromatography. J Chromatogr 251:17-34

Smolková-Keulemansová E, Krysl S (1980) Inclusion compounds in chromatography. J Chromatogr 184:347-361. https://doi. org/10.1016/S0021-9673(00)89005-6

Sonnendecker C, Zimmermann W (2019a) Domain shuffling of cyclodextrin glucanotransferases for tailored product specificity and thermal stability. FEBS Open Bio 9:384-395. https://doi. org/10.1002/2211-5463.12588

Sonnendecker C, Zimmermann W (2019b) Change of the product specificity of a cyclodextrin glucanotransferase by semi-rational mutagenesis to synthesize large-ring cyclodextrins. Catalyts 9:242. https://doi.org/10.3390/catal9030242

Sonnendecker C, Melzer S, Zimmermann W (2018) Engineered cyclodextrin glucanotransferases from Bacillus sp. G-825-6 produce large-ring cyclodextrins with high specificity. MicrobiologyOpen. https://doi.org/10.1002/mbo3.757

Sonnendecker C, Thürmann S, Przybylski C, Zitmann FD, Heinke N, Krauke Y, Monks K, Robitzki Belder D, Zimmermann W (2019) Large-ring cyclodextrins as chiral selectors for enantiomeric pharmaceuticals. Angew Chem Int Ed 58:6411-6414. https://doi.org/10.1002/anie.201900911

Stella VJ, Rajewski RA (1992) Derivatives of cyclodextrin exhibiting enhanced aqueous solubility and pharmaceutical uses thereof US Patent No. 5,134,127

Sybilska D, Smolková-Keulemansová E (1984) Application of inclusion compounds in chromatography. In: Inclusion compounds. Academic Press, London, vol 3, pp 173-243

Szejtli J (1977) Some application possibilities of cyclodextrins in pharmaceutical industries. Starch/Stärke 29:26-33. https://doi. org/10.1002/star.19770290107

Szejtli J (1978) Neue untersuchungsmethoden in der cyclodextrinchemie. Starch/Stärke 30:427-431. https://doi.org/10.1002/ star. 19780301207

Szejtli J (1982a) Cyclodextrins and their inclusion complexes. Akadémiai Kiadó, Budapest. ISBN 963-05-2850-9

Szejtli J (1982b) Cyclodextrins in food, cosmetics and toiletries. Starch/Stärke 34:379-385. https://doi.org/10.1002/star.19820 341106

Szejtli J (1983) Dimethyl- $\beta$-cyclodextrin as parenteral drug carrier. J Incl Phenom 1:135-150

Szejtli J (1984) Industrial applications of cyclodextrins. In: Atwood JL, Davies JED, MacNicol DD (eds) Inclusion compounds, vol 3. Academic Press, London, pp 331-390

Szejtli J (1985) Cyclodextrins: a new group of industrial basic materials. Nahrung Food 29:911-924

Szejtli J (1988) Cyclodextrin technology. Kluwer Academic Publishers, Dordrecht, p 450. ISBN: 90-277-2314-1

Szejtli J (1995) Selectivity/structure correlation in cyclodextrin chemistry. Supramol Chem 6:217-223. https://doi.org/10.1080/10610 279508032537

Szejtli J (1998) Introduction and general overview of cyclodextrin chemistry. Chem Rev 98:1743-1753

Szejtli J (2002) The role of cyclodextrins in chiral selective chromatography. Trends Anal Chem 21:379-388

Szejtli J (2003) Cyclodextrins in the textile industry. Starch/Stärke 55:191-196

Szejtli J (2004) Past, present and future of cyclodextrin research. Pure Appl Chem 76:1825-1845. https://doi.org/10.1351/pac2004761 01825 
Szejtli J, Szente L, Bánky-Előd E (1979) Molecular encapsulation of volatile, easily oxidizable labile flavour substances by cyclodextrins. Acta Chim Acad Sci Hung 101:27-46

Szejtli J, Gerloczy A, Fonagy A (1980a) Intestinal absorption of 14C-labelled $\beta$-cyclodextrin in rats. Arzeim Forsch 30:808-810

Szejtli J, Zsadon B, Fenyvesi É, Otta K, Tudos F (1980b) Hungarian Patent 181733, U.S. Patent 4,357,468 (1982)

Szente L, Fenyvesi É (2018) Cyclodextrin-enabled polymer composites for packaging. Molecules 23:1556. https://doi.org/10.3390/molec ules23071556

Szente L, Strattan CE (1991) Hydroxypropyl- $\beta$-cyclodextrins, preparation and physicochemical properties. In: Duchêne D (ed) New trends in cyclodextrins and derivatives. Editions de Santé, Paris, chapter 2, pp 55-96

Szente L, Szejtli J (1996) Cyclodextrins in pesticides. In: comprehensive supramolecular chemistry. In: Szejtli J, Osa T (eds), Pergamon Oxford, London, vol 3, pp 503-514

Szente L, Szemán J (2013) Cyclodextrins in analytical chemistry: host-guest type molecular recognition. Anal Chem 85:80248030. https://doi.org/10.1021/ac400639y

Taira H, Nagase H, Endo T, Ueda H (2006) Isolation, purification and characterization of large-ring cyclodextrins $\left(\mathrm{CD}_{36} \sim \mathrm{CD}_{39}\right)$. J Inclus Phenom Macrocycl Chem 56:23-28

Taka AL, Pillay K, Mbianda XY (2017) Nanosponge cyclodextrin polyurethanes and their modification with nanomaterials for the removal of pollutants from waste water: a review. Carbohydr Polym 159:94-107. https://doi.org/10.1016/j.carbp ol.2016.12.027

Terada Y, Yanase M, Takata H, Takaha T, Okada S (1997) Cyclodextrins are not the major cyclic alpha- $(1 \rightarrow 4)$-glucans produced by the initial action of cyclodextrin glucanotransferase on amylase. J Biol Chem 272:15729-15733

Thoma JA, French D (1958) Studies on the Schardinger dextrins. X. The interaction of cyclohexaamylose, iodine and iodide. Part I. Spectrophotometric studies. J Am Chem Soc 80:6142-6146. https://doi.org/10.1021/ja01555a060

Thoma JA, French D (1959) The dissociation constant for the cyclohexaamylose-iodine complex. J Phys Chem 62:1603. https://doi.org/10.1021/j150570a041

Thoma JA, French D (1960) The starch iodine iodide interaction. 1. Spectrophotometric investigations. J Am Chem Soc 82:41444147. https://doi.org/10.1021/ja01501a004

Thoma JA, French D (1961) The starch iodine iodide interaction. 2. Potentiometric investigations. J Phys Chem 65:1825-1828. https://doi.org/10.1021/j100827a032

Thoma JA, Stewart L (1965) Cycloamyloses. In: Starch, chemistry and technology, volume 1: fundamental aspects. In: Whistler RL, Paschall EF (eds) Academic Press, New York, chapter IX, pp 209-249

Thoma JA, Wright HB, French D (1959) Partition chromatography of homologous saccharides on cellulose columns. Archiv Biochem Biophys 85:452-460. https://doi.org/10.1016/00039861(59)90510-7

Tian BR, Xiao D, Hei TT, Ping R, Hua SY, Liu JY (2020) The application and prospects of cyclodextrin inclusion complexes and polymers in the food industry: a review. Polym Int 69:597-603. https://doi.org/10.1002/pi.5992

Tilden EB, Hudson CS (1939) Conversion of starch to crystalline dextrins by the action of a new type of amylase separated from cultures of Aerobacillus macerans. J Am Chem Soc 61:2900-2902

Tilden EB, Hudson CS (1942) Preparation and properties of the amylases produced by Bacillus macerans and Bacillus polymyxa. J Bacteriol 43:527-544

Tilden EB, Adams M, Hudson CS (1942) Purification of the amylase of Bacillus macerans. J Am Chem Soc 64:1432-1433
Topuz F, Uyar T (2019) Electrospinning of cyclodextrin functional nanofibers for drug delivery applications. Pharmaceutics 11:135. https://doi.org/10.3390/pharmaceutics 11010006

Uekama K, Hirayama F (1978) Inclusion complexation of prostaglan$\operatorname{din} \mathrm{F} 2 \alpha$ with $\alpha$ - and $\beta$-cyclodextrins in aqueous solution. Chem Pharm Bull 26:1195-1200

Uekama K, Otagiri M (1987) Cyclodextrins in drug carrier systems. Critical Rev Ther Drug Carrier Syst 3:1-40

Uekama K, Fujise A, Hirayama F, Otagiri M, Inaba K (1984) Improvement of dissolution characteristics and chemical stability of prostaglandins E1 by $\gamma$-cyclodextrin complexation. Chem Pharm Bull 32:275-279

Ulmann M (1932) The molecular size of the alpha-dextrin of $F$ Schardinger. Biochem Z 251:458-477

Ulmann M, Trogus M, Hess K (1932) Zur kenntnis des $\alpha$-dextrins von F. Schardinger. Ber Dtsch Chem Ges 65:682-686

Valente AJM, Söderman O (2014) The formation of host-guest complexes between surfactants and cyclodextrins. Adv Colloid Int 205:156-176. https://doi.org/10.1016/j.cis.2013.08.001

Van de Manakker F, Vermonden T, Van Nostrum CF, Hennink WE (2009) Cyclodextrin-based polymeric materials: synthesis, properties, and pharmaceutical/biomedical applications. Biomacromolecules 10:3157-3175. https://doi.org/10.1021/bm901065f

van Etten RL, Sebastian JF, Clowes GA, Bender ML (1967a) Acceleration of phenyl ester cleavage by cycloamyloses: a model for enzymatic specificity. J Am Chem Soc 89:3242-3253

van Etten RL, Clowes GA, Sebastian JF, Bender ML (1967b) The mechanism of the cycloamylose-accelerated cleavage of phenyl esters. J Am Chem Soc 89:3253-3262

Vaution C, Hutin M, Glomot F, Duchêne D (1987) The use of cyclodextrins in various industries. In: Duchêne D (ed) Cyclodextrins and their industrial uses. Éditions de Santé, Paris, chapter 8, pp 299-350

Vermet G, Degoutin S, Chai F, Maton M, Danjou PE, Martel B, Blanchemain N (2017) Cyclodextrin modified PLLA parietal reinforcement implant with prolonged antibacterial activity. Acta Biomater 53:222-232. https://doi.org/10.1016/j.actbi o.2017.02.017

Vetter W, Bester K (2006) Gas chromatographic enantioseparation of chiral pollutants-techniques and results. In: Busch KW and Busch MA (eds) Chiral separation, chapter 6, . Elsevier, Amsterdam, pp 131-228

Viernstein H, Wolschann P (2020) Cyclodextrin inclusion complexation and pharmaceutical applications. Scienceasia 46:254-262. https://doi.org/10.2306/scienceasia1513-1874.2020.048

Villalonga R, Cao R, Fragoso A (2007) Supramolecular chemistry of cyclodextrin in enzyme technology. Chem Rev 107:3088-3116. https://doi.org/10.1021/cr050253g

Villiers A (1891a) Sur la transformation de la fécule en dextrine par le ferment butyrique. Chimie Organique-Compte Rendus des Séances de l'Académie des Sciences (France) Février, CXII, pp. 435-437

Villiers A (1891b) Sur la transformation de la fécule en dextrine par le ferment butyrique. Bulletin de la Société Chimique de Paris. $1^{\text {er }}$ semestre, $3^{\text {ème }}$ série, tome $\mathrm{V}$, volume 45 , pp 468-470

Villiers A (1891c) Sur la fermentation de la fécule par l'action du ferment butyrique. Chimie Organique-Compte Rendus des Séances de l'Académie des Sciences (France) Juin, CXII, pp 536-538

Villiers A (1891d) Sur la fermentation de la fécule par l'action du ferment butyrique. Bulletin de la Société Chimique de Paris. $1^{\text {er }}$ semestre, $3^{\text {eme }}$ série, tome $\mathrm{V}$, vol 46, pp 470-472

Voncina, B (2011) Application of cyclodextrins in textile dyeing. In: Hauser P (ed) Textile dyeing. InTech, Tijeka: Croatia, chapter 17, pp 373-392. ISBN: 978-953-307-565-5 
Ward TJ, Armstrong DW (1986) Improved cyclodextrin chiral phasesa comparison and review. J Liq Chromatogr 9:407-423. https:// doi.org/10.1080/01483918608076644

Ward TJ, Armstrong DW (1988) Cyclodextrin-stationary phases. In: Zief M and Crane LJ (eds) Chromatographic chiral separations. Marcel Dekker Inc., New York, chapter, 5, pp 131-163

Wenz G (1994) Cyclodextrins as building blocks for supramolecular structures and functional units. Angew Chem Int Ed 33:803-822

Wenz G, Han BH, Müller A (2006) Cyclodextrin rotaxanes and polyrotaxanes. Chem Rev 106:782-817. https://doi.org/10.1021/cr970 $027+$

West C (2014) Enantioselective separations with supercritical fluids-review. Curr Anal Chem 10:99-120. https://doi. org/10.2174/1573411011410010009

Whelan WJ, Manners DJ, Rosenfeld E, Gottschalk A, French D, Bell DJ, Courtois JE, Hasside WZ (1960) Determination of starch structure by enzymes-Discussion. Bull Soc Chim Biol 42:1690-1700

Wilson EJ, Schoch TJ, Hudson CS (1943) The action of macerans amylase on the fractions from starch. J Am Chem Soc 65:1380-1383

Wood DJ, Hrsuka FE, Saenger W (1977) 1H NMR study of the inclusion of aromatic molecules in $\alpha$-cyclodextrin. J Am Chem Soc 99: $1735-1740$

Wu ZL, Song N, Menz R, Pingali B, Yang YW, Zheng YB (2015) Nanoparticles functionalized with supramolecular host-guest systems for nanomedicine and healthcare. Nanomedicine 10:1493-1514. https://doi.org/10.2217/NNM.15.1

Xiao Y, Ng SC, Tan TTY, Wang Y (2012) Recent development of cyclodextrin chiral stationary phases and their applications in chromatography. J Chromatogr A 1269:52-68. https://doi. org/10.1016/j.chroma.2012.08.049

Xu J, Wu L, Guo T, Zhang G, Wang C, Li H, Li X, Singh V, Chen W, Gref R, Zhang J (2019) A "ship-in-a-bottle" strategy to create folic acid nanoclusters inside the nanocages of $\gamma$-cyclodextrin metal-organic frameworks. Int J Pharm 556:89-96. https://doi. org/10.1016/j.ijpharm.2018.11.074

Yang JS, Yang L (2013) Preparation and application of cyclodextrin immobilized polysaccharides. J Mat Chem B 1:909-918. https ://doi.org/10.1039/c2tb00107a

Yamagiwa T, Kawaguchi AT, Saito T, Inoue S, Morita S, Watanabe K, Kitagishi H, Koji K, Inokuchi S (2014) Supramolecular ferric porphyrins and a cyclodextrin dimer as antidotes for cyanide poisoning. Hum Exp Toxicol. 33:360-8. https://doi. org/10.1177/0960327113499041

Yao XK, Huang P, Nie ZH (2019) Cyclodextrin-based polymer materials: from controlled synthesis to applications. Prog Polym Sci 93:1-35. https://doi.org/10.1016/j.progpolymsci.2019.03.004

Yokoo M, Kubota Y, Motoyama K, Higashi T, Taniyoshi M, Tokommaru H, Nishiyama R, Tabe Y, Mochinaga S, Sato A, Sueoka-Aragane N, Sueoka E, Arima H, Irie T, Kimura S (2015) 2 -Hydroxypropyl- $\beta$-cyclodextrin acts as a novel anticancer agent. PLoS ONE 10:e0141946. https://doi.org/10.1371/journ al.pone.0141946

Yuan Z, Zhang L (2016) Photoinduced controlled-release drug delivery systems for applications in nanomedicine. Curr Org Chem 20:1768-1785. https://doi.org/10.2174/13852728206661601120 01944

Yusoff SNM, Kamari A, Aljafree NFA (2016) A review of materials used as carrier agents in pesticide formulations. Int J Environ Sci Technol 13:2977-2994. https://doi.org/10.1007/s1376 2-016-1096-y

Zarzycki PK, Fenert BE, Głód BK (2016) Cyclodextrins-based nanocomplexes for encapsulation of bioactive compounds in food, cosmetics, and pharmaceutical products: principles of supramolecular complexes formation, their influence on the antioxidative properties of target chemicals, and recent advances in selected industrial applications. In: Grumezescu A (ed) Encapsulations. Nanotechnology in the agri-food industry, chapter 17, pp 717767. ISBN: 978-0-12-804378-3

Zhang J, Ma PX (2013) Cyclodextrin-based supramolecular systems for drug delivery: recent progress and future perspective. Adv Drug Deliv Rev 65:1215-1233. https://doi.org/10.1016/j. addr.2013.05.001

Zhang GQ, He LQ, Yuan MX, Li H, Chang T, Qin SJ (2018) Clean and green procedure for the synthesis of biodiesel from the esterification of free fatty acids and alcohol catalyzed by 6-O-(sulfobutyl)cyclodextrin. Russ J Appl Chem 91:1123-1128. https://doi. org/10.1134/S1070427218070091

Zhang DJ, Lv P, Zhou C, Zhao YL, Liao XL, Yang B (2019a) Cyclodextrin-based delivery systems for cancer treatment. Mat Sci Eng C Mater Biol Appl 96:872-886. https://doi.org/10.1016/j. msec.2018.11.031

Zhang YM, Xu QY, Liu Y (2019b) Molecular recognition and biological application of modified cyclodextrins. Sci China Chem 62:549-560. https://doi.org/10.1007/s11426-018-9405-3

Zhang YM, Liu YH, Liu Y (2020) Cyclodextrin-based multistimuliresponsive supramolecular assemblies and their biological functions. Adv Mater 32:1806158. https://doi.org/10.1002/ adma.201806158

Zimmer S, Grebe A, Bakke SS, Bode N, Halvorsen B, Ulas T, Skjelland M, De Nardo D, Labzin LI, Kerksiek A, Hempel C, Heneka MT, Hawxhurst V, Fitzgerald ML, Trebicka J, Bjorkhem I, Gustafsson JA, Westerterp M, Tall AR, Wright SD, Espevik T, Schultze JL, Nickenig G, Lutjohann D, Latz E (2016) Cyclodextrin promotes atherosclerosis regression via macrophage reprogramming. Sci Transl Med. https://doi.org/10.1126/scitranslmed.aad6100 